\title{
The transcription factor grainyhead-like 2 is a novel suppressor of the epithelial to mesenchymal transition
}

\author{
Benjamin Cieply \\ West Virginia University
}

Follow this and additional works at: https://researchrepository.wvu.edu/etd

\section{Recommended Citation}

Cieply, Benjamin, "The transcription factor grainyhead-like 2 is a novel suppressor of the epithelial to mesenchymal transition" (2012). Graduate Theses, Dissertations, and Problem Reports. 244.

https://researchrepository.wvu.edu/etd/244

This Dissertation is protected by copyright and/or related rights. It has been brought to you by the The Research Repository @ WVU with permission from the rights-holder(s). You are free to use this Dissertation in any way that is permitted by the copyright and related rights legislation that applies to your use. For other uses you must obtain permission from the rights-holder(s) directly, unless additional rights are indicated by a Creative Commons license in the record and/ or on the work itself. This Dissertation has been accepted for inclusion in WVU Graduate Theses, Dissertations, and Problem Reports collection by an authorized administrator of The Research Repository @ WVU.

For more information, please contact researchrepository@mail.wvu.edu. 
The transcription factor grainyhead-like 2 is a novel suppressor of the epithelial to mesenchymal transition

By

Benjamin Cieply

Dissertation submitted to the School of Medicine at West Virginia University in partial fulfillment of the requirements for the degree of

Doctor of Philosophy in Cancer Cell Biology

Michael Schaller, PhD, Committee Chairperson

John Michael Ruppert, M.D., PhD

Elena Pugacheva, PhD

Peter Stoilov, PhD

Alexey Ivanov, $\mathbf{P h D}$

Steven Frisch,PhD, mentor

\section{Morgantown, West Virginia \\ 2012}

Keywords: EMT, grainy head like 2, ZEB1, TGF- $\beta$, cancer stem cell/tumor initiating cell Copyright 2012 Benjamin Cieply 


\begin{abstract}
The transcription factor grainyhead like 2 is a novel suppressor of the epithelial to mesenchymal transition
\end{abstract}

Benjamin Cieply

The epithelial to mesenchymal transition (EMT) is a process that is essential for normal embryonic development as well as the healing of damaged adult tissues. In the context of cancer, oncogenic EMT induces enhanced invasion, survival and tumorigenicity which can promote disease progression and recurrence after therapy. Many factors that induce EMT during development and in culture are known and these include the transcription factors Twist, Snail1/2, ZEB1/2 and goosecoid. Transforming growth factor $\beta$ can induce EMT both in the contexts of wound healing and cancer, but some cell types are resistant to this stimulus.

Furthermore, knowledge of factors which stabilize the epithelial phenotype is limited but include the bone morphogenic protein family of ligands, the epithelial splicing regulatory proteins, and the mir200 micro-RNAs. However, transcription factors which suppress EMT remain surprisingly elusive. In pursuit of identifying such a factor we searched EMT microarrays for transcription factors which were downregulated and that had been previously known to regulate the EMT related process of wound healing. Grainy-head-like-2 (GRHL2) met these criteria so we tested its role in regulating EMT. We found that GRHL2 induced mesenchymal to epithelial transition (MET) and antagonized Twist induced EMT. Also, knockdown of GRHL2 made mammary epithelial cells permissive to TGF- $\beta$ induced EMT. GRHL2 knockdown in the presence of activated HRAS induced EMT which was dependent on autocrine TGF- $\beta$. The effect of GRHL2 was depended on direct repression of the ZEB1 promoter where it antagonized homeo-protein mediated transactivation. GRHL2 acted as a tumor suppressor as it enhanced anoikis, suppressed anchorage independent growth and invasion, and prevented tumor formation in xenograft assays. Wnt and TGF- $\beta$ were shown to down regulate GRHL2 by upregulating ZEB1 which directly repressed its promoter. This body of work has identified GRHL2 as novel suppressor of EMT and tumorigenicity, which engages in a reciprocal repression loop with the EMT inducing oncogene ZEB1. 


\section{Acknowledgements}

I would like to thank the following people:

Steve Frisch for being an excellent scientific and career mentor. I consider the training that I received in his lab to be exemplary. His laboratory research is always at the cutting edge of science and I would strongly recommend it for future trainees.

Fred Minnear and the admissions committee for accepting me into the program.

My thesis committee of Mike Schaller, Mike Ruppert, Peter Stoilov, Elena Pugacheva, and Alexey Ivanov who all provided excellent scientific and career related advice throughout my training. Each of them are esteemed scientist who take seriously the mentoring of trainees.

Scott Weed for organizing the Cancer Cell Biology Program.

Paul Monga was a great advisor and mentor during my post-bachelor research and provided me with incredible research opportunities and career guidance.

Darryl Sas was an excellent teacher and mentor during my undergraduate studies.

My wife Shawna Cieply and the rest of my family for supporting me. 


\section{Table of Contents}

Abstract................................................................

Acknowledgements.......................................................ii

Table of contents.......................................................

Chapter 1: Introduction and Literature Review...............................

Chapter 2: Suppression of the epithelial to mesenchymal transition by GRHL2...23

Chapter3: A reciprocal feedback loop between GRHL2 and ZEB1

controls EMT and tumor suppression.........................................54

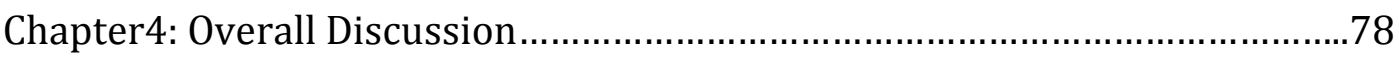

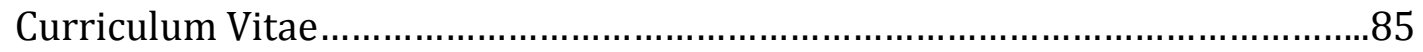




\section{Chapter 1}

\section{Introduction and Literature Review}




\section{Epithelial to Mesenchymal Transition}

Epithelial vs. mesenchymal phenotypes

Epithelial tissues commonly function as barriers which separate physiologically distinct compartments of multi-cellular organisms, for example, the lining of the gastrointestinal tract of mammals. Epithelial cells comprise such barriers and it is their gene expression profile which allows them to do so. The epithelial cell gene expression program is aimed at achieving two major characteristics: cell-cell adhesion and cell polarity, both of which are essential for the proper function of epithelial tissues. Epithelial-cadherin, or E-cadherin, is an integral membrane protein whose extracelluar domain interacts homophilically with the adjacent cell’s Ecadherin. The intracellular domain is the hub of a complex which regulates cortical actin assembly, cell polarity, signaling and gene expression, all of which contribute to the epithelial phenotype [1] [2]. The physical, fluid impermeable barrier of epithelial tissues is established by tight junctions (TJ) which are made up of epithelial specific 4-spanning transmembrane proteins, claudins and occludins. TJs also contribute to cell polarity by restricting the diffusion of integral membrane proteins between apical and baso-lateral membranes. $[3,4]$. The apical membrane of a polarized epithelial cell faces the lumen of a vessel and the baso-lateral membrane is attached to the adjacent cell and extracellular matrix. Epithelial cells are dependent on their basolateral membrane interactions for survival (see anoikis below). Epithelial cell polarity is critical for the proper function of the tissues that they comprise. For example, intestinal epithelial cells must have distinct glucose transporters localized to apical and baso-lateral membranes in order to facilitate the transcellular transport of glucose from the intestinal lumen into the blood.[5] The proper localization of epithelial transmembrane proteins is regulated by epithelial specific cytosolic vesicular transport involving genes such as ankyrin-G and RAB-25[6,7]. Apical-basolateral polarity is not only essential for the proper function of epithial tissues, it also has a tumor suppressive effect to be detailed below. 
In contrast to epithelial cells, all of the aforementioned genes are down-regulated/not expressed in mesenchymal cells, rendering mesenchymal cells incapable of interacting with adjacent cells to form barriers or layers. Mesenchymal cells lack the apical-basolateral polarity and are not as dependent on matrix interactions for survival.[8] They also exhibit an enhanced likelihood to migrate as individual cells.[9] Examples of mesenchymal cells in adult organisms are fibroblasts and mesenchymal stem cells(MSC). Fibroblasts exist within the stromal compartment of tissues and function to synthesize the extracellular matrix. MSCs are an example of adult stem cells which can differentiate into osteoblasts, adipocytes and chondrocytes[10] Microarray analysis of epithelial vs. mesenchymal cells reveals significant changes in the expression of several hundred genes, which further emphasizes the distinct epigenetic and phenotypic contrast between these two cell types.[11]

\section{Physiological roles of EMT/MET}

The stark contrast of epithelial and mesenchymal cell types is clear; however, cellular plasticity between these two distinct phenotypes has been widely documented and investigated. These processes have been termed either epithelial-mesenchymal-transition (EMT) or mesencymal-epithelial-transition (MET). EMT during embryonic development is essential, in fact, embryos lacking the EMT inducing transcription factors Snail 1 and 2 fail to gastrulate due to stable epithelial junctions of mesodermal cells which impede their migration to form the primitive streak. [12] [13]. Soon after primitive streak formation another example of epithelial/mesenchymal plasticity can be observed where epithelial junctions are required for proper neural tube closure [14-16] followed by an EMT required for neural crest delamination. These cells then migrate away from the neural tube and undergo an MET to form structures such as the notochord and somites. [17]. Later in development EMT/MET cycles can be observed during the formation of organs such as the heart and kidney.[17,18] 
In adult organisms, EMT has been implicated in regulating wound healing, inducing fibrosis and malignant progression of cancer. During epidermal wound healing, myofibroblasts are required for wound contractility as well as rebuilding the extracellular matrix; a portion of this cell population is generated through EMT mediated transdifferentiation of keratinocytes. Also, the keratinocytes at the leading edge of the wound exhibit a partial EMT which facilitates migration of the attached epithelial sheet. [19-21] [22,23]. An example of EMT contributing to disease pathogenesis is in fibrotic tissue where a significant fraction of the fibroblasts (and myofibroblasts), which produce the excess collagen and thus fibrosis, are generated via TGF- $\beta$ induced EMT of the epithelial cells within the organ. [17,24,25]

\section{Oncogenic roles of EMT}

Most of the attributes of a tumor cell which contribute to its malignancy originated as normal processes within the organism but are improperly regulated in the context of the tumor. The most obvious example of this is cell proliferation and growth. EMT is another example, and as described above it is an essential process for normal development and wound healing. However, when employed inappropriately by a tumor cell, EMT can contribute to multiple facets of malignant progression. These are described in detail below.

\section{Cancer stem cell/ tumor initiating cells and EMT}

The hypothesis that malignancies are driven by tumor specific stem cells has long been investigated and discussed in the hematopoietic field dating back to 1967; Daniel Bergsagel said that “...studies will have to be initiated to elucidate the properties of the two types of stem cells so that therapeutic measures can be developed to eliminate the leukemic stem line...” [26]. Roughly 30 years later, experimental evidence began to emerge showing that, only a specific sub-fraction of primary leukemic cells were able to recapitulate the disease in mice while the vast majority of the cells could not, these became known as leukemic stem cells.[27-29] Subsequently, it was found that, (using the same criteria, namely, the ability to seed tumors in mice) an analogous population existed in solid tumors, and were coined “cancer stem cells” or "tumor initiating 
cells(TIC)”. [30,31] As in leukemia, the tumor initiating cells of solid tumors made up only a very small fraction of the cells. Since these initial studies, it has been demonstrated that the proportion of CSC in a tumor population can vary dramatically between patients and tumor types, but it is consistent that tumors are comprised of at least 2 distinct populations: tumorigenic and non-tumorigenic.[32] Tumor heterogeneity and the existence of TICs represents a daunting complication with respect to patient treatment because even a single TIC left alive after treatment can drive the recurrence of the entire disease and a single TIC that has disseminated from the primary tumor can drive the formation of a distant metastasis. On the other hand they represent exciting opportunity, as TIC specific targeted therapies would revolutionize cancer treatment. Because of this, TICs and CSCs are at the center of an entire field of cancer research.

The origin of CSCs or TICs is controversial [32]. In breast cancer, one model which has been elucidated is that TIC/CSC's can be generated from non-tumorigenic/non-CSC population via a passage through the EMT. Al-Hajj et al. 2003, used the surface antigenic phenotype of CD44 ${ }^{\mathrm{HIGH}} / \mathrm{CD} 24^{\mathrm{LOW}}$ to isolate tumorigenic cells from heterogeneous tumor cell populations. Mani et al. 2008, then showed that immortalized mammary epithelial cells acquired a CD $44^{\mathrm{HIGH}} / \mathrm{CD} 24^{\mathrm{LOW}}$ and tumorigenic phenotype after having undergone EMT [33]. Since that discovery there have been numerous reports linking EMT with TIC properties in breast and other types of cancer cells. [9, 34,35]. This theoretically raises the possibility that any cell with-in a carcinoma can become a TIC, if, first they are induced to undergo an EMT. This confounds even further the paradigm of tumor heterogeneity, but, it identified a tangible characteristic of this otherwise enigmatic cell population providing the rationale for investigating the EMT process with the aim of identifying TIC/CSCs specific drugable targets.

EMT and anoikis

Anoikis is a term that describes the phenomenon where epithelial cells are dependent on their matrix attachment for survival and detatchement from appropriate matrix induces apoptosis[8]. The apoptosis 
mechanism induced by detachment is not specific to this context and is regulated by common pro and antiapoptotic genes. What establishes anoikis sensitivity has been the underlying question in the field since its discovery. A clue to the answer of this question was included in the original anoikis report showing that epithelial cells and not mesenchymal cells were sensitive.[8] Consistent with this finding, it has become well established that EMT induces anoikis resistance [36-38] and the mechanisms for this are emerging.

\section{E-cadherin and anoikis}

E-cadherin is at the center of at least three anoikis sensitizing complexes. We recently reported that the epithelial specific cytoskeletal and E-cadherin associated gene, ankyrinG, sequestered a transcription factor, NRAGE, in the cytoplasm preventing its repression of the pro-apoptotic gene p14ARF. The EMT mediated down regulation of ankryin $\mathrm{G}$ and E-cadherin expression led to the nuclear translocation of NRAGE, repression of p14 ARF and anoikis resistance.[39] In another report, E-cadherin knockdown induced anoikis resistance, an effect mediated in part by beta-catenin hypophosphorylation, stabilization, and nuclear translocation[40] Also, homophilic interaction of E-cadherins engages the Hippo pathway[41](HIPPO regulation of anoikis is detailed below). In summary, E-cadherin can sensitize epithelial cells to anoikis by regulating:

ankyrinG/NRAGE/p14ARF axis, Wnt/beta-catenin, and HIPPO, but this is unlikely a comprehensive view of Ecadherin’s role in anoikis and this will be a subject of future research.

Epithelial cell polarity, HIPPO, Wnt, TGF- $\beta$, and anoikis

Disruption of epithelial apical/baso-lateral polarity is associated with EMT and this is a result of downregulation and/or mis-localization of key polarity complexes [42-44] These polarity complexes define the distinct membranes of epithelial cells and are the apical membrane complex CRUMBS, the apical/basolateral border complex composed of PAR genes, and the baso-lateral complex scribble. $[45,46]$ There is substantial evidence that epithelial cell polarity is critical for anoikis sensitivity due to activation of the HIPPO (LATS in 
human) kinase cascade that leads to the cytoplasmic sequestration of the YAP/TAZ transcriptional co-activators as well as inhibition of Wnt and TGF- $\beta$ signalling. Evidence that supports this model is summarized as follows.

The HIPPO kinase signaling pathway is essential for establishing the proper size of organs during development. ([47]). The cue that engages the HIPPO cascade is cell-cell contacts that in turn promote the formation of the epithelial cell polarity complexes crumbs and scribble; the HIPPO signaling components interact with these polarity complexes leading to the phosphorylation and sequestration of YAP/TAZ. [48-50] Based on recent findings a strong case can be made that sequestration of YAP/TAZ establishes epithelial cell sensitivity to anoikis. Luminal clearance in the MCF10a mammary mophogeneiss assay, a process mediated by anoikis was shown to be dependent on scribble and cell polarity [51]. A link between YAP/TAZ and anoikis was first reported by Zhao et al where detachment from matrix caused YAP phosphorylation(and inactivation), which proved to be essential for anoikis sensitivity. However the targets of YAP/TAZ, prevent anoikis, where not identified. [52] Cordenonsi et al.[50] showed that EMT caused the mis-localization of scribble from cell contact, which activated TAZ, and enhanced the formation of mammospheres (anchorage independent, anoikis resistant colonies). In this report, TAZ activation induced expression of the apoptosis inhibitor survivin, but its functional significance was not investigated. A worthy hypothesis, which remains to be tested, is that 1. EMT induces the loss of epithelial cell polarity complexes leading to the inactivation of HIPPO signaling, and activation of YAP/TAZ, then 2. YAP/TAZ activate the expression of anti-apoptotic genes such as survivin 3 . suppresses anoikis. The connections between 1-2 and 2-3 remain to be experimentally supported. It is also interesting to note that confluent cells are significantly more sensitive to anoikis[53] and it is in confluent cells that Hippo kinase cascade is engaged. Whether Hippo is involved in the difference in anoikis sensitivity between sub-confluent and confluent cells also remains to be tested.

Aside from inhibiting direct transactivation of YAP/TAZ pro-survival gene targets, HIPPO/LATS mediated sequestration of YAP/TAZ can inhibit Wnt and TGF- $\beta$ through protein-protein interactions between 
YAP/TAZ and Wnt and TGF- $\beta$ pathway components. First, the TGF- $\beta$ 1/ TGF- $\beta$ R1/R2 activated, Smad3, was shown to exist in a complex with YAP/TAZ; crumbs-LATS mediated phosphorylation and sequestration of YAP/TAZ caused cytoplasmic sequestration of Smad3. This effectively inhibited TGF- $\beta$ /Smad3 mediated transactivation. Second, cytoplasmic TAZ also interacted with and inhibited disheveled, which maintained GSK3 $\beta$ activity and $\beta$-catenin degradation thus inhibiting canonical Wnt signaling [49,54,55]. Neither study assayed for anoikis, however, the protective effects of Wnt and TGF- $\beta$ signaling are known $[40,56]$ and these data further support a role for polarity complex induced HIPPO/LATS activation in establishing anoikis sensitivity. It does, however establish a dual role for YAP/TAZ depending on their localization; in the nucleus they activate pro-survival genes that inhibit anoikis, on the other hand in the cytoplasm, they mediate the HIPPO/LATS induced inhibition of Wnt and TGF $\beta$. Regardless, it is clear that engagement of the HIPPO/LATS pathway by cell contacts and polarity complexes is critical for epithelial cell sensitivity to anoikis, and loss of epithelial cell polarity associated with EMT can partially explain the gain of anoikis resistance.

To summarize, E-cadherin and polarity complexes establish epithelial cell sensitivity to anoikis by sequestering pro-survival transcription factors such as NRAGE, $\beta$-catenin, Smad3, YAP and TAZ in the cytoplasm. Many of the detailed mechanisms involved remain unclear. For example, how do (if either) Ecadherin and polarity complexes directly activate the LATS kinase cascade and are their functions dependent on one another? Which TGF- $\beta /$ Smad3 target genes are essential for anoikis resistance? Do Smad independent functions of TGF- $\beta$ inhibit anoikis? These questions and others will require future investigation.

Invasion

One of the most well known aspects of oncogenic EMT is the acquisition of invasive properties. The major characteristic that links EMT to invasion is the loss of E-cadherin expression. It has been widely 
documented that the cell-cell interaction mediated by E-cadherin favors a state where the cells are much less likely to invade the surrounding matrix. In fact, expression of ectopic E-cadherin prevented invasion in cancer cell lines; and clinically E-cadherin loss is used as a marker of invasive cancer by pathologists. [57-61] The mechanism involved in E-cadherin mediated suppression of invasion, could involve any one of the pathways that it is known to interact with, some of which are described above. However, a more simplistic perspective is that it is more energetically favorable for the extracellular domain of E-cadherin to interact with the E-cadherin molecules of an adjacent epithelial cell than with components of extracellular matrix. The relative abundance of E-cadherin on the surface of epithelial cells would make this explanation plausible and suggest that Ecadherin prevents invasion physically, rather than biologically. This model is supported by results where the anti-invasive effect of E-cadherin was reversed by an E-cadherin blocking antibody, which suggests that the extracellular homophillic E-cadherin interactions were preventing invasion[57,62].

A second physical barrier exists to prevent invasion of epithelial cells and that is the extracellular matrix. Increased MMP expression and secretion is also associated with EMT and contributes to invasion. Upregulation of MMPs 1, 2, and 9 have been shown to be associated with EMT and enhanced MMP expression allows a recently EMT'd tumor cell to degrade matrix after it has down regulated E-cadherin and detached from its epithelial cell-cell associations[63-66]. Single cell motility is also enhanced by EMT and this effect has been attributed to upregulation of mesenchymal genes such as vimentin, CD44, hyaluronan synthase 2 and fibronectin [67-72]. Overall, EMT increases a tumor cell's ability to invade away from the primary tumor and through the extracellular matrix due to loss of epithelial adhesion genes, gain of MMPs which degrade matrix, and gain of genes that enhance single cell motility.

\section{Chemoresistance and evasion of immune surveillance}


The advantage of a mesenchymal phenotype with respect to immune surveillance has been supported by in vivo evidence. Injection of tumor cell lines into immune- competent mice resulted in the expected immune response and rejection. However, in some cases the tumors arose over time and exhibited a distinct mesenchymal morphology and gene expression profile suggesting that EMT contributed to the evolution of an immune-resistant tumor. [73] A mechanism was not proposed, however in a separate study, it was shown that EMT and the associated TGF- $\beta$ secretion resulted in the activation of regulatory T-cells, which induced immune avoidance and tumor progression [74]. Similar to the pro-survival effect that EMT invokes in the context of immune surveillance, it has been displayed by various groups that EMT induces resistance to cytotoxic(chemical agent), radiation and even some targeted cancer therapies, [75-78].

In some experimental contexts MET was shown to enhance metastatic colonization and in fact, has been proposed as a requirement for the formation of secondary tumors.[79] Therefore, regulators of EMT/MET could be observed as tumor suppressive or oncogenic depending on the stage of tumor progression under investigation. Nevertheless, the recurring theme observed when studying the phenotypes associated with EMT in the context of cancer is enhanced tumor cell survival and increased aggressiveness. Resistance to cell death induced by loss of matrix association (anoikis), immune surveillance, and therapeutic interventions can be acquired by a tumor cell via EMT. In addition, EMT induces local invasiveness and tumorigenicity/posttherapy recurrence; and the TIC/CSC properties of EMT'd tumor cells is still of great interest even in the context where MET was needed to produce the parenchyma of a distant metastasis. The gene expression, signaling, and cellular mechanisms that regulate each of these malignant properties are rational targets for the research and development of novel cancer therapies; however, theoretically, a treatment strategy that inhibited or reversed EMT would have a multi-faceted and potentially profound effect. The hope of cancer researchers who study EMT mechanisms is to identify molecular targets, which could be manipulated for this purpose. 
Micro environmental and transcriptional regulation of EMT, as is currently understood, is summarized in the next section.

\section{Regulation of EMT}

\section{EMT inducing transcription factors}

As can be deduced from the above section, the most distinct and impactful molecular changes associated with EMT is the loss of epithelial gene expression. For example, it is the loss of polarity genes that liberates the pro-survival transcription factors YAP and TAZ to protect cells from anoikis, and the loss of E-cadherin suffices to enhance invasion. Consistent with this, many of the established EMT inducing factors are transcriptional repressors of epithelial genes. Snail and ZEB family of transcription factors are the direct repressors of epithelial genes and bind to E-boxes (DNA sequences resembling CANNTG) in the upstream promoter region and recruit repressors such as CTBP (ZEB1) and PRC2 (Snail) to silence gene expression and induce EMT [80-83]. Other EMT inducing transcription factors include Twist, goosecoid, FOXC2 and their expression leads to epithelial gene repression albeit indirectly, and in most cases through up-regulation of Snail and/or ZEB repressors[11,17]. In accordance with the oncogenic role of EMT, expression of these transcription factors has been shown to be associated with malignant progression in mouse models and human cancer [11,84]; Hartwell, 2006 \#3\}[85-87].

More recently numerous members of the homeobox transcription factor super family have been reported to induce oncogenic EMT, these include: LBX1, SIX1, DLX4, and prospero homoebox 1. SIX1 and LBX1 were identified as activators of ZEB1 expression, the LBX1 effect being a direct transactivation while the mechanism of SIX1 remained unclear. [88-94] These results are consistent with the role of homeoproteins in the induction of developmental EMT [95,96], it is also interesting to note that well characterized inducers of EMT, goosecoid and ZEB1 are homeobox genes. A comprehensive view of homoebox transcription factors 
that regulate EMT will require further research, and perhaps more systematic approaches due to the vast size of this family of genes.

TGF- $\beta$

The TGF- $\beta$ family of ligands and the cellular responses they induce in the context of development, physiology and disease are at the center of a massive field of research. The TGF- $\beta$ signally pathway is fairly well characterized molecularly. There are around 30 genes in the TGF- $\beta$ family but we will focus on two sub classes: TGF $\beta$ and BMP. TGF- $\beta$ ligands bind to TGF- $\beta$ R1/R2 heterodimer which serine phosphorylate Smad2 and 3 inducing their nuclear translocation. In the same manner BMP ligands bind BMPR1A/R1B heterodimer phosphorylating Smad 1 and 5. In each case the "R" Smads (1, 2, 3, 5) interact with Smad 4 in the nucleus to modulate transcription.

The target genes activated by TGF- $\beta /$ Smad3 vary from the growth inhibitor p15 to the EMT inducer ZEB1 [97,98]. Depending on which is activated by TGF- $\beta$, the overall effect can be tumor suppressive or oncogenic $[99,100]$. What exactly dictates cellular responsiveness, ie, growth arrest vs. EMT, to TGF- $\beta$ is poorly understood. One proposed mechanism was discussed earlier in the anoikis section, where cell-cell contacts and epithelial polarity complexes sequestered Smad 3 in the cytoplasm [54]. However, the effect of Smad cytoplasmic sequestration would be to inhibit its transactivation of all target genes including ZEB1. Why and when TGF- $\beta /$ Smad3 activates ZEB1 expression and EMT must depend on other co-factors, which modulate Smad 3 nuclear function and/or repress ZEB1 expression. Such a factor remained un-identified until the present work.

A “permissive environment” for TGF- $\beta$ induced EMT can be established in cell culture by modifying the culture conditions to stimulate various micro environmental cues, these include Wnt, FGF2, TNF- $\alpha$, EGF(R), mechanotransduction from extracellular matrix, or factors in the "senescent cell secretory phenotype" 
(SASP) [101-104,105 S Scheel \#2817]. How these secondary stimuli enhance the EMT response to TGF- $\beta$ is unclear. Identifying pathways that these stimuli converge upon and then testing them for their effect on EMT would be a potentially productive research strategy.

\section{EMT inhibitory factors}

BMPs are functional antagonists of TGF- $\beta$ induced EMT that activate Smads 1/5 compete with Smad 2/3 for the limited pool of Smad4. MET induced by BMP7 has been reported and BMP extracellular antagonists gremlin and chordin enhance TGF- $\beta$ induced EMT. The effects of BMPs can be mimicked by TGF $\beta$ R2 inhibitors $[9,106,107]$. Thus, by antagonizing the TGF- $\beta$ pathway, BMPs represent the only known natural extracellular stimuli which induce MET, but the underlying mechanisms of this are largely unknown.

The mir200 family of micro RNAs are negative regulators of EMT, which function by directly inhibiting ZEB1 and ZEB2 translation. Interestingly, ZEB1 and ZEB2 are repressors of mir200 promoters creating a loop of negative regulation between ZEBs and mir200s. [87,98,108-111]

Epithelial specific mRNA splicing factors ESRP1/2 were recently discovered and they function to influence the generation of splicoforms of genes that are unique to epithelial cells. Loss of ESRP associated with EMT leads to mesenchymal splicoform production. Knockdown of ESRP1 induced mesenchymal properties including up-regulation of vimentin and fibronectin and loss cell polarity. E-cadherin protein was not down regulated, however, it failed to localize properly to cell junctions, rendering it in active. These data show that the epithelial gene splicing program influences cellular phenotype; however the splicoforms responsible for this effect remain to be determined. [112] [113] These are the major negative regulators of EMT: BMPs, mir200s, and ESRP; what is clearly a knowledge gap in the EMT field are the transcription factors that prevent EMT/induce MET, and a gene with these novel properties will be described here.

\section{Grainyhead transcription factors}


Grainyhead(aka NTF-1) is a transcription factor expressed in drosophila whose name originated from the observation that its mutation in flies produced anatomically misshaped (or grainy)heads. It is critical for processes such as wound healing, epidermal barrier formation, and wing hair polarity (planar cell polarity)[114116]. The domain structure of GRH includes an N-terminal transactivation domain (similar to that of SP1), a DNA binding domain unique to grainyhead family factors, and a C terminal dimerization domain. [117] [118] Drosophila grh is known for its transactivation mediated by direct recruitment of the core TAF/TFIID transcriptional machinery to specific promoters[119]; targets include stit and ddc both essential genes involved in epidermal integrity.[120,121]. GRH can also repress transcription accomplished by either competing with co-activators for promoter binding or by recruiting polycomb-repressor complex via direct binding to dring (a PRC compontent)[122-124]. The mechanisms that dictate the various effects of GRH on target genes are not understood. GRH can be activated by Erk phosphorylation [120], and perhaps, it represses otherwise; or repression vs. activation could speculatively depend on whether GRH is binding to the promoter as a monomer or dimer, ie, whether there are one or two putative binding sites in the target promoter.

\section{Mammalian grainyheads}

Three homologues of dGRH are expressed in mammals: GRH-like-1,2,3. Their domain structures also include the TA, DNA binding and dimerization domains. Despite their high homology with dGRH and each other, the 3 GRHL proteins exhibit distinct tissue expression patterns in both development and in adult tissues.[125,126].

And, while they share some common target genes, they also have unique ones and knockout mice for each gene exhibit distinct phenotypes. GRHL1 null mice are viable but display delayed hair growth and eventual hair loss attributed to deficient expression of its direct target desmosomal cadherin 1 (DSG-1)[127]. GRHL2 and 3 homozygous null mice are early embryonic lethal due to neural tube defects [16] but crossing their 
heterozygotes reveals a redundant function of the two in wound healing dependent in part on their direct activation of the Rho-GEF-19 promoter[128]; Rho-GEF-19 is essential for the planar cell polarity dependent directed epithelial sheet migration during wound healing[129-131] . Neither GRHL2 nor 3 activate DSG-1 and GRHL1 fails to activate Rho-GEF-19. Furthermore, GRHL3 is essential and GRHL2 is dispensable for epidermal barrier formation due to unique activation of the protein cross-linking enzyme, transglutaminase 1 , by GRHL3[128]. GRHL mediated repression of genes is yet to be reported in mammalian tissues.

In two separate, unbiased in-vivo screens, GRHL2 was identified as an activator of epithelial cell-cell adhesion and was shown to directly activate the E-cadherin and claudin-4 promoters [14,15]. GRHL1 and 3 were not tested for redundancy in these contexts. In the context of cancer, only GRHL3 has been mechanistically studied to date. Two groups have shown a model where GRHL3 is a direct activator of the tumor suppressor, PTEN and a repressor of the onco-mir-21 gene. This model was proposed to explain the phenotype of GRHL3 conditional deletion in the epidermis resulting in squamous cell carcinoma formation and identifies it as a tumor suppressor gene. [132,133]

Therefore the mammalian grainyhead family of transcription factors are key players in embryonic development, wound healing, epidermal integrity, cell polarity, and epithelial cell-cell adhesion, all consistent with the known functions of the well characterized drosophila grh gene. Tumor suppressive role of GRHL3 in SCC brings into question the roles of the other two family members in cancer. Base on the epithelial-mesenchymal plasticity observed during wound healing dependent on TGF- $\beta$, the regulation of wound healing by GRHL2 and the activation of epithelial genes by GRHL2 we hypothesized that GRHL2 was a novel transcriptional regulator of EMT/MET. The next two chapters of this thesis will show that GRHL2 is a potent inhibitor of EMT and can induce MET. This effect is due to a direct repression of the ZEB1 promoter by GRHL2. GRHL2 also suppressed TGF- $\beta /$ Smad dependent transactivation. In-vivo, GRHL2 was down-regulated in human claudinlow breast cancer, renal cell carcinoma, recurrent tumors in mice and it suppressed tumorigenicity in xenograft 
assays. In experimental systems, GRHL2 enhanced anoikis, suppressed anchorage-independent-

mammosphere-growth, invasion and sensitivity to chemo-therapeutics. Micro-environmental factors Wnt and

TGF- $\beta$ collaborated to down-regulate GRHL2 and this was surprisingly dependent on direct repression by

ZEB1. Therefore this thesis has established that GRHL2 is a tumor suppressor gene that engages in a reciprocal negative repression loop with ZEB1, which regulates EMT and tumorigenicity.

1. Qin Y, Capaldo C, Gumbiner BM, Macara IG: The mammalian Scribble polarity protein regulates epithelial cell adhesion and migration through E-cadherin. J Cell Biol 2005, 171:1061-1071.

2. Baum B, Georgiou M: Dynamics of adherens junctions in epithelial establishment, maintenance, and remodeling. $J$ Cell Biol 192:907-917.

3. Forster C: Tight junctions and the modulation of barrier function in disease. Histochem Cell Biol 2008, 130:55-70.

4. Tsukita S, Yamazaki Y, Katsuno T, Tamura A, Tsukita S: Tight junction-based epithelial microenvironment and cell proliferation. Oncogene 2008, 27:6930-6938.

5. Thorens B: Facilitated glucose transporters in epithelial cells. Annu Rev Physiol 1993, 55:591-608.

6. Kizhatil K, Yoon W, Mohler PJ, Davis LH, Hoffman JA, Bennett V: Ankyrin-G and beta2-spectrin collaborate in biogenesis of lateral membrane of human bronchial epithelial cells. J Biol Chem 2007, 282:2029-2037.

7. Senga K, Mostov KE, Mitaka T, Miyajima A, Tanimizu N: Grainyhead-like 2 regulates epithelial morphogenesis by establishing functional tight junctions through the organization of a molecular network among claudin3, claudin4, and Rab25. Mol Biol Cell 23:2845-2855.

8. Frisch SM, Francis H: Disruption of epithelial cell-matrix interactions induces apoptosis. J Cell Biol 1994, 124:619-626.

9. Scheel C, Eaton EN, Li SH, Chaffer CL, Reinhardt F, Kah KJ, Bell G, Guo W, Rubin J, Richardson AL, et al.: Paracrine and autocrine signals induce and maintain mesenchymal and stem cell States in the breast. Cell 145:926-940.

10. Khanna KK, Keating KE, Kozlov S, Scott S, Gatei M, Hobson K, Taya Y, Gabrielli B, Chan D, Lees-Miller SP, et al.: ATM associates with and phosphorylates p53: mapping the region of interaction. Nat Genet 1998, 20:398-400.

11. Taube JH, Herschkowitz JI, Komurov K, Zhou AY, Gupta S, Yang J, Hartwell K, Onder TT, Gupta PB, Evans KW, et al.: Core epithelial-to-mesenchymal transition interactome gene-expression signature is associated with claudinlow and metaplastic breast cancer subtypes. Proc Natl Acad Sci U S A 107:15449-15454.

12. Carver EA, Jiang R, Lan $\mathrm{Y}$, Oram KF, Gridley $\mathrm{T}$ : The mouse snail gene encodes a key regulator of the epithelialmesenchymal transition. Mol Cell Biol 2001, 21:8184-8188.

13. Nieto MA, Sargent MG, Wilkinson DG, Cooke J: Control of cell behavior during vertebrate development by Slug, a zinc finger gene. Science 1994, 264:835-839.

14. Pyrgaki C, Liu A, Niswander L: Grainyhead-like 2 regulates neural tube closure and adhesion molecule expression during neural fold fusion. Dev Biol 353:38-49.

15. Werth M, Walentin K, Aue A, Schonheit J, Wuebken A, Pode-Shakked N, Vilianovitch L, Erdmann B, Dekel B, Bader M, et al.: The transcription factor grainyhead-like 2 regulates the molecular composition of the epithelial apical junctional complex. Development 137:3835-3845.

16. Rifat Y, Parekh V, Wilanowski T, Hislop NR, Auden A, Ting SB, Cunningham JM, Jane SM: Regional neural tube closure defined by the Grainy head-like transcription factors. Dev Biol 345:237-245.

17. Thiery JP, Acloque H, Huang RY, Nieto MA: Epithelial-mesenchymal transitions in development and disease. Cell 2009, 139:871-890. 
18. Davies JA, Perera AD, Walker CL: Mechanisms of epithelial development and neoplasia in the metanephric kidney. Int J Dev Biol 1999, 43:473-478.

19. Hudson LG, Newkirk KM, Chandler HL, Choi C, Fossey SL, Parent AE, Kusewitt DF: Cutaneous wound reepithelialization is compromised in mice lacking functional Slug (Snai2). J Dermatol Sci 2009, 56:19-26.

20. Kusewitt DF, Choi C, Newkirk KM, Leroy P, Li Y, Chavez MG, Hudson LG: Slug/Snai2 is a downstream mediator of epidermal growth factor receptor-stimulated reepithelialization. J Invest Dermatol 2009, 129:491-495.

21. Savagner P, Kusewitt DF, Carver EA, Magnino F, Choi C, Gridley T, Hudson LG: Developmental transcription factor slug is required for effective re-epithelialization by adult keratinocytes. J Cell Physiol 2005, 202:858-866.

22. Radisky DC, Kenny PA, Bissell MJ: Fibrosis and cancer: do myofibroblasts come also from epithelial cells via EMT? J Cell Biochem 2007, 101:830-839.

23. Weber CE, Li NY, Wai PY, Kuo PC: Epithelial-mesenchymal transition, TGF-beta, and osteopontin in wound healing and tissue remodeling after injury. $J$ Burn Care Res 33:311-318.

24. Kalluri R, Neilson EG: Epithelial-mesenchymal transition and its implications for fibrosis. J Clin Invest 2003, 112:1776-1784.

25. Carew RM, Wang B, Kantharidis P: The role of EMT in renal fibrosis. Cell Tissue Res 347:103-116.

26. Bergsagel DE: The chronic leukemias: a review of disease manifestations and the aims of therapy. Can Med Assoc $J$ 1967, 96:1615-1620.

27. Terpstra W, Prins A, Ploemacher RE, Wognum BW, Wagemaker G, Lowenberg B, Wielenga JJ: Long-term leukemiainitiating capacity of a CD34-subpopulation of acute myeloid leukemia. Blood 1996, 87:2187-2194.

28. Bonnet D, Dick JE: Human acute myeloid leukemia is organized as a hierarchy that originates from a primitive hematopoietic cell. Nat Med 1997, 3:730-737.

29. Lapidot T, Sirard C, Vormoor J, Murdoch B, Hoang T, Caceres-Cortes J, Minden M, Paterson B, Caligiuri MA, Dick JE: A cell initiating human acute myeloid leukaemia after transplantation into SCID mice. Nature 1994, 367:645-648.

30. Al-Hajj M, Wicha M, Benito-Hernandez A, Morrison S, Clarke M: Prospective identification of tumorigenic breast cancer cells. Proc Natl Acad Sci U S A 2003, early edition:1-6.

31. Singh SK, Clarke ID, Terasaki M, Bonn VE, Hawkins C, Squire J, Dirks PB: Identification of a cancer stem cell in human brain tumors. Cancer Res 2003, 63:5821-5828.

32. Gupta PB, Chaffer CL, Weinberg RA: Cancer stem cells: mirage or reality? Nat Med 2009, 15:1010-1012.

33. Mani SA, Guo W, Liao MJ, Eaton EN, Ayyanan A, Zhou AY, Brooks M, Reinhard F, Zhang CC, Shipitsin M, et al.: The epithelial-mesenchymal transition generates cells with properties of stem cells. Cell 2008, 133:704-715.

34. Chu PY, Hu FW, Yu CC, Tsai LL, Yu CH, Wu BC, Chen YW, Huang PI, Lo WL: Epithelial-mesenchymal transition transcription factor ZEB1/ZEB2 co-expression predicts poor prognosis and maintains tumor-initiating properties in head and neck cancer. Oral Oncol.

35. Pirozzi G, Tirino V, Camerlingo R, Franco R, La Rocca A, Liguori E, Martucci N, Paino F, Normanno N, Rocco G: Epithelial to mesenchymal transition by TGFbeta-1 induction increases stemness characteristics in primary non small cell lung cancer cell line. PLoS One 6:e21548.

36. Tiwari N, Gheldof A, Tatari M, Christofori G: EMT as the ultimate survival mechanism of cancer cells. Semin Cancer Biol 22:194-207.

37. Drasin DJ, Robin TP, Ford HL: Breast cancer epithelial-to-mesenchymal transition: examining the functional consequences of plasticity. Breast Cancer Res 13:226.

38. Klymkowsky MW, Savagner P: Epithelial-mesenchymal transition: a cancer researcher's conceptual friend and foe. Am J Pathol 2009, 174:1588-1593.

39. Kumar S, Park SH, Cieply B, Schupp J, Killiam E, Zhang F, Rimm DL, Frisch SM: A pathway for the control of anoikis sensitivity by E-cadherin and epithelial-to-mesenchymal transition. Mol Cell Biol 31:4036-4051.

40. Onder TT, Gupta PB, Mani SA, Yang J, Lander ES, Weinberg RA: Loss of E-cadherin promotes metastasis via multiple downstream transcriptional pathways. Cancer Res 2008, 68:3645-3654. 
41. Kim NG, Koh E, Chen X, Gumbiner BM: E-cadherin mediates contact inhibition of proliferation through Hippo signaling-pathway components. Proc Natl Acad Sci U S A.

42. Godde NJ, Galea RC, Elsum IA, Humbert PO: Cell polarity in motion: redefining mammary tissue organization through EMT and cell polarity transitions. J Mammary Gland Biol Neoplasia 15:149-168.

43. Moreno-Bueno G, Portillo F, Cano A: Transcriptional regulation of cell polarity in EMT and cancer. Oncogene 2008, 27:6958-6969.

44. Xu J, Lamouille S, Derynck R: TGF-beta-induced epithelial to mesenchymal transition. Cell Res 2009, 19:156-172.

45. Aranda V, Nolan ME, Muthuswamy SK: Par complex in cancer: a regulator of normal cell polarity joins the dark side. Oncogene 2008, 27:6878-6887.

46. Pieczynski J, Margolis B: Protein complexes that control renal epithelial polarity. Am J Physiol Renal Physiol 300:F589-601.

47. Pan D: Hippo signaling in organ size control. Genes Dev 2007, 21:886-897.

48. Willecke M, Hamaratoglu F, Kango-Singh M, Udan R, Chen CL, Tao C, Zhang X, Halder G: The fat cadherin acts through the hippo tumor-suppressor pathway to regulate tissue size. Curr Biol 2006, 16:2090-2100.

49. Varelas X, Wrana JL: Coordinating developmental signaling: novel roles for the Hippo pathway. Trends Cell Biol 22:88-96.

50. Cordenonsi M, Zanconato F, Azzolin L, Forcato M, Rosato A, Frasson C, Inui M, Montagner M, Parenti AR, Poletti A, et al.: The Hippo transducer TAZ confers cancer stem cell-related traits on breast cancer cells. Cell 147:759-772.

51. Zhan L, Rosenberg A, Bergami KC, Yu M, Xuan Z, Jaffe AB, Allred C, Muthuswamy SK: Deregulation of scribble promotes mammary tumorigenesis and reveals a role for cell polarity in carcinoma. Cell 2008, 135:865-878.

52. Zhao B, Li L, Wang L, Wang CY, Yu J, Guan KL: Cell detachment activates the Hippo pathway via cytoskeleton reorganization to induce anoikis. Genes Dev 26:54-68.

53. Frisch SM, Vuori K, Kelaita D, Sicks S: A role for Jun-N-terminal kinase in anoikis; suppression by bcl-2 and crmA. J Cell Biol 1996, 135:1377-1382.

54. Varelas X, Samavarchi-Tehrani P, Narimatsu M, Weiss A, Cockburn K, Larsen BG, Rossant J, Wrana JL: The Crumbs complex couples cell density sensing to Hippo-dependent control of the TGF-beta-SMAD pathway. Dev Cell 19:831-844.

55. Varelas X, Miller BW, Sopko R, Song S, Gregorieff A, Fellouse FA, Sakuma R, Pawson T, Hunziker W, McNeill H, et al.: The Hippo pathway regulates Wnt/beta-catenin signaling. Dev Cell 18:579-591.

56. Cieply B, Riley Pt, Pifer PM, Widmeyer J, Addison JB, Ivanov AV, Denvir J, Frisch SM: Suppression of the EpithelialMesenchymal Transition by Grainyhead-like-2. Cancer Res 72:2440-2453.

57. Vleminckx K, Vakaet L, Jr., Mareel M, Fiers W, van Roy F: Genetic manipulation of E-cadherin expression by epithelial tumor cells reveals an invasion suppressor role. Cell 1991, 66:107-119.

58. Moll R, Mitze M, Frixen UH, Birchmeier W: Differential loss of E-cadherin expression in infiltrating ductal and lobular breast carcinomas. Am J Pathol 1993, 143:1731-1742.

59. Schipper JH, Frixen UH, Behrens J, Unger A, Jahnke K, Birchmeier W: E-cadherin expression in squamous cell carcinomas of head and neck: inverse correlation with tumor dedifferentiation and lymph node metastasis. Cancer Res 1991, 51:6328-6337.

60. Frixen UH, Behrens J, Sachs M, Eberle G, Voss B, Warda A, Lochner D, Birchmeier W: E-cadherin-mediated cell-cell adhesion prevents invasiveness of human carcinoma cells. J Cell Biol 1991, 113:173-185.

61. Behrens J, Weidner KM, Frixen UH, Schipper JH, Sachs M, Arakaki N, Daikuhara Y, Birchmeier W: The role of Ecadherin and scatter factor in tumor invasion and cell motility. Exs 1991, 59:109-126.

62. Kinsella AR, Lepts GC, Hill CL, Jones M: Reduced E-cadherin expression correlates with increased invasiveness in colorectal carcinoma cell lines. Clin Exp Metastasis 1994, 12:335-342.

63. Jorda M, Olmeda D, Vinyals A, Valero E, Cubillo E, Llorens A, Cano A, Fabra A: Upregulation of MMP-9 in MDCK epithelial cell line in response to expression of the Snail transcription factor. J Cell Sci 2005, 118:3371-3385. 
64. Miyoshi A, Kitajima Y, Kido S, Shimonishi T, Matsuyama S, Kitahara K, Miyazaki K: Snail accelerates cancer invasion by upregulating MMP expression and is associated with poor prognosis of hepatocellular carcinoma. $\mathrm{Br} \mathrm{J}$ Cancer 2005, 92:252-258.

65. Miyoshi A, Kitajima Y, Sumi K, Sato K, Hagiwara A, Koga Y, Miyazaki K: Snail and SIP1 increase cancer invasion by upregulating MMP family in hepatocellular carcinoma cells. Br J Cancer 2004, 90:1265-1273.

66. Yokoyama K, Kamata N, Fujimoto R, Tsutsumi S, Tomonari M, Taki M, Hosokawa H, Nagayama M: Increased invasion and matrix metalloproteinase-2 expression by Snail-induced mesenchymal transition in squamous cell carcinomas. Int J Oncol 2003, 22:891-898.

67. Ivaska J, Pallari HM, Nevo J, Eriksson JE: Novel functions of vimentin in cell adhesion, migration, and signaling. Exp Cell Res 2007, 313:2050-2062.

68. Kim Y, Lee YS, Choe J, Lee H, Kim YM, Jeoung D: CD44-epidermal growth factor receptor interaction mediates hyaluronic acid-promoted cell motility by activating protein kinase $\mathrm{C}$ signaling involving Akt, Rac1, Phox, reactive oxygen species, focal adhesion kinase, and MMP-2. J Biol Chem 2008, 283:22513-22528.

69. Toole BP, Zoltan-Jones A, Misra S, Ghatak S: Hyaluronan: a critical component of epithelial-mesenchymal and epithelial-carcinoma transitions. Cells Tissues Organs 2005, 179:66-72.

70. Toole BP: Hyaluronan: from extracellular glue to pericellular cue. Nat Rev Cancer 2004, 4:528-539.

71. Zoltan-Jones A, Huang L, Ghatak S, Toole BP: Elevated hyaluronan production induces mesenchymal and transformed properties in epithelial cells. J Biol Chem 2003, 278:45801-45810.

72. Perris R, Perissinotto D: Role of the extracellular matrix during neural crest cell migration. Mech Dev 2000, 95:3-21.

73. Knutson KL, Lu H, Stone B, Reiman JM, Behrens MD, Prosperi CM, Gad EA, Smorlesi A, Disis ML: Immunoediting of cancers may lead to epithelial to mesenchymal transition. J Immunol 2006, 177:1526-1533.

74. Kudo-Saito C, Shirako H, Takeuchi T, Kawakami Y: Cancer metastasis is accelerated through immunosuppression during Snail-induced EMT of cancer cells. Cancer Cell 2009, 15:195-206.

75. Barr S, Thomson S, Buck E, Russo S, Petti F, Sujka-Kwok I, Eyzaguirre A, Rosenfeld-Franklin M, Gibson NW, Miglarese $\mathrm{M}$, et al.: Bypassing cellular EGF receptor dependence through epithelial-to-mesenchymal-like transitions. Clin Exp Metastasis 2008, 25:685-693.

76. Buck E, Eyzaguirre A, Rosenfeld-Franklin M, Thomson S, Mulvihill M, Barr S, Brown E, O'Connor M, Yao Y, Pachter J, et al.: Feedback mechanisms promote cooperativity for small molecule inhibitors of epidermal and insulin-like growth factor receptors. Cancer Res 2008, 68:8322-8332.

77. Li X, Lewis MT, Huang J, Gutierrez C, Osborne CK, Wu MF, Hilsenbeck SG, Pavlick A, Zhang X, Chamness GC, et al.: Intrinsic resistance of tumorigenic breast cancer cells to chemotherapy. J Nat/ Cancer Inst 2008, 100:672-679.

78. Woodward WA, Chen MS, Behbod F, Alfaro MP, Buchholz TA, Rosen JM: WNT/beta-catenin mediates radiation resistance of mouse mammary progenitor cells. Proc Natl Acad Sci U S A 2007, 104:618-623.

79. Kalluri R, Weinberg RA: The basics of epithelial-mesenchymal transition. J Clin Invest 2009, 119:1420-1428.

80. Grooteclaes M, Deveraux Q, Hildebrand J, Zhang Q, Goodman RH, Frisch SM: C-terminal-binding protein corepresses epithelial and proapoptotic gene expression programs. Proc Natl Acad Sci U S A 2003, 100:4568-4573.

81. Grooteclaes ML, Frisch SM: Evidence for a function of CtBP in epithelial gene regulation and anoikis. Oncogene 2000, 19:3823-3828.

82. Cano A, Perez-Moreno MA, Rodrigo I, Locascio A, Blanco MJ, del Barrio MG, Portillo F, Nieto MA: The transcription factor snail controls epithelial-mesenchymal transitions by repressing E-cadherin expression. Nat Cell Biol 2000, 2:76-83.

83. Herranz N, Pasini D, Diaz VM, Franci C, Gutierrez A, Dave N, Escriva M, Hernandez-Munoz I, Di Croce L, Helin K, et al.: Polycomb complex 2 is required for E-cadherin repression by the Snail1 transcription factor. Mol Cell Biol 2008, 28:4772-4781.

84. Mani SA, Yang J, Brooks M, Schwaninger G, Zhou A, Miura N, Kutok JL, Hartwell K, Richardson AL, Weinberg RA: Mesenchyme Forkhead 1 (FOXC2) plays a key role in metastasis and is associated with aggressive basal-like breast cancers. Proc Natl Acad Sci U S A 2007, 104:10069-10074. 
85. Foubert E, De Craene B, Berx G: Key signalling nodes in mammary gland development and cancer. The Snail1Twist1 conspiracy in malignant breast cancer progression. Breast Cancer Res 12:206.

86. Spaderna S, Schmalhofer O, Wahlbuhl M, Dimmler A, Bauer K, Sultan A, Hlubek F, Jung A, Strand D, Eger A, et al.: The transcriptional repressor ZEB1 promotes metastasis and loss of cell polarity in cancer. Cancer Res 2008, 68:537-544.

87. Wellner U, Schubert J, Burk UC, Schmalhofer O, Zhu F, Sonntag A, Waldvogel B, Vannier C, Darling D, zur Hausen A, et al.: The EMT-activator ZEB1 promotes tumorigenicity by repressing stemness-inhibiting microRNAs. Nat Cell Biol 2009, 11:1487-1495.

88. Leu MH, Huang CC, Pan MR, Chen HH, Hung WC: Prospero homeobox 1 promotes epithelial-mesenchymal transition in colon cancer cells by inhibiting E-cadherin via miR-9. Clin Cancer Res.

89. Zhang L, Yang M, Gan L, He T, Xiao X, Stewart MD, Liu X, Yang L, Zhang T, Zhao Y, et al.: DLX4 Upregulates TWIST and Enhances Tumor Migration, Invasion and Metastasis. Int J Biol Sci 8:1178-1187.

90. Sun YY, Lu M, Xi XW, Qiao QQ, Chen LL, Xu XM, Feng YJ: Regulation of epithelial-mesenchymal transition by homeobox gene DLX4 in JEG-3 trophoblast cells: a role in preeclampsia. Reprod Sci 18:1138-1145.

91. Yu M, Smolen GA, Zhang J, Wittner B, Schott BJ, Brachtel E, Ramaswamy S, Maheswaran S, Haber DA: A developmentally regulated inducer of EMT, LBX1, contributes to breast cancer progression. Genes Dev 2009, 23:1737-1742.

92. Micalizzi DS, Christensen KL, Jedlicka P, Coletta RD, Baron AE, Harrell JC, Horwitz KB, Billheimer D, Heichman KA, Welm AL, et al.: The Six1 homeoprotein induces human mammary carcinoma cells to undergo epithelialmesenchymal transition and metastasis in mice through increasing TGF-beta signaling. J Clin Invest 2009, 119:2678-2690.

93. McCoy EL, Iwanaga R, Jedlicka P, Abbey NS, Chodosh LA, Heichman KA, Welm AL, Ford HL: Six1 expands the mouse mammary epithelial stem/progenitor cell pool and induces mammary tumors that undergo epithelialmesenchymal transition. J Clin Invest 2009, 119:2663-2677.

94. Ono H, Imoto I, Kozaki K, Tsuda H, Matsui T, Kurasawa Y, Muramatsu T, Sugihara K, Inazawa J: SIX1 promotes epithelial-mesenchymal transition in colorectal cancer through ZEB1 activation. Oncogene.

95. Gouti M, Briscoe J, Gavalas A: Anterior Hox genes interact with components of the neural crest specification network to induce neural crest fates. Stem Cells 29:858-870.

96. Chen YH, Ishii M, Sucov HM, Maxson RE, Jr.: Msx1 and Msx2 are required for endothelial-mesenchymal transformation of the atrioventricular cushions and patterning of the atrioventricular myocardium. $B M C D e v$ Biol 2008, 8:75.

97. Thillainadesan G, Chitilian JM, Isovic M, Ablack JN, Mymryk JS, Tini M, Torchia J: TGF-beta-dependent active demethylation and expression of the p15ink4b tumor suppressor are impaired by the ZNF217/CoREST complex. Mol Cell 46:636-649.

98. Gregory PA, Bracken CP, Smith E, Bert AG, Wright JA, Roslan S, Morris M, Wyatt L, Farshid G, Lim YY, et al.: An autocrine TGF-beta/ZEB/miR-200 signaling network regulates establishment and maintenance of epithelialmesenchymal transition. Mol Biol Cell 22:1686-1698.

99. Massague J: TGFbeta in Cancer. Cell 2008, 134:215-230.

100. Massague J: TGFbeta signalling in context. Nat Rev Mol Cell Biol 13:616-630.

101. Shirakihara T, Horiguchi K, Miyazawa K, Ehata S, Shibata T, Morita I, Miyazono K, Saitoh M: TGF-beta regulates isoform switching of FGF receptors and epithelial-mesenchymal transition. EMBO J 30:783-795.

102. Chua HL, Bhat-Nakshatri P, Clare SE, Morimiya A, Badve S, Nakshatri H: NF-kappaB represses E-cadherin expression and enhances epithelial to mesenchymal transition of mammary epithelial cells: potential involvement of ZEB1 and ZEB-2. Oncogene 2007, 26:711-724.

103. Ohashi S, Natsuizaka M, Wong GS, Michaylira CZ, Grugan KD, Stairs DB, Kalabis J, Vega ME, Kalman RA, Nakagawa $M$, et al.: Epidermal growth factor receptor and mutant p53 expand an esophageal cellular subpopulation capable of epithelial-to-mesenchymal transition through ZEB transcription factors. Cancer Res 70:4174-4184. 
104. Laberge RM, Awad P, Campisi J, Desprez PY: Epithelial-mesenchymal transition induced by senescent fibroblasts. Cancer Microenviron 5:39-44.

105. Gjorevski N, Boghaert E, Nelson CM: Regulation of Epithelial-Mesenchymal Transition by Transmission of Mechanical Stress through Epithelial Tissues. Cancer Microenviron 5:29-38.

106. Samavarchi-Tehrani P, Golipour A, David L, Sung HK, Beyer TA, Datti A, Woltjen K, Nagy A, Wrana JL: Functional genomics reveals a BMP-driven mesenchymal-to-epithelial transition in the initiation of somatic cell reprogramming. Cell Stem Cell 7:64-77.

107. Candia AF, Watabe T, Hawley SH, Onichtchouk D, Zhang Y, Derynck R, Niehrs C, Cho KW: Cellular interpretation of multiple TGF-beta signals: intracellular antagonism between activin/BVg1 and BMP-2/4 signaling mediated by Smads. Development 1997, 124:4467-4480.

108. Park SM, Gaur AB, Lengyel E, Peter ME: The miR-200 family determines the epithelial phenotype of cancer cells by targeting the E-cadherin repressors ZEB1 and ZEB2. Genes Dev 2008, 22:894-907.

109. Brabletz S, Brabletz T: The ZEB/miR-200 feedback loop--a motor of cellular plasticity in development and cancer? EMBO Rep 11:670-677.

110. Howe EN, Cochrane DR, Richer JK: Targets of miR-200c mediate suppression of cell motility and anoikis resistance. Breast Cancer Res 13:R45.

111. Gregory PA, Bert AG, Paterson EL, Barry SC, Tsykin A, Farshid G, Vadas MA, Khew-Goodall Y, Goodall GJ: The miR200 family and miR-205 regulate epithelial to mesenchymal transition by targeting ZEB1 and SIP1. Nat Cell Biol 2008, 10:593-601.

112. Warzecha CC, Jiang P, Amirikian K, Dittmar KA, Lu H, Shen S, Guo W, Xing Y, Carstens RP: An ESRP-regulated splicing programme is abrogated during the epithelial-mesenchymal transition. EMBO J 29:3286-3300.

113. Warzecha CC, Sato TK, Nabet B, Hogenesch JB, Carstens RP: ESRP1 and ESRP2 are epithelial cell-type-specific regulators of FGFR2 splicing. Mol Cell 2009, 33:591-601.

114. Bray SJ, Kafatos FC: Developmental function of Elf-1: an essential transcription factor during embryogenesis in Drosophila. Genes Dev 1991, 5:1672-1683.

115. Mace KA, Pearson JC, McGinnis W: An epidermal barrier wound repair pathway in Drosophila is mediated by grainy head. Science 2005, 308:381-385.

116. Lee $\mathrm{H}$, Adler PN: The grainy head transcription factor is essential for the function of the frizzled pathway in the Drosophila wing. Mech Dev 2004, 121:37-49.

117. Dynlacht BD, Attardi LD, Admon A, Freeman M, Tjian R: Functional analysis of NTF-1, a developmentally regulated Drosophila transcription factor that binds neuronal cis elements. Genes Dev 1989, 3:1677-1688.

118. Wang S, Samakovlis C: Grainy head and its target genes in epithelial morphogenesis and wound healing. Curr Top Dev Biol 98:35-63.

119. Dynlacht BD, Hoey T, Tjian R: Isolation of coactivators associated with the TATA-binding protein that mediate transcriptional activation. Cell 1991, 66:563-576.

120. Kim M, McGinnis W: Phosphorylation of Grainy head by ERK is essential for wound-dependent regeneration but not for development of an epidermal barrier. Proc Natl Acad Sci U S A 108:650-655.

121. Wang S, Tsarouhas V, Xylourgidis N, Sabri N, Tiklova K, Nautiyal N, Gallio M, Samakovlis C: The tyrosine kinase Stitcher activates Grainy head and epidermal wound healing in Drosophila. Nat Cell Biol 2009, 11:890-895.

122. Harrison MM, Botchan MR, Cline TW: Grainyhead and Zelda compete for binding to the promoters of the earliestexpressed Drosophila genes. Dev Biol 345:248-255.

123. Tuckfield A, Clouston DR, Wilanowski TM, Zhao LL, Cunningham JM, Jane SM: Binding of the RING polycomb proteins to specific target genes in complex with the grainyhead-like family of developmental transcription factors. Mol Cell Biol 2002, 22:1936-1946.

124. Huang JD, Dubnicoff T, Liaw GJ, Bai Y, Valentine SA, Shirokawa JM, Lengyel JA, Courey AJ: Binding sites for transcription factor NTF-1/Elf-1 contribute to the ventral repression of decapentaplegic. Genes Dev 1995, 9:3177-3189. 
125. Wilanowski T, Tuckfield A, Cerruti L, O'Connell S, Saint R, Parekh V, Tao J, Cunningham JM, Jane SM: A highly conserved novel family of mammalian developmental transcription factors related to Drosophila grainyhead. Mech Dev 2002, 114:37-50.

126. Auden A, Caddy J, Wilanowski T, Ting SB, Cunningham JM, Jane SM: Spatial and temporal expression of the Grainyhead-like transcription factor family during murine development. Gene Expr Patterns 2006, 6:964-970.

127. Wilanowski T, Caddy J, Ting SB, Hislop NR, Cerruti L, Auden A, Zhao LL, Asquith S, Ellis S, Sinclair R, et al.: Perturbed desmosomal cadherin expression in grainy head-like 1-null mice. EMBO J 2008, 27:886-897.

128. Boglev Y, Wilanowski T, Caddy J, Parekh V, Auden A, Darido C, Hislop NR, Cangkrama M, Ting SB, Jane SM: The unique and cooperative roles of the Grainy head-like transcription factors in epidermal development reflect unexpected target gene specificity. Dev Biol 349:512-522.

129. Dworkin S, Jane SM, Darido C: The planar cell polarity pathway in vertebrate epidermal development, homeostasis and repair. Organogenesis 7:202-208.

130. Darido C, Jane SM: Grhl3 and GEF19 in the front rho. Small GTPases 1:104-107.

131. Caddy J, Wilanowski T, Darido C, Dworkin S, Ting SB, Zhao Q, Rank G, Auden A, Srivastava S, Papenfuss TA, et al.: Epidermal wound repair is regulated by the planar cell polarity signaling pathway. Dev Cell 19:138-147.

132. Darido C, Georgy SR, Wilanowski T, Dworkin S, Auden A, Zhao Q, Rank G, Srivastava S, Finlay MJ, Papenfuss AT, et al.: Targeting of the Tumor Suppressor GRHL3 by a miR-21-Dependent Proto-Oncogenic Network Results in PTEN Loss and Tumorigenesis. Cancer Cell 20:635-648.

133. Bhandari A, Gordon W, Dizon D, Hopkin AS, Gordon E, Yu Z, Andersen B: The Grainyhead transcription factor Grhl3/Get1 suppresses miR-21 expression and tumorigenesis in skin: modulation of the miR-21 target MSH2 by RNA-binding protein DND1. Oncogene. 


\section{Chapter 2 \\ Suppression of the epithelial to mesenchymal transition by grainyhead like 2}

Published in:

Cieply B, Riley Pt, Pifer PM, Widmeyer J, Addison JB, Ivanov AV, Denvir J, Frisch SM: Suppression of the Epithelial-Mesenchymal Transition by Grainyhead-like-2. Cancer Res 72:2440-2453. 
Grainyhead genes are involved in wound healing and developmental neural tube closure. In light of the high degree of similarity between the epithelial-mesenchymal transitions (EMT) occurring in wound healing processes and the cancer stem cell-like compartment of tumors, including TGF- $\beta$-dependence, we investigated the role of the Grainyhead gene, Grainyhead-Like-2 (GRHL2) in oncogenic EMT. GRHL2 was down-regulated specifically in the claudin-low subclass breast tumors and in basal-B subclass breast cancer cell lines. GRHL2 suppressed TGF- $\beta$-induced, Twist-induced or spontaneous EMT, enhanced anoikis-sensitivity, and suppressed mammosphere generation in mammary epithelial cells. These effects were mediated in part by suppression of ZEB1 expression via direct repression of the ZEB1 promoter. GRHL2 also inhibited Smad-mediated transcription and it upregulated mir200b/c as well as the TGF- $\beta$ receptor antagonist, BMP2. Lastly, ectopic expression of GRHL2 in MDA-MB-231 breast cancer cells triggered a mesenchymal-to-epithelial transition and restored sensitivity to anoikis. Taken together, our findings define a major role for GRHL2 in the suppression of oncogenic EMT in breast cancer cells. 


\section{INTRODUCTION}

The oncogenic EMT is a transcriptional re-programming event that endows restricted subclasses of tumor cells with enhanced metastatic and stem cell-like properties. These properties include increased migration/invasion, chemo- and radiation-resistance, anoikis-resistance and extraordinary tumor initiation frequency, a cancer stem cell-like capability $(1,2)$. In breast cancer, two subclasses of tumors, "claudin-low" and "metaplastic", exhibit frank EMT-like gene expression signatures. These are among the most aggressive and least treatmentresponsive tumors (3).

In general, TGF- $\beta$ signaling can either promote or suppress tumorigenicity and progression $(4,5)$. It can suppress tumors through Smad-mediated induction of cyclin dependent kinase-inhibitor genes such as p15, and inactivating mutations in this pathway occur in certain tumors. In other contexts, however, TGF- $\beta$ can promote tumor progression by supporting oncogenic EMT induction, through both transcriptional and nontranscriptional mechanisms. For example, in claudin-low and metaplastic mammary tumors -- as well as in the stem cell-like CD $44^{\text {high }} / \mathrm{CD} 24^{\text {low }}$ tumor cell subpopulation fractionated from breast tumors of other subclasses -TGF- $\beta$ pathway components are strikingly up-regulated and, indeed, TGF- $\beta$ receptor kinase inhibitors partially revert the EMT-related gene expression profile $(3,6)$. This indicates a pro-tumorigenic role of the TGF$\beta$ pathway in this context.

Cell culture models confirm these conclusions. An extensively characterized SV40 large T/hTERTimmortalized mammary epithelial cell line, HMLE, exhibits spontaneous EMT in a subpopulation of CD $44^{\text {high }} / \mathrm{CD} 24^{\text {low }}$ cells (7). This EMT is accompanied by up-regulation of autocrine TGF- $\beta$ signaling, mainly through down-regulation of antagonists such as BMP2/4. Reversion to an epithelial phenotype could be achieved by inhibition of this signaling pathway. Moreover, even Twist-induced EMT in this system was partially dependent upon autocrine TGF- $\beta$ signaling, demonstrating its functional significance in multiple contexts. 
The similarities between oncogenic and wound-healing-related EMT, including TGF- $\beta$-dependence, have been documented (8-10). In this light, we hypothesized that perhaps other “dedicated” wound-healing genes might prove important in oncogenic EMT. Grainyhead family genes have been shown to play an important role in wound-healing, epidermal integrity and the mechanistically related process of embryonic neural tube closure (11-14). Relevant, albeit limited, Grainyhead family target genes identified so far include E-cadherin, claudin-4, desmoglein-1, transglutaminase-1, rho-GEF19, several Zelda-target genes expressed during the maternal-zygotic transition in Drosophila, and telomerase (11, 12, 14-17). With regard to cancer, GRHL2 gene amplification has been noted in several tumor types, including breast cancer, and suppressed death receptor expression, conferring resistance to apoptosis mediated by the corresponding ligands, indicating that GRHL2 was a potential oncogene (18). On the other hand, GRHL3 was recently shown to suppress squamous cell carcinoma, due to its activation of PTEN expression (19).

Inspired by its role in wound-healing, we hypothesized and report here that GRHL2 suppressed EMT mediated by the TGF- $\beta$ signaling pathway. Consistent with this effect, GRHL2 was down-regulated specifically in EMT-dependent mammary tumors (claudin-low, metaplastic) and cell lines (basal B). ZEB1 was found to be required for EMT and was a direct target for repression by GRHL2. GRHL2 also enhanced anoikissensitivity. These data suggest an EMT-suppressive function of GRHL2 that is down-regulated in the context of TGF- $\beta$ /EMT-driven tumor types. 
MATERIALS AND METHODS

Cell lines

HMLE, HMLE+twist-ER, and HMLE+Ras cells (HMLER) were generous contributions from R. Weinberg (The Whitehead Institute). HMLE and HMLE+Twist-ER were grown in a 1:1 mixture of MEGM (Lonza) and [DME/F12(Gibco)+5\% horse serum+1X penicillin-streptomycin-glutamine (PSG) +10 $\mu \mathrm{g} / \mathrm{ml}$ insulin, $10 \mathrm{ng} / \mathrm{ml}$ EGF, $0.5 \mu \mathrm{g} / \mathrm{ml}$ hydrocortisone], where indicated, 4-hydroxytamixofen (10ng/ml) was added to the HMLE+Twist-ER cells to activate the Twist-ER protein. HMLER cells were grown in MEGM. MDA-MB231LN were provided by E. Pugacheva (West Virginia University) and were grown in Advanced DMEM (Invitrogen)+10\% fetal bovine serum+1X penicillin-streptomycin-glutamine (PSG).

Generation of stable cell lines by retroviral transduction.

Human GRHL2 was amplified from a template purchased from Open Biosystems (MHS4426-99625903) and subcloned by standard molecular biology methods into the pMIG or MSCV-IRES-puro retrovirus (Addgene; XhoI site). Retroviruses were packaged and amplified in GP2+293T cells by transfection of $4.5 \mu$ g of retroviral plasmid and $2.5 \mu \mathrm{g}$ of pCMV-VSV-G per $60 \mathrm{~mm}^{2}$ dish of cells, using Mirus TransIT reagent. Viral supernatants were collected forty-eight hours later, filtered through 0.45 micron filters (Whatman) and 0.6 ml of supernatant was used to infect one well of a 6-well dish of target cells by centrifugation at 1400 rpm for one hour followed by 6 hour to overnight incubation. Infected cells were either selected for puromycin ( $2 \mu \mathrm{g} / \mathrm{ml}$ for HMLE, 0.5 $\mu \mathrm{g} / \mathrm{ml}$ for MDA-MB-231) or flow-sorted for GFP, followed by western blot analysis to verify expression.

Generation of stable cell knockdown cell lines by lentiviral transduction, and transient knockdown (siRNA). GRHL2, ZEB1 and scrambled control shRNAs were purchased from Open Biosystems in the pGIPZ vector. (Catalogue numbers: shGRHL2a: RHS4430-99291384; shGRHL2b: RHS4430-99614394 . shZEB1a: V3LHS_356186 and shZEB1b: 3 V3LHS_356187; the latter were also sub-cloned into vector pTRIPz using 
Mlu1/Xho fragments). SiZEB1 Smartpool was from Dharmacon catalogue number (L-006564-01-0005) and was transfected transiently using Lipofectamine RNAi-max (Invitrogen).

\section{Mammosphere assay}

Mammospheres were seeded at $1 \times 10^{4}$ cells/ well of a 6 well Ultra Low Cluster Plate (Corning) and grown for 7 to 10 days in the appropriate growth media $+0.5 \%$ methylcellulose (MC). Wells were fed every third day with 1ml media+MC. Total mammospheres/well were counted and the size cutoff was set at 150mm in diameter; the same cells were plated at $2 \times 10^{5}$ cells/well of a 6-well plate and the number of cells was counted each day for 4 days, to measure normal growth rate. Error bars represent the standard deviation of replicates.

\section{$\underline{\text { Anoikis assays }}$}

Cells were dissociated using TrypLE Express (Invitrogen), counted and a fixed amount (1x10 $0^{5}$ to $2 \times 10^{5}$ cells/well of a 6-well Ultra-Low Attachment Cluster Dish (Costar) were suspended in normal growth media $+0.5 \% \mathrm{MC}$ for the indicated for 6 to 24 hours to induce anoikis. For Cell Death ELISA (CDE) analysis of apoptotic DNA fragmentation, the cells were collected in 3 volumes of media and then spun down at 1500rpm for 3min. The pellet was then washed with D-PBS (Invitrogen) transferred to a microfuge tube, pelleted at 7,000 rpm for 15 seconds and lysed in PBS+0.5\% Triton X 100+10mM EDTA (Note: the lysis buffer with the Cell Death ELISA kit from Roche was found to lyse cells inadequately). Lysates were incubated on ice for fifteen minutes with occasional mixing, and then centrifuged at 13,000rpm for 12 minutes. The supernatants were subjected to the CDE according to the manual provided with the kit (Roche). Alternatively, percentage cell death was determined by a trypan blue exclusion assay, wherein cells were suspended in same manner but collected and re-suspended in Accumax (Innovative Cell Technology) to ensure a single cell suspension. After brief incubation (2-3min) trypan blue was added to this solution and the \% dead cells were immediately counted on a hemacytometer. All samples were analyzed in either duplicate or triplicate, and time-zero cell death values were subtracted from the data presented here. 


\section{Three dimensional culture}

3D Matrigel culture methods were adapted from :(20). To summarize, $2.5 \times 10^{3}$ cells/well were seeded onto 8 well chamber slides (Labtek) where 45ul Matrigel(Trevigen) had been evenly distributed. The cells were overlaid with the appropriate growth media (see above) $+2.5 \%$ matrigel. After 6 days in culture 3D migration/invasion was quantified by counting the number of structures which had formed protrusions vs. those which grew as lobular structures defined by their contact with matrix. (see images for clarification). At least 200 structures were counted per experiment; error bars represent the standard deviation across three samples.

\section{Microarray methods}

RNA isolated by RNeasy Plus kit (Qiagen) was quantified using Nanodrop (Fisher Scientific). The RNA quality was check on Bioanalyzer (Agilent). Two hundred fifty nanograms of each RNA sample with an RIN value greater than seven was processed using the Ambion WT Expression Kit according to the manufacturer’s instructions. The typical yield from the reaction was 6-9 micrograms of cDNA. The required amount of cDNA (5.5 micrograms) was processed for fragmentation and biotin labeling using the Gene Chip WT Terminal

Labeling Kit (Affymetrix). The efficiency of fragmentation reaction was checked via Agilent Bioanalyzer. The entire reaction of fragmented and biotin-labeled cDNA (50 microliters) with added hybridization controls was hybridized to the human GeneChip 1.0 ST Exon Arrays (Affymetrix) at $45^{\circ} \mathrm{C}$ for 17 hours in GeneChip Hybridization Oven 640 (Affymetrix). Human GeneChip 1.0 ST Exon Arrays were stained using FS 450_0001 protocol in Affymetrix GeneChip Fluidics Station 450. Briefly: Biotin-labeled cDNA was reacted using two rounds of washes with a solution containing a streptavidin-phycoerythrin complex, with an intermediate treatment of biotin-labeled anti-streptadvidin antibody to amplify the signal. Phycoerythrin labeling was detected within the Affymetrix GeneChip Scanner 3000 7G plus using 532 nm light and detected by a photomultiplier tube. Expression Consol software (Affymetrix) was used to check quality controls of 
hybridized chips. All chips that passed quality controls were RMA normalized using Expression Console software. The microarray data were deposited into the NCBI GEO database as accession number GSE36081.

To examine the extent to which GRHL2 affects the propensity to undergo Epithelial to Mesenchymal Transition (EMT), we compared the relative expression of genes in an identified EMT signature (21) to the relative expression of genes in cells with constitutive GRHL2 expression. Specifically, we obtained the expression profile of the 251 Core EMT signature genes from table S1 of (21) and computed the mean log ratio of the relative expression. We restricted the genes to those which appeared on our array platform and computed the Pearson Correlation coefficient of those genes to the log expression ratio of GRHL2-regulated genes compared to the control.

\section{$\underline{\text { Reporter assays }}$}

HMLE were transiently transfected using Lipofectamine 2000 (Invitrogen) at a $1 \mu \mathrm{g}$ DNA:2ul Lipofectamine ratio. $1.5 \mu \mathrm{g}$ DNA/well of a 12 well was the maximum amount of DNA found to be tolerable. Transfection mixtures were incubated for 20 minutes in $200 \mu \mathrm{l}$ Opti-MEM (Invitrogen) and then added to the cells in normal growth media lacking antibiotics. Cells were incubated for $4 \mathrm{~h}$ then re-fed with normal growth media. Lysates were made by washing the cells once with PBS then lysing in 1x Cell Culture Lysis Buffer (Promega). Lysates were centrifuged at 13, 000 rpm for 10 minutes and the supernatants were assayed for luciferase and $\beta$ galactosidase activity as internal control. Luciferase assay reagent was obtained from Promega and the $\beta$ galactosidase $2 \mathrm{X}$ assay reagent was $200 \mathrm{mM}$ sodium phosphate (pH 7.3), $2 \mathrm{mM} \mathrm{MgCl}_{2}, 100 \mathrm{mM} 2-$ mercaptoethanol, and $1.33 \mathrm{mg} / \mathrm{ml}$ o-nitrophenylgalactoside. The Smad reporter construct 3TP-Lux was from Addgene. The ZEB1 promoter-luciferase construct in pGL3 (22) was kindly provided by Antonio Garcia de Herreros (Barcelona, Spain). CMV-LacZ or TK-LacZ were used as internal controls. The GRHL2 clone was purchased from Open biosystems, cat \# MHS4426-99625903, and the coding sequence was cloned into the 
XhoI site of pcDNA3.1+ . Sub-fragments of the ZEB1 promoter were generated and cloned into pGL3promoter (MluI-BglII) using the following primers: Fragment 1: ZPfr1-f:Ttaat ACGCGT CCTTAAGGTCCTGCACGGCG, ZPfr1-r: tatat agatct AAGTTCCGCTTGCCAGCAGC; Fragment 2: ZPfr2-f: TtaatACGCGT CTAGCCTCTCTTTCAATCCA, ZPfr2-r: tatatagatctTCCGCCCCCCGCACCCCGGGGC; Fragment 3: ZPfr3-f: TtaatACGCGTCACGCGAGGCGTGGGACTGA, ZPfr3-r: tatat agatct GGATGCCGGGAAACCGTAGG; Fragment 4: ZPfr4-f: Ttaat ACGCGT GCCTCCCTCTCCCCACCACA, ZPfr4-r: tatat agatct ACCGCACCTGGTTTACGACA; Fragment 5: ZPfr5-f: TtaatACGCGT GCGGACCGGGTGTGGGAGGC, ZPfr5-r: tatat agatct TACCTGACCCGCGCAGCCCG; Fragment 6: ZPfr6-f: Ttaat ACGCGT GCCTCTCTCCGGTCGCCGCG, ZPfr6-r: tatatagatct GGGGCAGGGAGGGATCTGGC, Fragment 7:

ZPfr7-f: Ttaat ACGCGT GGGCAGCCGCGGCGGGTGTG, ZPfr7-r: tatat agatct ACCGTGGGCACTGCTGAATT.

The primers used to mutate the fragment 4 construct (using Stratagene Quickchange II XL kit) were: Mutf:gtaaagccgggagtgtcgtcccacaggtgcggtagatctgcg;Mut-r: cgcagatctaccgcacctgtgggacgacactcccggctttac Immunofluorescence

For Smad2 localization, TGF- $\beta$ ( $5 \mathrm{ng} / \mathrm{ml}$ ) was added for $6 \mathrm{~h}$ and the coverslips were fixed with $4 \%$ paraformaldehyde(PFA) in PBS for 10minutes. PFA was quenched with $100 \mathrm{mM}$ glycine in PBS. Cells were permeabilized with $0.2 \%$ TX100 in PBS at 4 degrees for 10minutes, washed twice with PBS, and blocked for one hour in: $\mathrm{PBS}+10 \%$ goat serum $+0.1 \%$ Tween-20+0.1\%BSA. Primary and secondary antibodies were diluted in blocking buffer. Primary antibodies were as follows: SMAD2, Cell Signaling, rb, 1:200. Secondary: rb Alexa 555(red), Molecular Probes, 1:1000. Mounting media: Prolong Gold w/ DAPI (Invitrogen). 
For E-Cadherin, vimentin and GRHL2 the cells were fixed in $100 \%$ Methanol at $-20^{\circ} \mathrm{C}$ for at least 1 hour. They were then washed twice with PBS and blocked as above. Ecadherin, ms, BD, 1:200; Vimentin, rb, Cell Signalling, 1:200; GRHL2, rb, Sigma, 1:200. Secondaries used were anti-mouse Alexa 555 (red) or anti-rabbit Alexa 488(green) or A555 (red), (Molecular Probes), diluted 1:1000. Coverslips were mounted in Prolong Gold as above. Images were produced using the Axiovert 200M microscope, AxioCam MRM camera, and Axio Vision 4.3.1 software (Zeiss).

\section{$\underline{\text { CHIP }}$}

5 x100mm dishes of 4-OHT-induced HMLE+twist-ER (+GRHL2, in some experiments) were each fixed in 1.2ml 10\% electron microscopy grade paraformaldehyde for 10 minutes. Following quenching with glycine, CHIP was performed exactly as described previously (23) with the following antibodies: (3.3 $\mu$ g each): GRHL2 (Sigma); Histone H3 (Cell Signaling), or non-immune rabbit IgG (Pierce). CHIP-derived DNA was analyzed by PCR using the following primer sets: ZEBf6: GCGAGGCGTGGGACTGATGG; ZEBr6: AAAGTGGAGGCTCGGCGGC; $\quad$ ZEBf10: $\quad$ CTGCACGGCGATGACCGCT; $\quad$ ZEBr10: TTCCGCTTGCCAGCAGCCTC; $\quad$ GAPDH-f: ATGGTTGCCACTGGGGATCT; $\quad$ GAPDH-r: TGCCAAAGCCTAGGGGAAGA. For qPCR analysis, CHIP DNAs were analyzed using 2X Power-Sybr Green Master Mix (Applied Biosystems) and signals were calculated relative to input DNA using the “ $\Delta \Delta$-Ct” method; a correction of $1.5 \mathrm{X}$ was applied to adjust for the higher efficiency of GAPDH amplification compared with ZEB1 amplification obtained in a control reaction using lysates from GRHL2-null cells. The primer set used was F8: GCCGCCGAGCCTCCAACTTT; R8: TGCTAGGGACCGGGCGGTTT.

\section{Western blotting}

SDS-PAGE was conducted using 4-20\% gradient Tris Glycine gels, (Invitrogen). Proteins were immobilized by electophoretically transferring them to a PVDF filter (Immobilon FL, Millipore) in 5\% MeOH containing 
Tris-Glycine transfer buffer. Filters were blocked in PBS+5\% non-fat milk, primary antibodies were incubated in PBS+0.1\% Tween20+5\% non-fat milk, secondaries were incubated in PBS+0.1\% Tween20+5\%milk+0.01\% SDS. Primaries were typically incubated for $2 \mathrm{~h}$ to overnight, secondaries were incubated for $1 \mathrm{~h}$. Primaries used were: Ecadherin, ms, BD Biosciences(BD); Vimentin, ms, Santa Cruz Bio-Tech(SCBT); N-Cadherin, ms, BD; CD44(HCAM), ms, SCBT; ESRP1/2, ms, (Contributed by Russ Carstens, University of Pennsylvania, Philadelphia, Pa); Actin, ms, Millipore; Akt, rb or ms, Cell Signaling(CS); GRHL2, rb, Sigma; Zeb1, rb, Sigma or rb, CS; Ankyrin-G, rb, S.M.F. custom generated (23); total-Smad2/3,ms, BD; phospho-Smad2/3, rb, CS; NF2(merlin), rb, SCBT. Secondary antibodies for chemi-luminescence were either anti-mouse or anti-rabbit, conjugated to horseradish peroxidase (Biorad) and were used at 1:3000 dilution; western blots were developed using (ECL-West Pico, Pierce). Fluorescently tagged secondary antibodies were mouse IRDye 800CW or rabbit IRDye 680LT (Li-Cor) used at 10:000 and detected using the Odyssey Infrared Imaging System (Li-Cor). Fluorescent images were converted to gray scale.

\section{Other bioinformatics methods}

We obtained GRHL2 expression data from NCBI Gene Expression Omnibus (accession number GSE10885

(3)). We compared the log expression of GRHL2 among the tumor types Basal, Claudin, Her2, Luminal, and Normal. We performed a Tukey HSD test to determine which comparisons among these groups demonstrated statistically significant differences; family-wise 95\% confidence intervals for the log expression were plotted. Statistical analyses were performed using R version 2.13.1 (www.r-project.org).

\section{RESULTS.}

Loss of GRHL2 Expression is Associated with a Mesenchymal Phenotype 


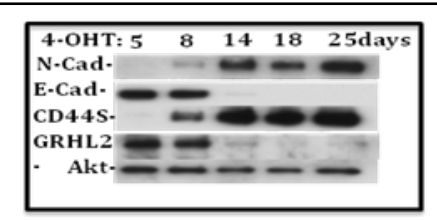

Figure 1a. Twist downregulates GRHL2. HMLE cells with tamoxifen-inducible twist (twist-ER) were induced with 4-hydroxytamoxifen for the indicated periods of time and analyzed for epithelial, mesenchymal and tumor intiating cell (CD44) marker genes.

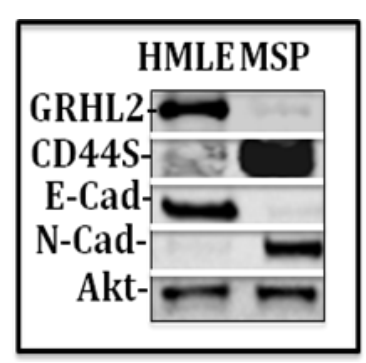

Figure 1b. GRHL2 is down-regulated in the Mesenchymal SubPopulation (MSP) cells relative to parental HMLE cells.
Based on the specific expression of GRHL2 in mouse epithelia (12-14, 24), we investigated its potential regulation during EMT. Using HMLE cells that express a twist-ER fusion -- a previously characterized model of inducible EMT (21) -- we analyzed the levels of GRHL2 over a time-course of twist induction by tamoxifen and found that, indeed, GRHL2 protein was

Figure 1c. GRHL2 is down-regulated specifically in "basal B" subclass of breast cancer cell lines characterized by Neve, et al. (42).

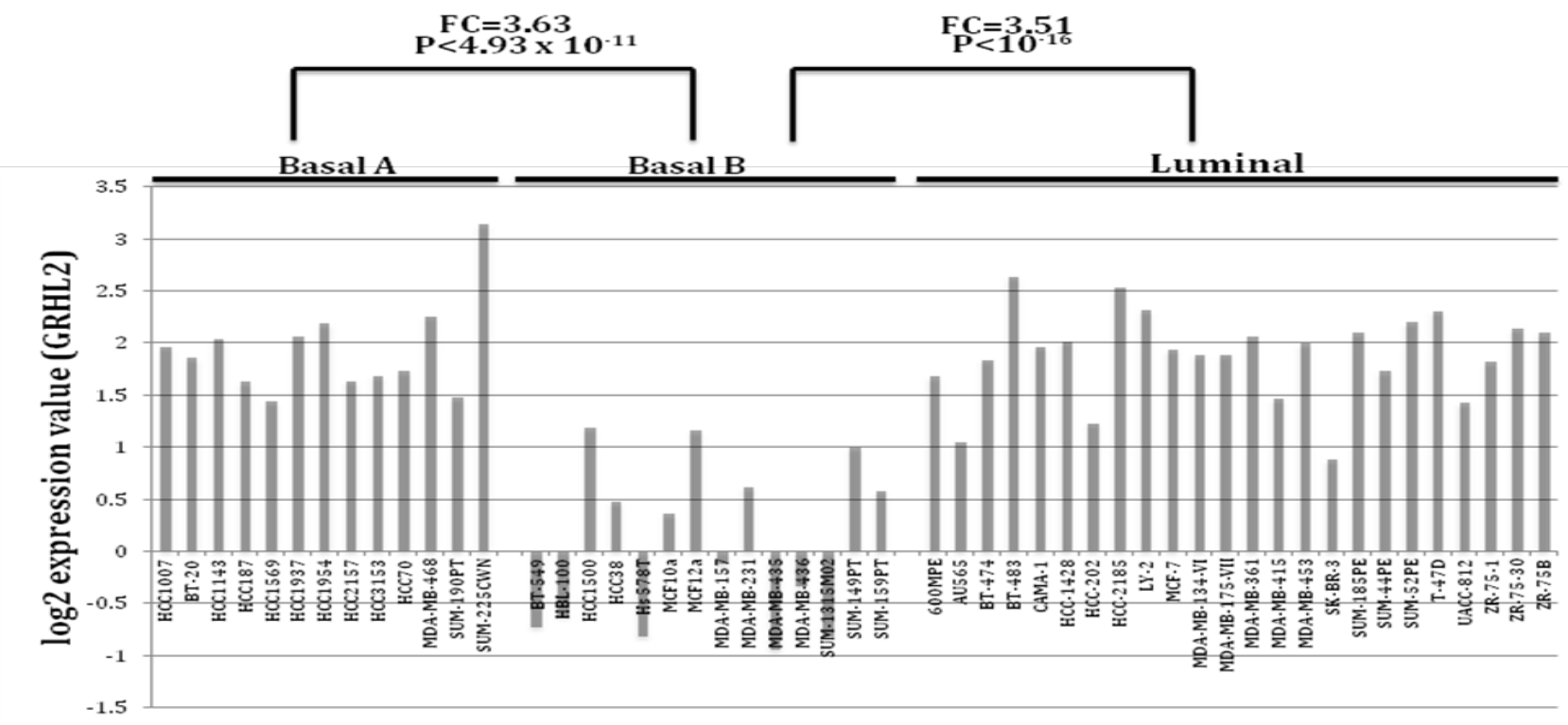

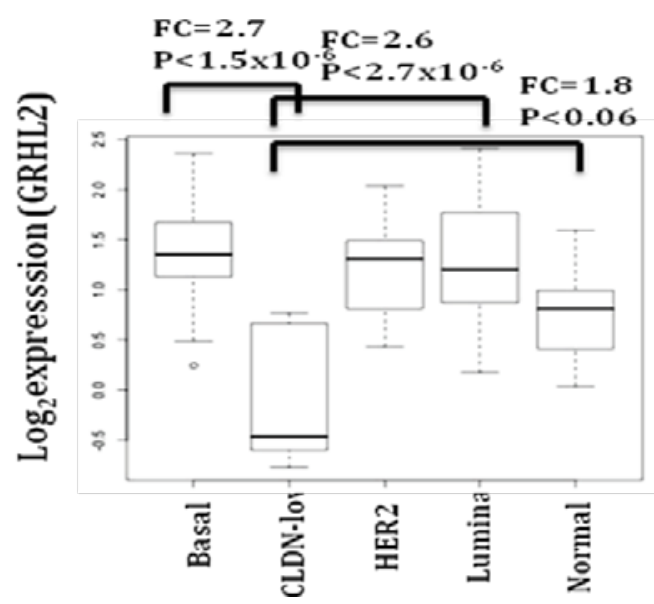

Figure 1d. GRHL2 is down-regulated specifically in the "claudin-low" subclass of breast cancer cell lines characterized by Hennessy, et al. (3). down-regulated during EMT with kinetics similar to the loss of

E-cadherin and gain of N-cadherin (Figure 1a). Consistent with this finding, spontaneous, stable EMT in a subpopulation of HMLE cells (“Mesenchymal Subpopulation”) obtained by sorting for CD44 ${ }^{\text {high }}$ phenotype, described previously (7), also displayed low GRHL2 expression (figure 1b). 


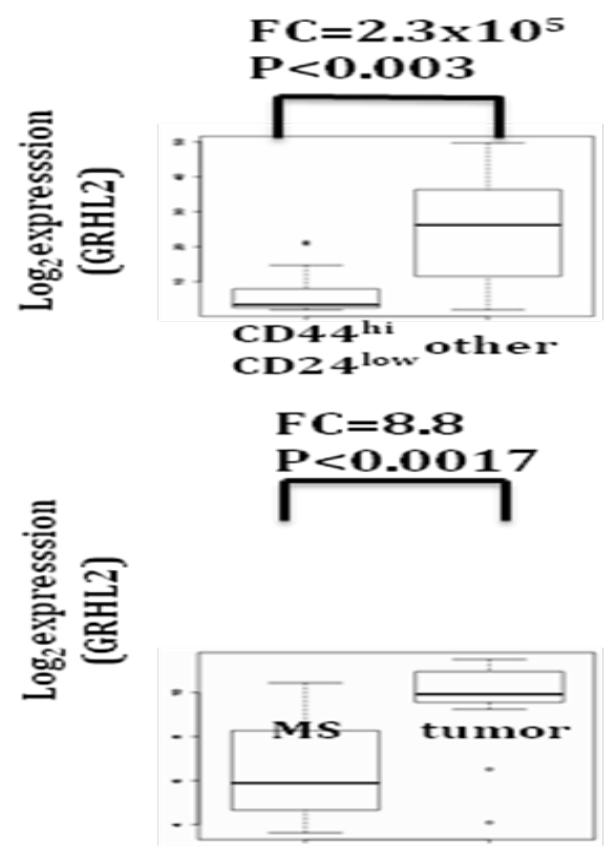

Figure 1e. GRHL2 is down-regulated specifically in the tumor initiating/mesenchymal cell subpopulation characterized by Creighton, et al (25).

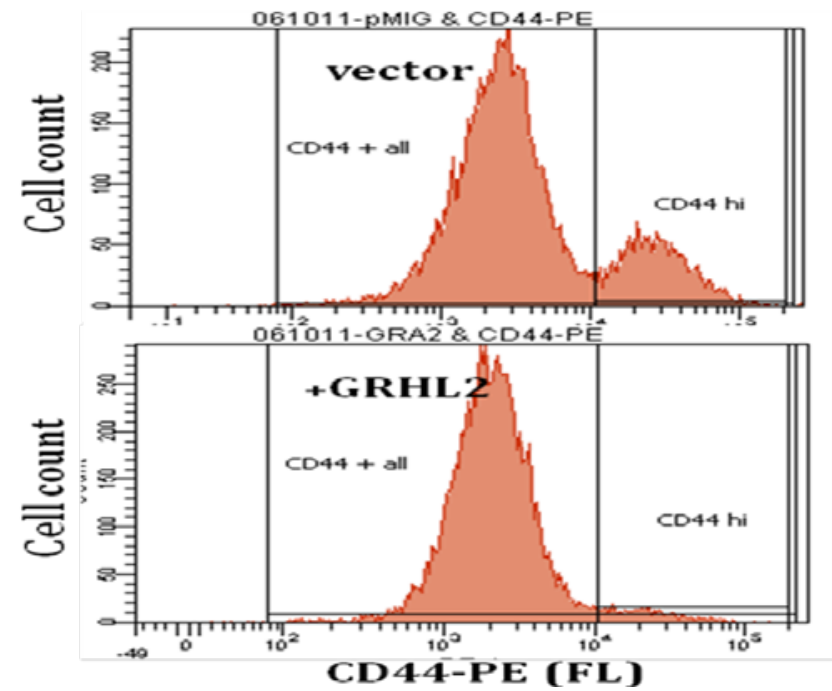

Figure 2a. Ectopic expression of GRHL2 suppresses the CD44 expression in the spontaneously occurring mesenchymal subpopulation of HMLE cells (“MSP”). HMLE+Twist-ER cells (without 4-OHT) infected with GRHL2 or empty retroviral vector (pMIG) were analyzed for CD44 expression by FACS.
Breast cancer cell lines have been classified by gene expression profiles. One particular subclass, basal B, was characterized by a mesenchymal profile. GRHL2 was dramatically down-regulated, specifically in this subclass (figure 1c).

Analogously, the "claudin-low” subclass of mammary tumor samples - also characterized by mesenchymal gene expression profile and poor prognosis-expressed substantially lower levels

of GRHL2 than other subclasses, which, in fact, showed a modest up-regulation, compared to normal breast tissue (figure 1d, and see Discussion). GRHL2 was also down-regulated dramatically in a different tumor type 
characterized by EMT, clear cell renal carcinoma (figure S1). Moreover, chemoresistant subpopulations of primary breast tumor cells obtained after chemotherapy of patients by sorting for CD $44^{\text {high }} / \mathrm{CD} 24^{\text {low }}$ marker

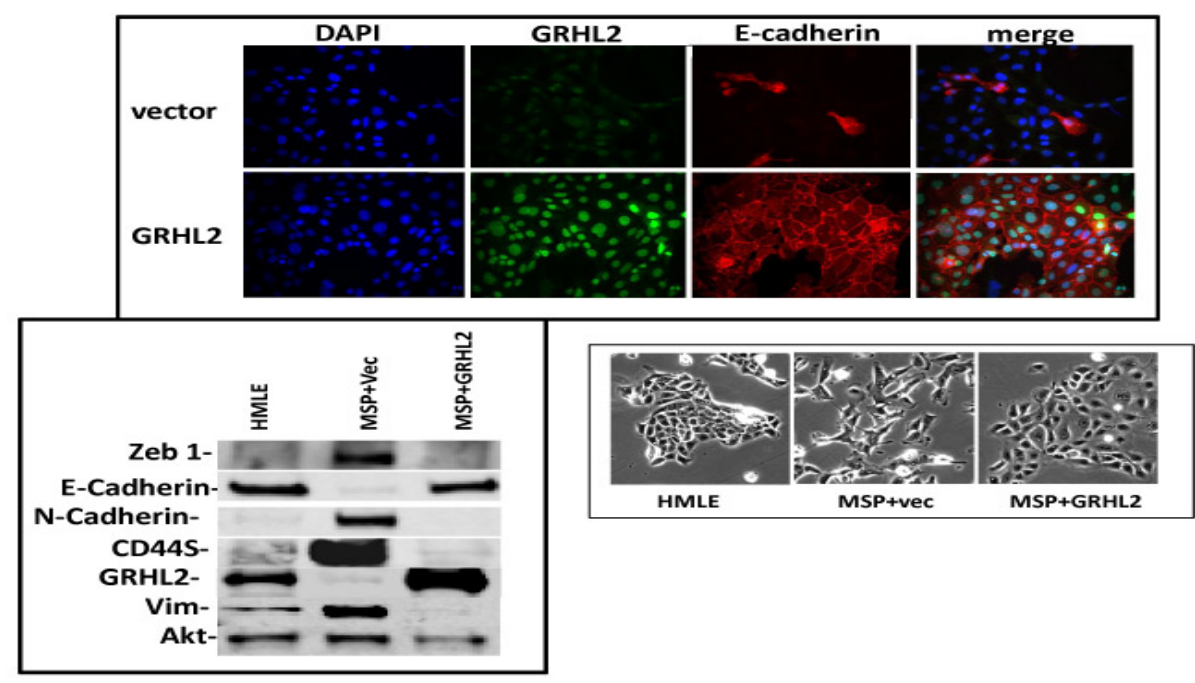

expression or mammosphere

generation (25) expressed

decreased levels of GRHL2 as

well (figure 1e).

These data suggested that

GRHL2 loss is a widespread

characteristic of both primary and

cultured tumor cells that have

Figure 2b. GRHL2 reverts MSP cells to an epithelial phenotype. The CD44 ${ }^{\text {high }}$ mesenchymal sub-population of HMLE, obtained by flow-sorting of HMLE cells, were infected with empty vector or GRHL2 and then (top panel) stained for the indicated proteins by immunofluorescence or (lower panel) probed for epithelial and mesenchymal marker genes by western blotting.

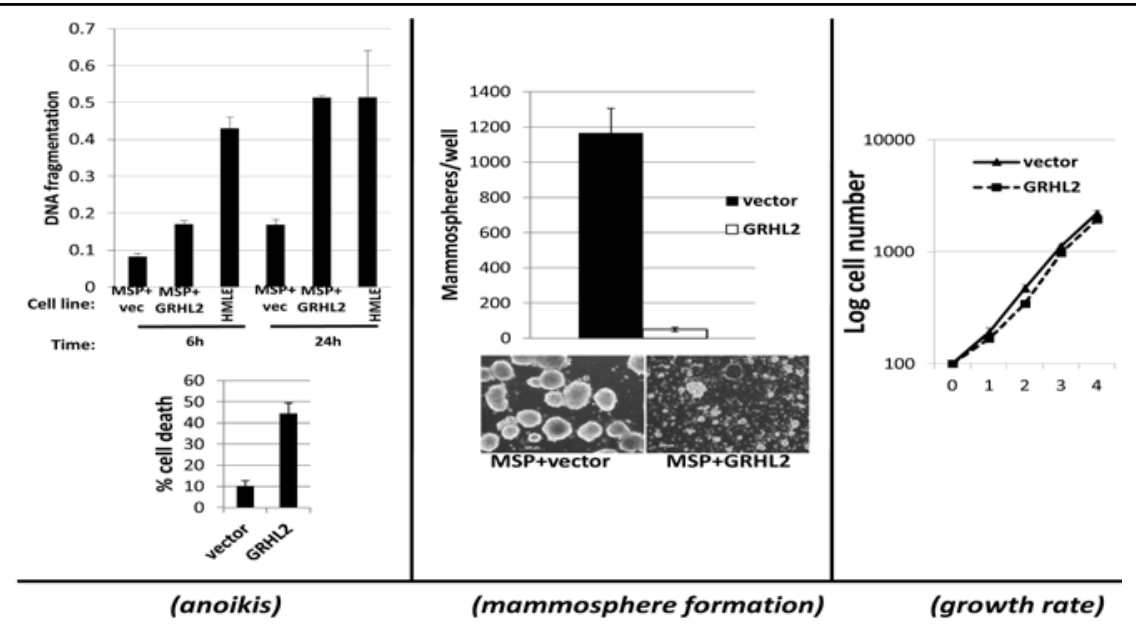

Figure 2c. GRHL2 expression in MSP cells restores anoikis-sensitivity (left panels: top graph represents a DNA fragmentation ELISA assay, lower graph represents a trypan blue-permeability assay) and reduces mammosphere (middle panels), without affecting growth rate (right panel). informed the hypothesis that GRHL2 down-regulation was functionally important for EMT.

\section{GRHL2 is an EMT suppressor}

The spontaneously occurring, CD44 ${ }^{\text {high }} \mathrm{CD} 24^{\text {low }}$ MSP cells within the heterogeneous HMLE cell line are characterized by EMT, attributed to autocrine signaling pathway activation

(7). Infection of HMLE cells with a GRHL2 expression construct and selection for the infected cells using a

GFP marker caused the disappearance of the CD44 ${ }^{\text {high }}$ subpopulation (figure 2a) within a few days after infection, suggesting a conversion effect rather than selective growth (as demonstrated below). 
To further characterize this phenomenon, we isolated MSP cells from the HMLE cell line by flow sorting and infected these with the GRHL2 retrovirus. Based on E-cadherin immunofluorescence and western blotting for epithelial and mesenchymal markers, GRHL2 reverted MSP back to an epithelial phenotype (figure 2b). Anoikis-resistance and the ability to form mammospheres are key characteristics associated with EMT in HMLE cells. GRHL2 expression in the MSP cells restored anoikis-sensitivity and reduced mammosphere formation dramatically, without affecting adherent cell growth (figure 2c).

These data indicated that GRHL2 reverted the spontaneous EMT and accompanying tumor initiating cell characteristics of MSP cells. To test the effect of GRHL2 in other scenarios of EMT, we expressed it constitutively in HMLE+Twist-ER cells and in the prototypical EMT-like/triple-negative breast cancer cell line, MDA-MB-231, where it caused dramatic reversion of EMT and anoikis-resistance in both cases (figures 2d,

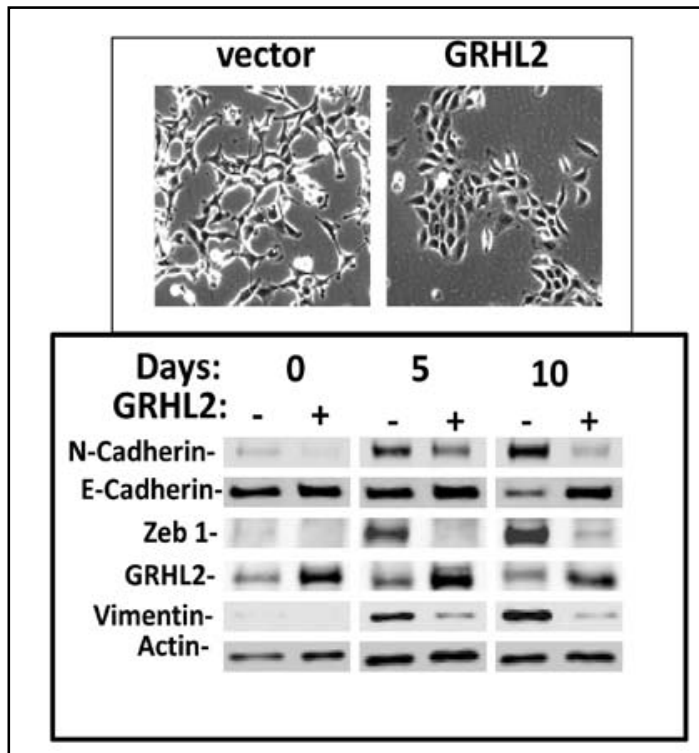

Figure 2d. GRHL2 suppresses Twist-induced EMT. HMLE+twist-ER expressing either empty vector or GRHL2 were treated with 4OHT (to activate the twist transgene) for 7 days, and (top panel) photographed to record morphology. (lower panel): Time course of changes in epithelial and mesenchymal marker genes after induction of the twist gene with 4OHT, in cells with or without ectopic GRHL2 expression.
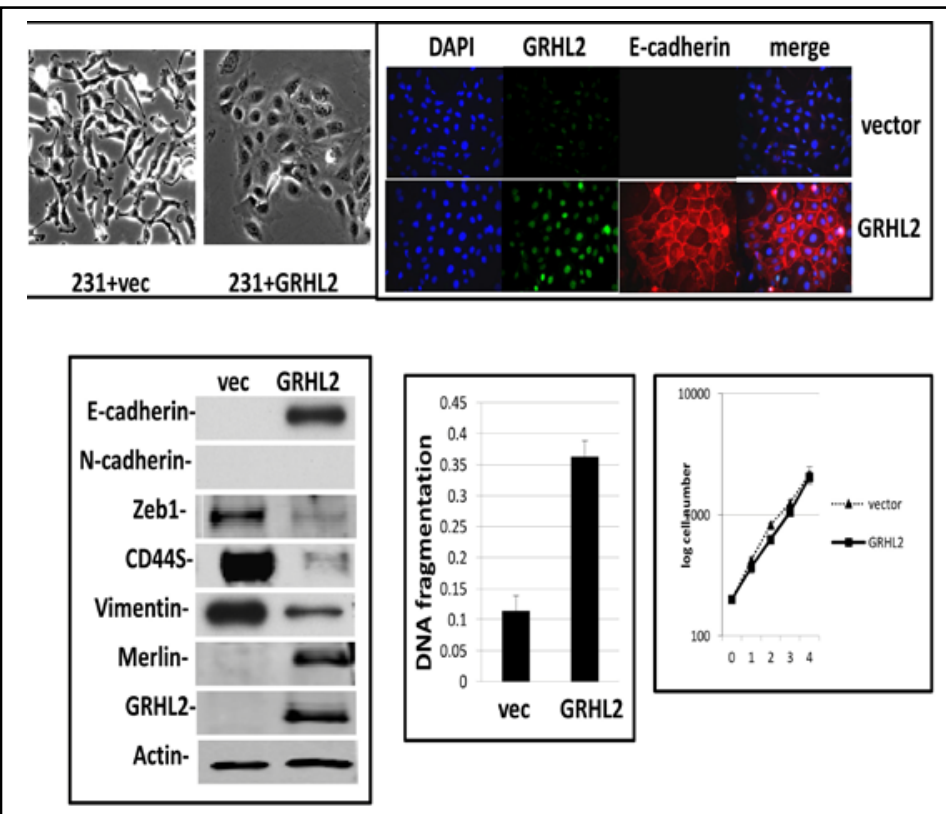

Figure 2e. GRHL2 suppresses EMT and anoikis-resistance in MDA-MB-231LN cells. MDA-MB-231LN expressing either empty vector or GRHL2 were analyzed for morphology (phase contrast microscopy,top left), E-cadherin expression and localization (immunofluorescence, top right), expression of epithelial and mesenchymal markers (western blotting, bottom left), anoikis-sensitivity (DNA fragmentation ELISA (middle) and adherent growth rate (lower right).

indicating a surprisingly broad specificity for this effect. 
GRHL2 suppresses TGF- $\beta$-induced EMT.

MSP cells and Twist-expressing HMLE cells rely on autocrine TGF- $\beta$ signaling for their maintenance of mesenchymal and tumor-initiating properties (7), suggesting that GRHL2 could be suppressing EMT through

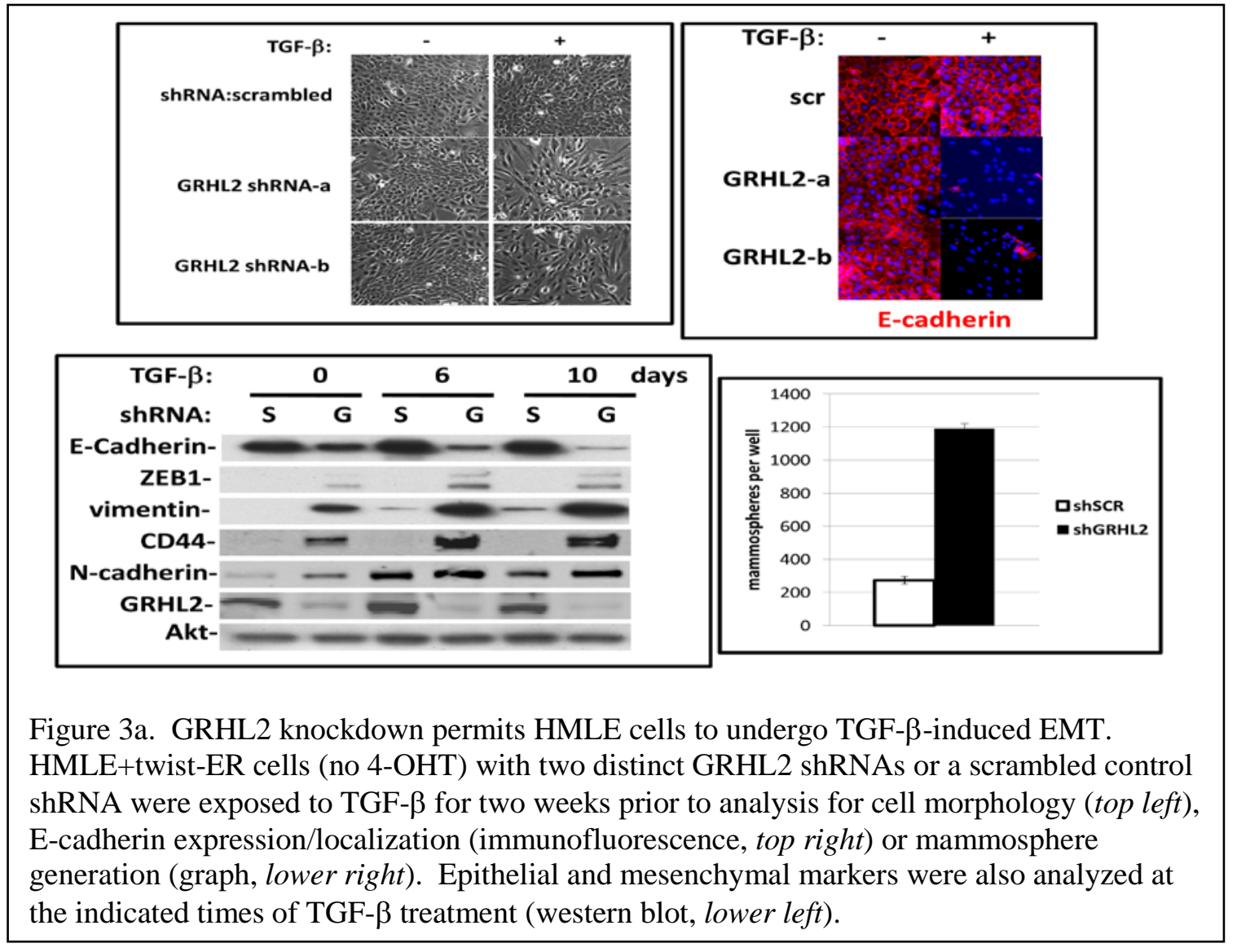

this common

pathway. We

confirmed that

twist-mediated

EMT and

acquisition of

anoikis-resistance

were TGF- $\beta$ -

dependent by using

LY364947, a

specific inhibitor of

the TGF- $\beta$ R1

kinase activity

(figure S2). Because this inhibitor mimicked the effects of ectopic GRHL2 in some respects, we tested the effect of GRHL2 on TGF- $\beta$-induced EMT. TGF- $\beta$ alone was previously reported to be insufficient for EMT induction in HMLE, a process requiring activation of multiple pathways (7). When GRHL2 was partially depleted by two distinct shRNAs, TGF- $\beta$ alone induced EMT more efficiently than in cells with control shRNA (figure 3a). GRHL2 knockdown facilitated several activities of TGF- $\beta$ : induction of a mesenchymal morphology, down-regulation of epithelial specific genes (E-cadherin, ESRP1 and ankyrin-G - an epithelial cytoskeletal protein that regulates anoikis (23)), and up-regulation of vimentin as well as the tumor initiating 
cell marker, CD44S; surprisingly, TGF- $\beta$ induced N-cadherin partly independently of GRHL2 expression.

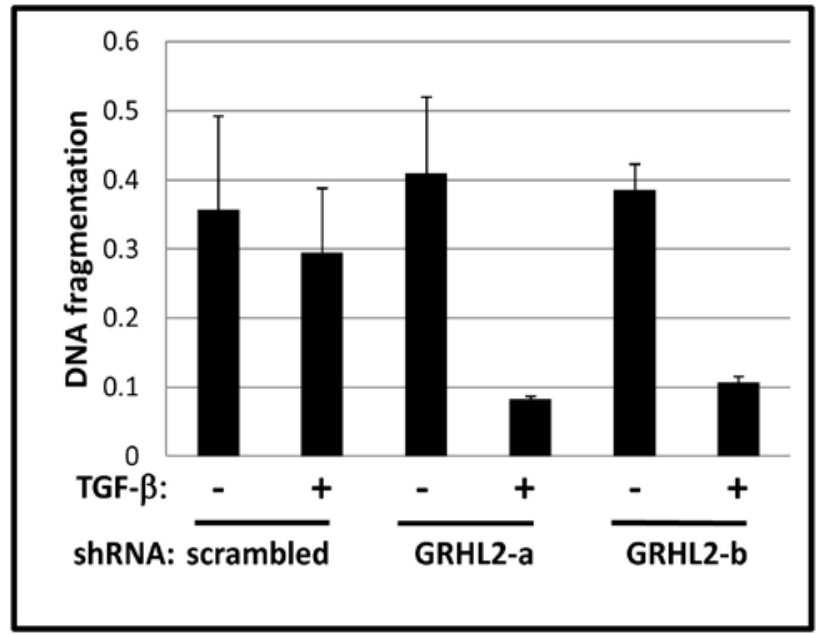

Figure $3 b$. GRHL2 suppresses the ability of TGF- $\beta$ to confer anoikis-resistance. The cell lines described above were assayed for anoikis by DNA fragmentation after two weeks incubation with or without TGF- $\beta$.
Coincident with this facilitation of EMT, GRHL2

knockdown also permitted TGF- $\beta$ to confer a

mammosphere-generating, anoikis-resistant state

(figure 3a,b). GRHL2 also suppressed another feature

of EMT, the formation of large protrusive structures

during the growth of colonies in three-dimensional

matrigel culture, indicative of invasive potential

(figure S3).

These results suggested that signaling downstream of

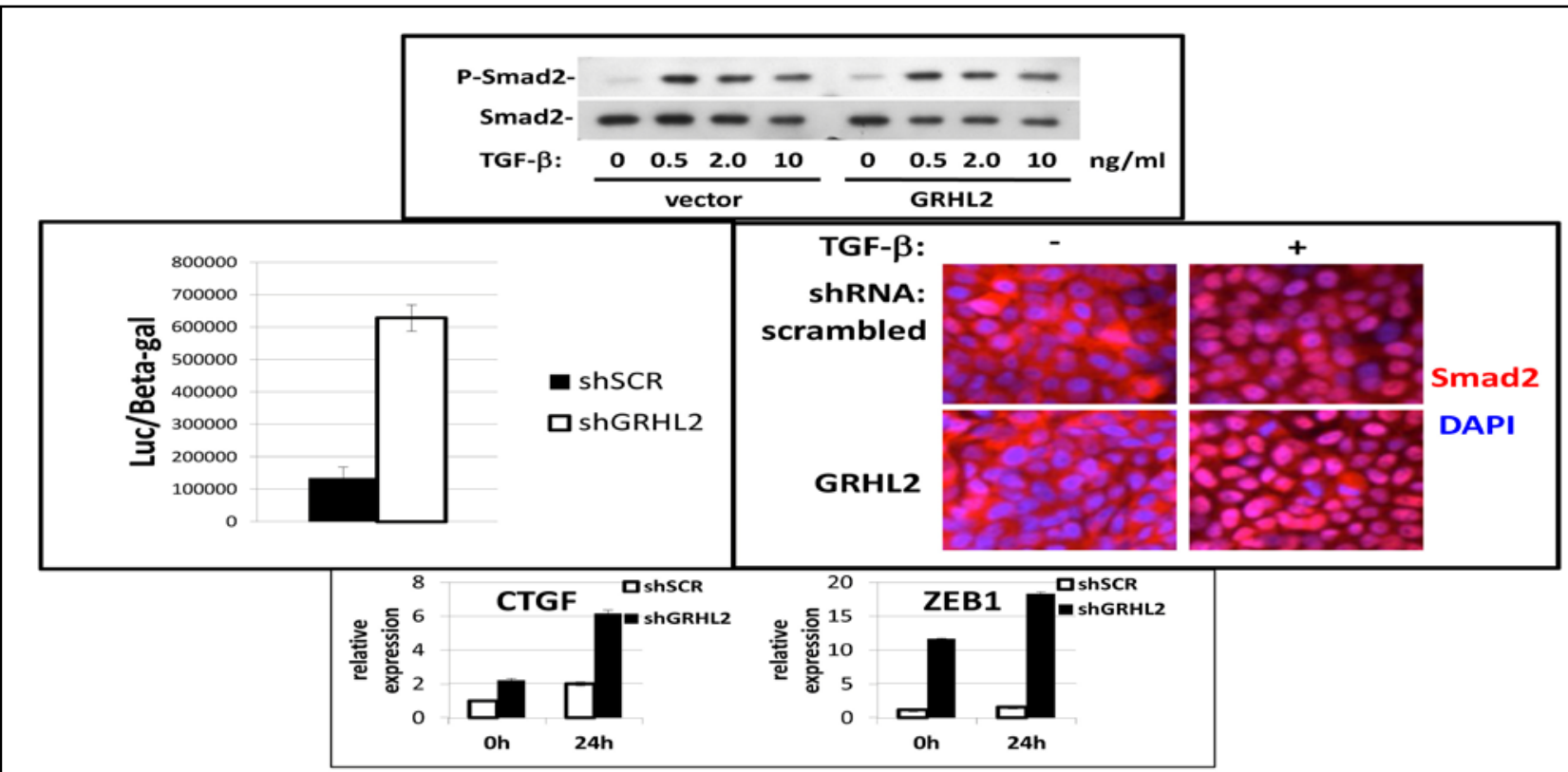

Figure 3c. GRHL2 inhibits Smad-mediated transcription. (left panel): Effect of stable GRHL2 knockdown on activity of a Smad-responsive reporter construct (3TP-lux) was determined by luciferase assays of transiently transfected HMLE+twist-ER cells (no 4-OHT) expressing either scrambled or GRHL2a shRNA that were treated with TGF- $\beta$ for sixteen hours prior to lysis; values are luciferase activity normalized to an internal co-transfected $\beta$-galactosidase control. (lower panel): Effect of stable GRHL2 knockdown on induction of TGF- $\beta$ /Smad target genes, CTGF and ZEB1, by exogenous TGF- $\beta$, determined by qRTPCR. (top panel): No effect of GRHL2 on phosphorylation of Smad2/3. MSP cells expressing empty vector or GRHL2 were treated with the indicated concentrations of TGF- $\beta$ for $24 \mathrm{~h}$ and analyzed for total and phospho-smad2/3. (right panel): No effect of GRHL2 on nuclear translocation of Smad2. The GRHL2 knockdown or control cells described in part a were treated with TGF-B for six hours and analvzed for Smad2 localization bv immunofluorescence. 
the TGF- $\beta$ receptor might be suppressed by GRHL2. We focused on Smad-mediated transcription, as it plays

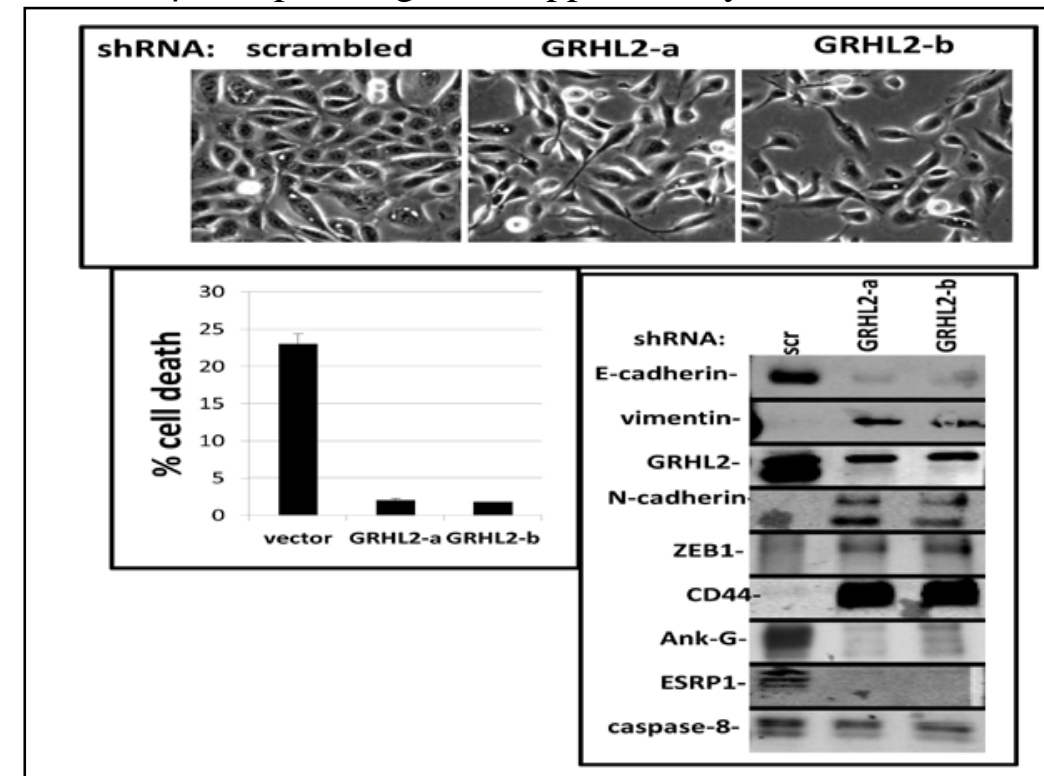

Figure 3d. GRHL2 knockdown induces EMT in HMLE cells with Ras (HMLER). HMLER expressing two distinct GRHL2 shRNAs or scrambled shRNA control were imaged using phase contrast microscopy (top), immunoblotted for epithelial and mesenchymal markers (right) or assayed for anoikis (trypan blue exclusion, left panel).

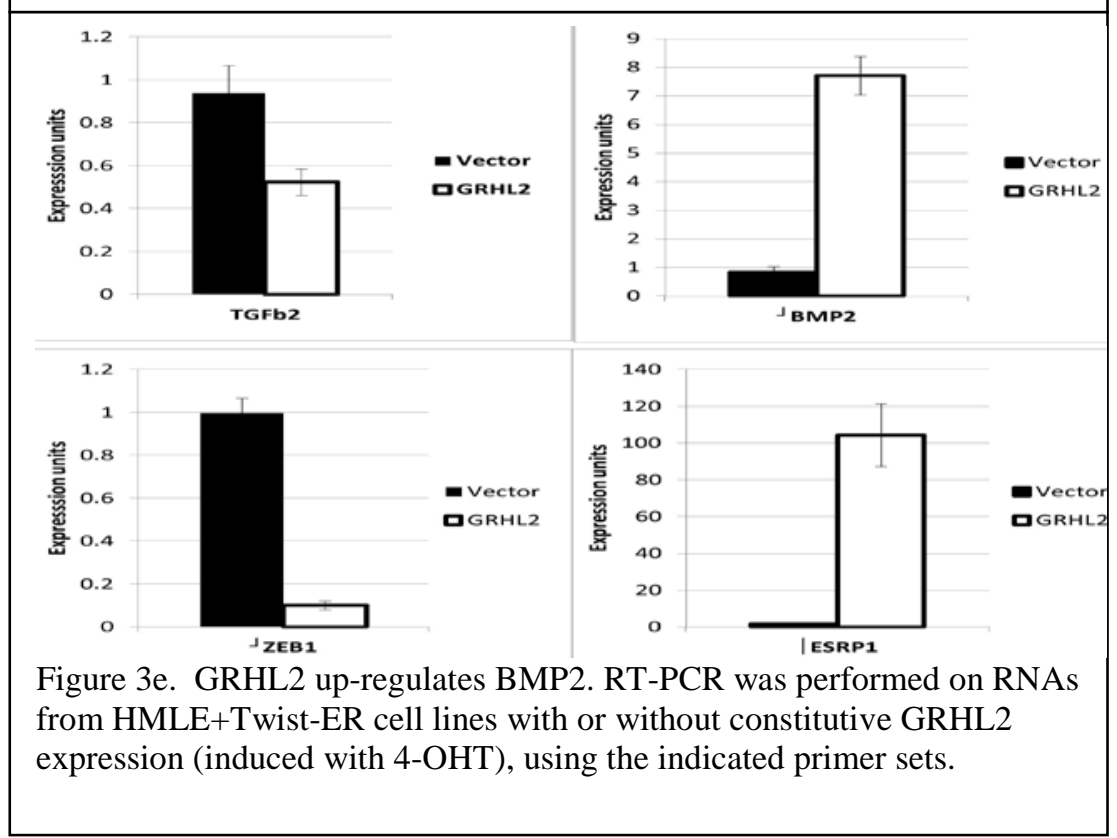

an important, although not exclusive role in the response to exogenous TGF- $\beta$-mediated EMT (4). Using a well-characterized reporter assay (3TP-lux; (4)), GRHL2 knockdown stimulated TGF- $\beta /$ Smad mediated transcription by $\sim 4.6 \mathrm{X}$ relative to control cells (figure 3c). Correspondingly, GRHL2 knockdown promoted the induction of the TGF- $\beta /$ Smad target genes, CTGF (26) and ZEB1 (27), by exogenous TGF- $\beta$. Surprisingly, there was no discernable effect of GRHL2 on either the phosphorylation or nuclear translocation of Smad2, suggesting that other mechanisms of inhibition were operative (see Discussion). These results indicated that GRHL2 inhibited Smad-mediated transcription in response to exogenous

TGF- $\beta$. 
In HMLE

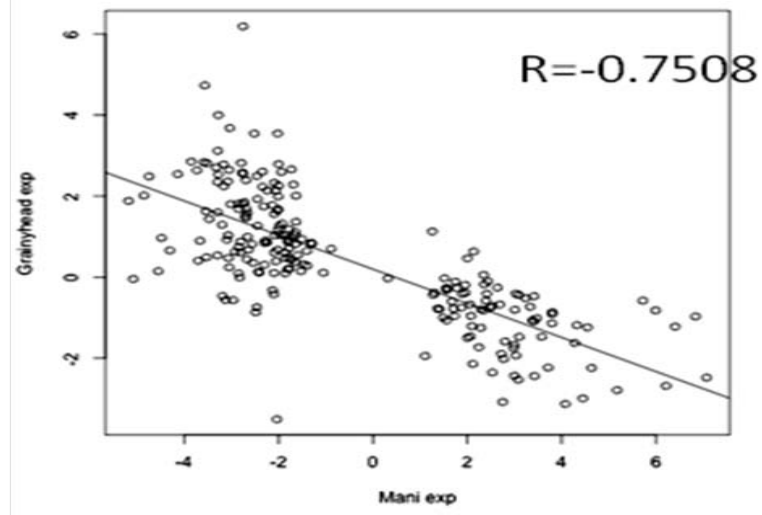

Figure 4a. HMLE+Twist-ER expressing either empty vector or GRHL2 were induced with 4-OHT for 17 days; four days following removal, RNAs were isolated and compared by microarray profiling. Gene changes due to GRHL2 were compared to those due to Twist in the same cell line; a regression plot of this comparison is shown.

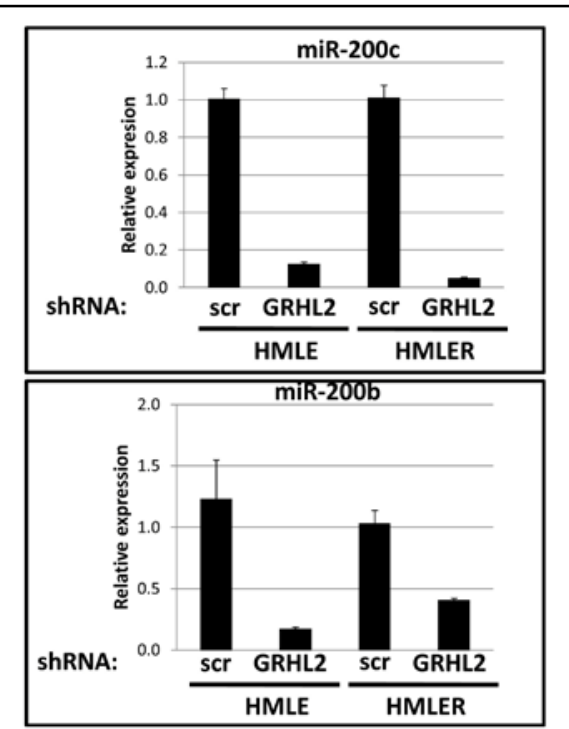

Figure 4b. GRHL2 up-regulates mir-200b/c. RNAs from HMLE or HMLER cells expressing GRHL2 or control shRNAs were compared for the indicated mir-200 transcripts by RT-PCR.

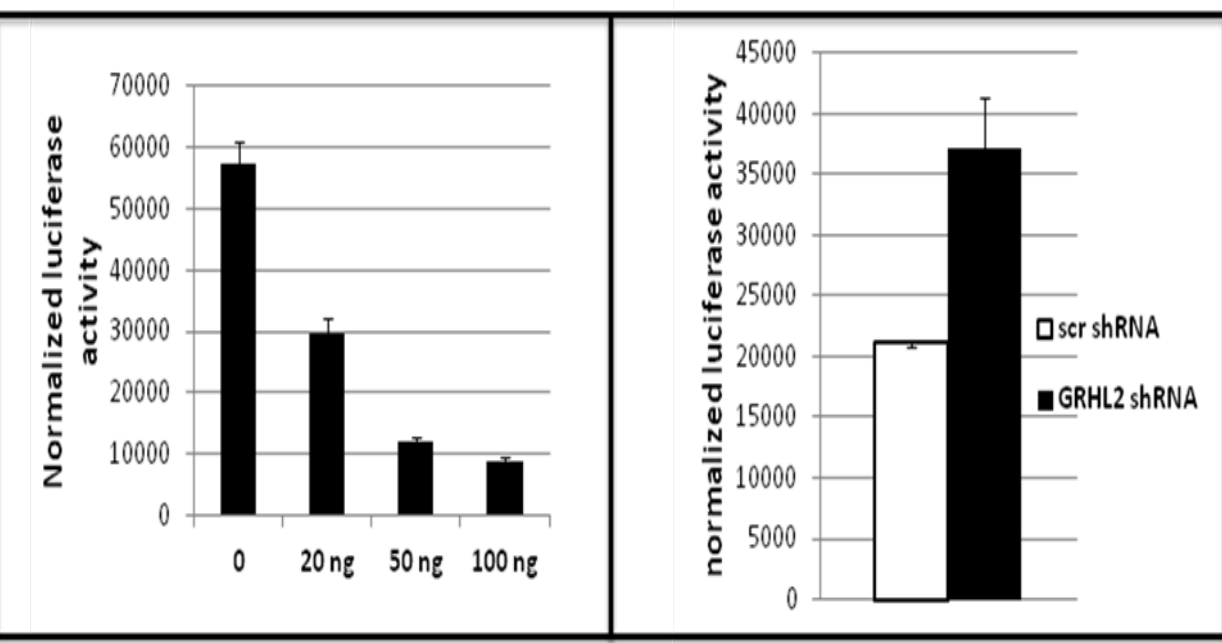

Figure 4c. GRHL2 represses the ZEB1 promoter. (left panel): MSP cells were cotransfected with a ZEB1 promoter-luciferase reporter construct, with the indicated input amounts of GRHL2 expression vector or equal amounts of empty vector. Values represent the relative luciferase activity normalized to an internal $\beta$-galactosidase control; (right panel): HMLE+Twist-ER cells (no 4-OHT) with stable GRHL2 knockdown or control (scrambled) knockdown were assayed for luciferase activity after transient transfection of the ZEB1 promoter. induce EMT --i.e., even

without exogenous TGF- $\beta$--

based on the criteria used above

(Figure 3d). This EMT was

clearly dependent upon

autocrine TGF- $\beta$ signaling, in

that LY364947 reversed it

(Figure S4). The TGF- $\beta$

signaling antagonists BMP2

and-4 were previously shown to

be down-regulated in MSP cells

relative to normal HMLE, 
which promoted autocrine TGF- $\beta$ signaling (7). Interestingly, BMP2 expression was activated by GRHL2

(figure 3e), consistent with the idea that GRHL2 suppressed not only TGF- $\beta$ signaling in response to exogenous ligands but also (by comparison with reported data on the same cell lines (7)) autocrine signaling.

\section{GRHL2 Represses ZEB-1 expression}

Suppression of EMT by GRHL2 could occur by a diversity of mechanisms. To elucidate one or more of these in an unbiased manner, we performed a microarray-based gene expression profiling comparing the HMLETwist cells with or without GRHL2 expression. This analysis revealed that genes regulated by GRHL2 (GEO database accession number GSE36081) correlated negatively ( $\mathrm{R}=-.7508)$ with genes regulated during EMT (by multiple transcription factors) in the HMLE system, validating the EMT-suppressive effect of GRHL2 (Figure 4a). The genes regulated by GRHL2 included markers of epithelial vs. mesenchymal phenotypes, several of which were ZEB1 target genes; transcription factors implicated in the control of EMT were also noted.

Interestingly, one of the major down-regulated GRHL2 target genes was the E-cadherin repressor/EMT inducer ZEB1, as shown by RT-PCR (figure 3e) and Western blotting in MSP cells (figure 2b), MDA-MB-231 cells (figure 2e), HMLE+shGRHL2 cells with TGF- $\beta$ (figure 3a), HMLER+shGRHL2 cells (figure 3d) and HMLE+Twist-ER cells (figure 2d). Functional consequences of ZEB1 down-regulation (28) such as the upregulation of mir-200b/c (figure 4b) and ESRP1 (figure 3e) were also evident . The down-regulation of ZEB1 by GRHL2 was investigated further as a potential mechanism for suppression of EMT. 


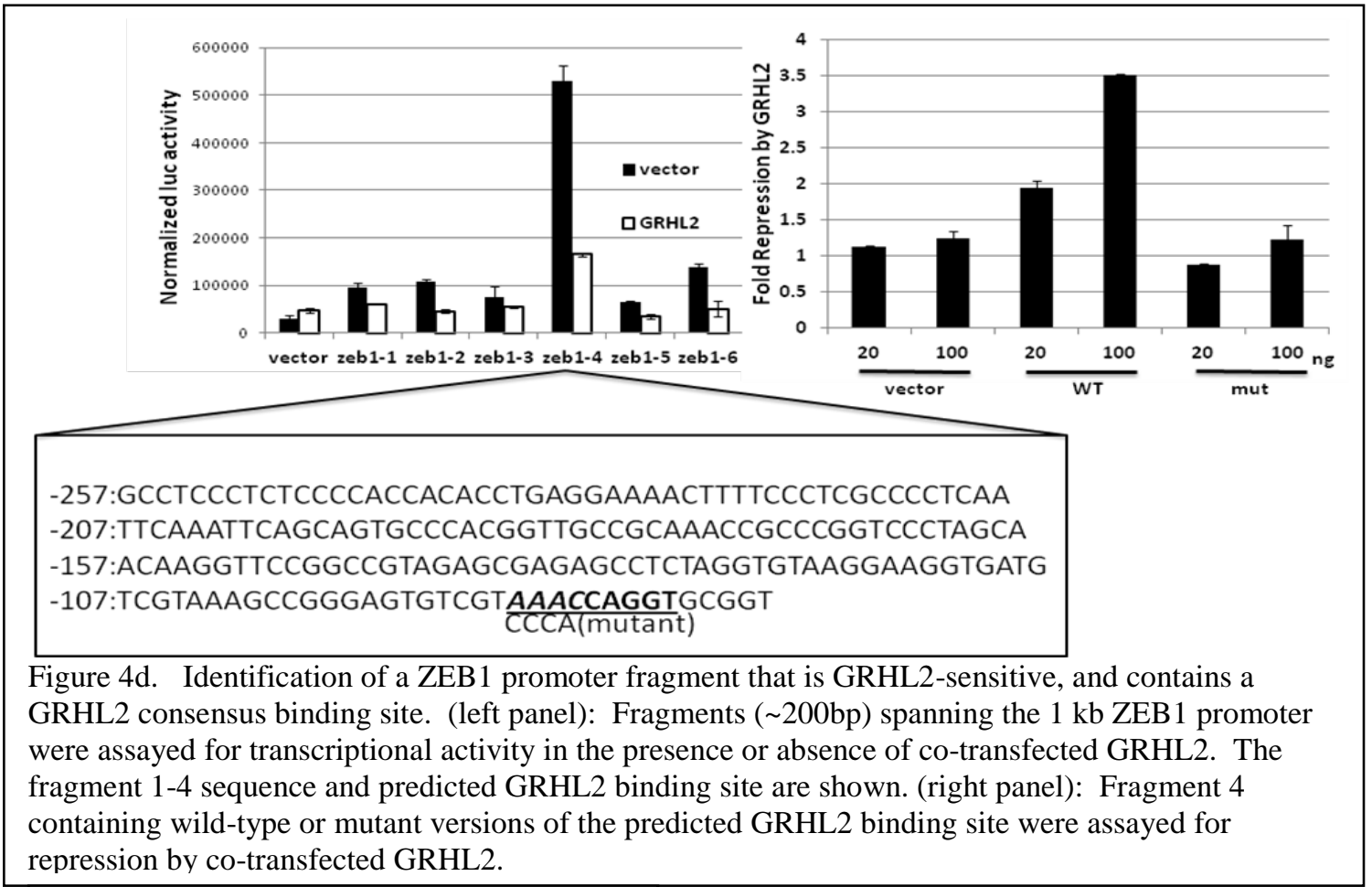

To determine

whether the ZEB1

gene could be a

direct target for

GRHL2, we co-

transfected the

previously

characterized ZEB1

promoter (22)

together with

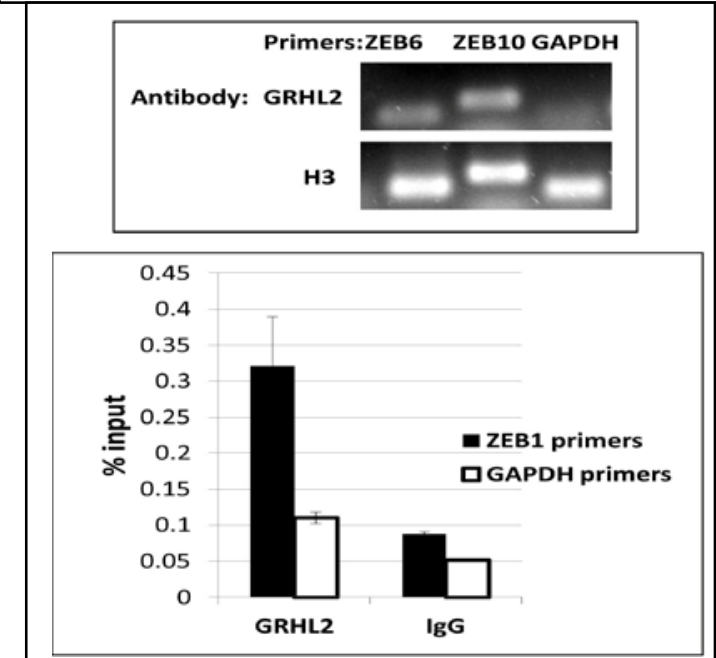

Figure 4e. GRHL2 protein interacts with the ZEB1 promoter. Chromatin from

HMLE+Twist-ER+GRHL2 (upper panel) or MDA-MB-231+GRHL2 (lower panel) was immunoprecipitated with GRHL2, histone $\mathrm{H} 3$ or non-immune antibody and analyzed by gel-based PCR or qPCR, using the indicated CHIP primers.

GRHL2 into the MSP cells (which express low endogenous GRHL2). This revealed a marked repression of the ZEB1 promoter by GRHL2, as did the converse experiment, transfection of the ZEB1 promoter into cells with or without knockdown of endogenous GRHL2 (figure 4c).

Inspection of the $\sim 1 \mathrm{~kb}$ of promoter sequence that was GRHL2responsive revealed several potential binding sites for grainyhead proteins. We tested 200bp nested fragments of the ZEB1 upstream region, in the context of an SV40 promoter, for repression by GRHL2, and identified one fragment (fragment 4) that was highly repressed. This fragment contained a consensus GRHL2 binding site and also carried a strong enhancer; the repression by GRHL2 was completely eliminated by a four-base mutation of this consensus site (figure 4d). To determine whether the ZEB1 promoter was a direct target for repression by GRHL2, CHIP 
analysis was performed, demonstrating a strong enrichment of PCR signal using GRHL2 antibody, with respect to non-immune IgG or a primer set (using GRHL2 antibody) representing an unrelated region of the genome (figure 4e). These results indicated that GRHL2 repressed ZEB1 expression and interacted directly with the ZEB1 promoter.

Suppression of ZEB1 is critical for the suppression of EMT by GRHL2.

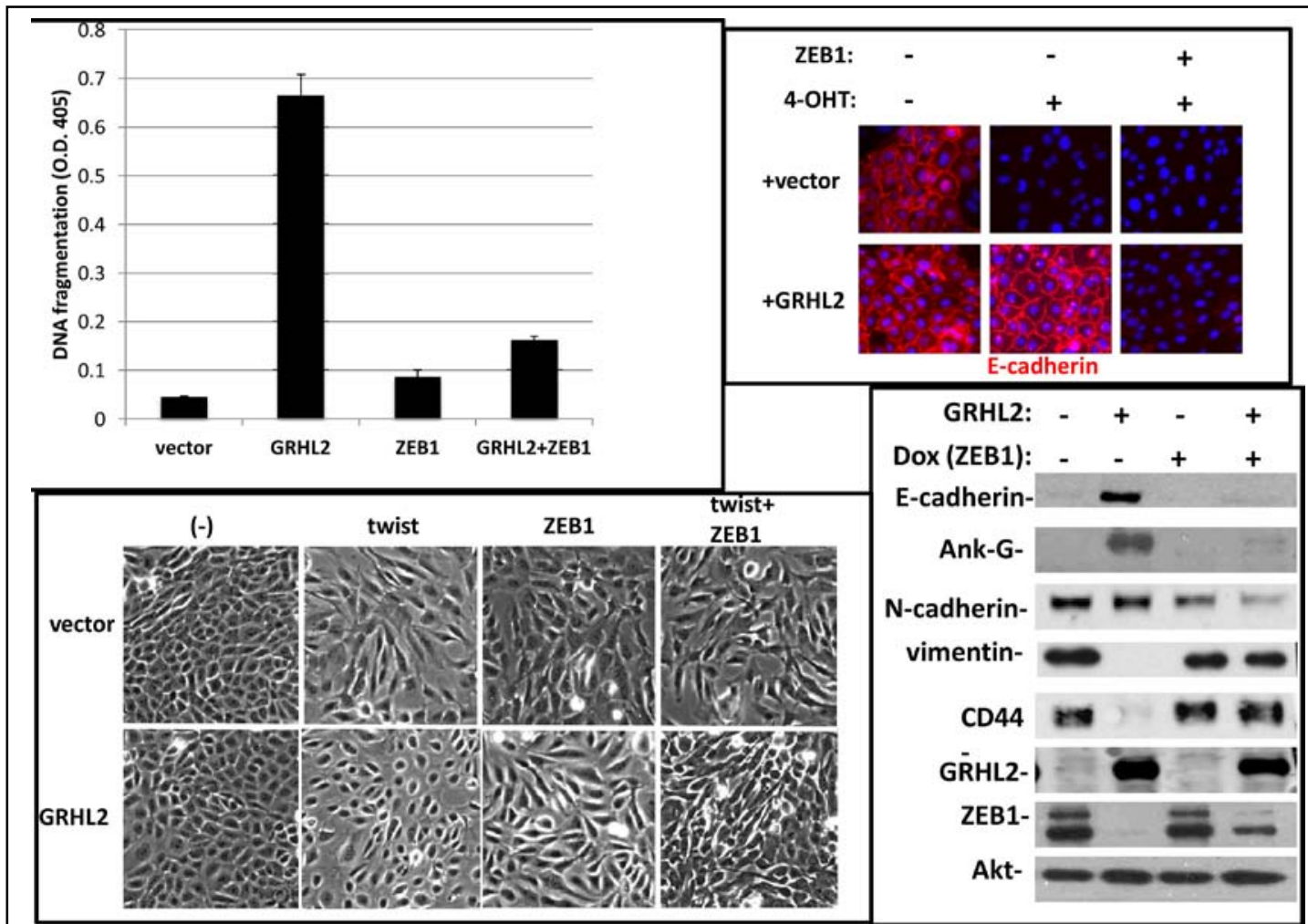

Figure 5a. ZEB1 restores EMT capability and anoikis-resistance in cells that express GRHL2 constitutively. HMLE+twist-ER with or without constitutive GRHL2 expression and with empty vector or ectopic ZEB1 expression vector were treated with 4OHT and then analyzed for anoikis (DNA fragmentation ELISA, top left); E-cadherin expression/localization (immunofluorescence, top right), cell morphology (phase contrast, lower left) and expression of epithelial and mesenchymal markers (western blot, lower right).
ZEB1 plays a critical role in EMT in response to various stimuli including TGF- $\beta$ (29-33), informing the hypothesis that GRHL2 suppressed EMT, at least in part, by repressing ZEB1 expression. To test this, ZEB1 was expressed ectopically, using a

doxycycline-inducible promoter, in the HMLE+twistER+GRHL2 cells. By the criteria of morphology, expression of epithelial and mesenchymal markers, and anoikis-resistance, ZEB1 restored EMT that had previously been blocked by GRHL2 expression (figure 5a). Analogous effects of ZEB1 expression were also 


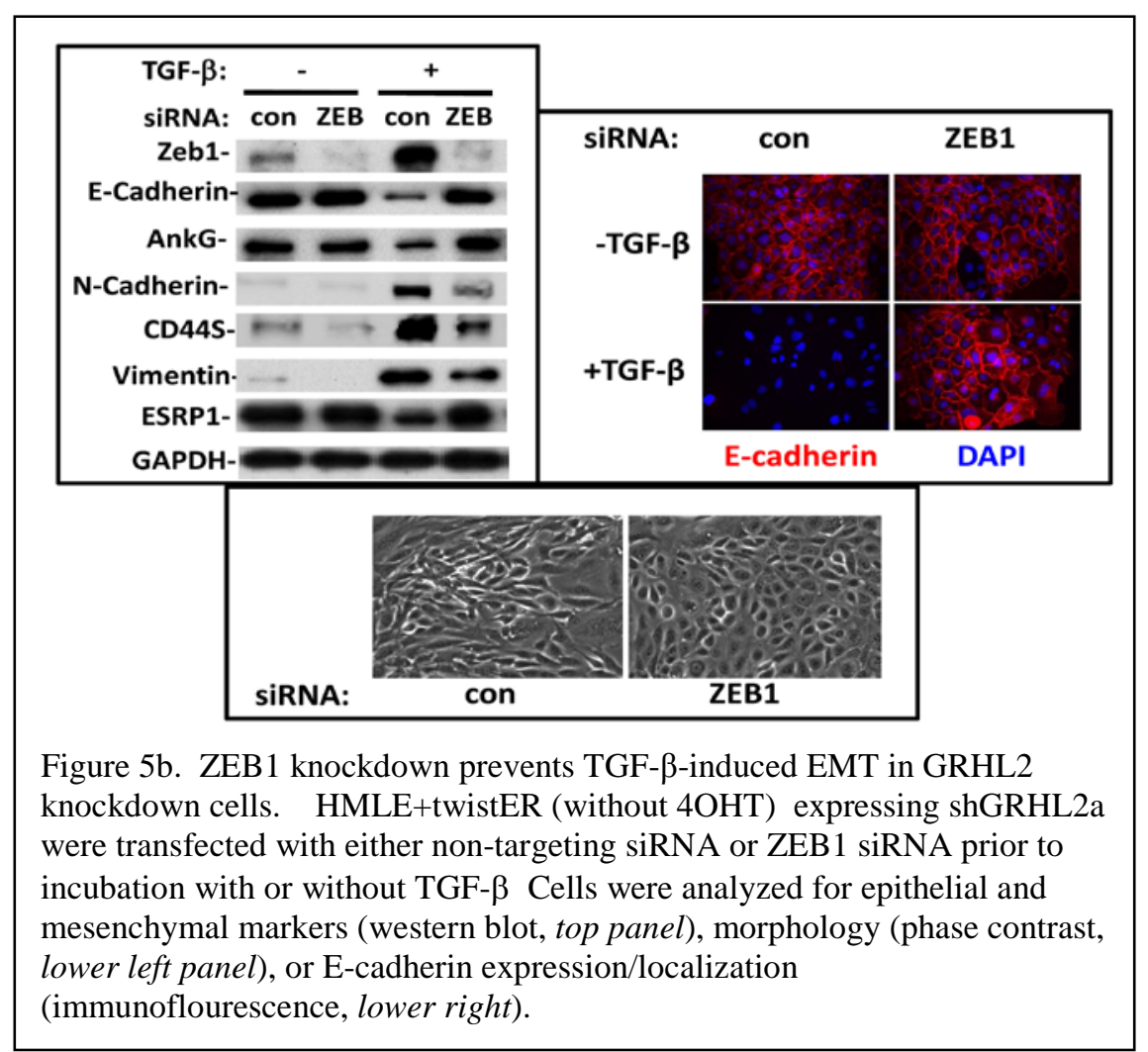

observed in MSP cells that had been

reverted to an epithelial phenotype by

stable GRHL2 expression (figure S5).

Conversely, in the HMLE cells where

GRHL2 knockdown predisposed the cells

toward

TGF- $\beta$ induced EMT, ZEB1 knockdown

blocked this induction (Figure 5b).

Similarly, EMT that was induced by

GRHL2 knockdown in HMLER cells

was reversed by ZEB1 knockdown

(figure S6). These results indicated that

the repression of ZEB1 was a key mechanism by which GRHL2 suppressed EMT.

\section{DISCUSSION.}

Mammalian GRHL2 is a transcription factor that plays important role in epidermal junctions, in part due to activation of target genes including claudin-4 and E-cadherin. Consistent with this role, the Drosophila Grainyhead gene is among the first transcription factors utilized in the maternal to zygotic transition (MZT) during embryonic development (16), and the three mammalian Grainyhead genes are critical for embryonic and adult wound healing (11-14). In light of the fact that wound-healing is orchestrated in part by TGF- $\beta$ signaling (9), the suppressive effect of GRHL2 on this pathway suggests that GRHL2 may contribute to the resolution phase of wound-healing, wherein transient EMT-like cell conversions in keratinocytes are instructed to reverse. 
The suppressive effect of GRHL2 on oncogenic EMT may be understood by analogy to this function, given the similarities between the two contexts of EMT (8).

The significance of mammalian Grainyhead proteins in cancer is emerging. GRHL3 was recently shown to function as a tumor suppressor in squamous cell carcinoma, acting, at least in part, as a direct activator of PTEN expression (19); EMT-related issues were not examined, however. The GRHL2 gene shows frequent amplification in unclassified breast tumor samples, and has been proposed as a potential oncogene in breast cancer, due, in part, to its suppression of death receptor expression (18). Consistent with this, modest upregulation of GRHL2 mRNA was observed in luminal A, B and HER2-positive tumor types (figure 1d) (although it is unclear whether this is an artifactual result of expansion of the epithelial cell compartment relative to normal mammary gland during tumor outgrowth). By contrast, our results show that GRHL2 is down-regulated in EMT models and EMT-driven tumor subclasses, and that it suppresses TGF- $\beta$-induced ZEB1 expression; in light of the established pro-tumorigenic potential of ZEB1, this result predicts that GRHL2 will specifically suppress EMT-like tumors (34, 35).

These results can be reconciled in light of the diametrically opposed, context-dependent effects of TGF- $\beta$ : growth arrest and tumor suppression in certain tumors vs. tumor promotion in others (4). In breast cancer, fewer than $10 \%$ of patients have tumor types (claudin-low, metaplastic) in which EMT/TGF- $\beta$ contributes critically to tumor progression, while in the majority of tumors (other basal, luminal A,B and HER2-positive subclasses) - which most transgenic mouse models emulate-TGF- $\beta$ is tumor-suppressive The results here indicate that GRHL2 interferes with the response to TGF- $\beta$ by at least two mechanisms, interference with Smad2/3 mediated transcriptional activation and direct repression of the ZEB1 promoter (diagrammed in figure 6). Consistent with previous observations in other systems (28, 37), ZEB1 was required for EMT in response to Twist, TGF- $\beta$ and spontaneous conversion. GRHL2 also up-regulated mir-200b/c, 
consistent with a critical role of the established ZEB1/mir-200 feed-forward regulatory loop in EMT (28). The precise mechanism by which GRHL2 represses the ZEB1 promoter may relate to Grainyhead proteins’ ability to repress transcription, by recruiting polycomb repression complex components or by interfering with the binding of a transactivator $(16,38)$.

The mechanism by which GRHL2 inhibits Smad-mediated transcription is unresolved at present. Previous work has shown that ZEB1 protein can bind to the Smad2/3 complex, enhancing transactivation (39); our preliminary observations indicated that this mechanism did not apply in our system. Smad2/3 nuclear vs. cytoplasmic localization is regulated by phosphorylation as well as signaling from the Crumbs polarity complex through Hippo pathway components (26). These mechanisms were, however, unlikely to explain the suppression by GRHL2, because Smad phosphorylation and nuclear translocation were not apparently affected. Other nuclear proteins that affect Smad2/3 transactivation, such as TGIF, Ski, and Sno (4), remain to be tested

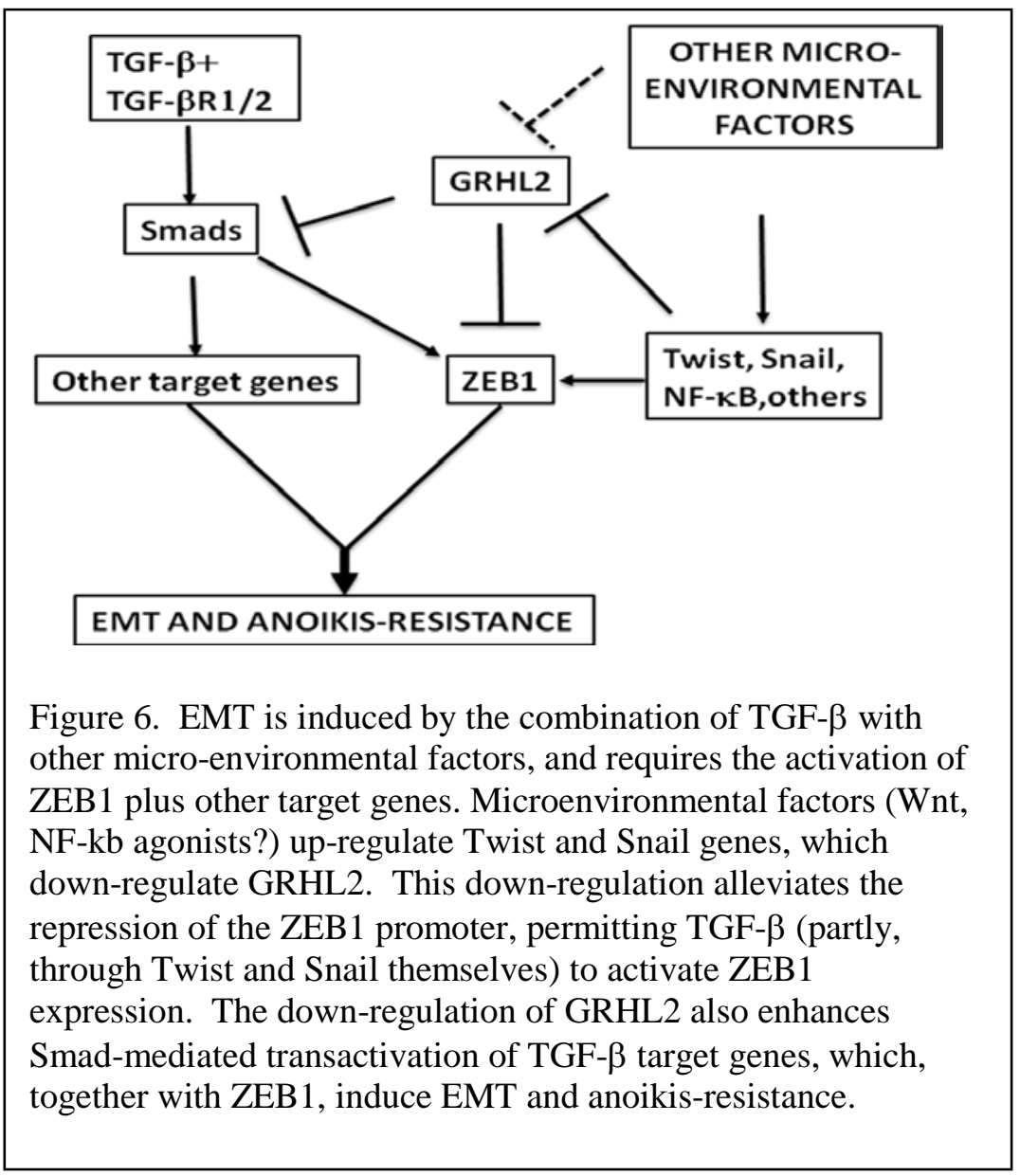
in the context of GRHL2.

TGF- $\beta$-induced EMT is a highly restricted phenomenon in cell culture models, occurring in only a small number of epithelial cell lines (40). In fact, we observed that the mouse mammary epithelial cell line NMuMg, commonly used to study this phenomenon, has undetectable GRHL2 expression, while other mouse mammary lines that are unresponsive do express GRHL2 (figure S7). These results are consistent with the previous 
finding that additional factors from the tumor microenvironment confer TGF- $\beta$-responsiveness upon HMLE cells, suggesting that one or more of these factors could function by down-regulating GRHL2 (7). More generally, the GRHL2 expression profile in breast cancer samples and cell lines indicate that GRHL2 is a general barrier to EMT. Accordingly, GRHL2 prevented TGF- $\beta$ from conferring anoikis-resistance, mammosphere formation (a tumor initiating cell behavior), and invasive growth in three-dimensional culture, predicting a tumor-suppressive effect in this context.

These results also suggest that GRHL2 may be a useful biomarker for tumors predicted to respond to TGF- $\beta$ receptor inhibitory drugs currently in clinical trials (41): GRHL2-null tumors, being susceptible to the tumorpromoting effects of TGF- $\beta$, are predicted to respond specifically to this class of drugs, an approach that could improve their efficacy substantially.

\section{REFERENCES}

1. Polyak K, Weinberg RA. Transitions between epithelial and mesenchymal states: acquisition of malignant and stem cell traits. Nat Rev Cancer 2009; 9: 265-73.

2. Thiery JP, Acloque H, Huang RY, Nieto MA. Epithelial-mesenchymal transitions in development and disease. Cell 2009; 139: 871-90.

3. Hennessy BT, Gonzalez-Angulo AM, Stemke-Hale K, et al. Characterization of a naturally occurring breast cancer subset enriched in epithelial-to-mesenchymal transition and stem cell characteristics. Cancer Res 2009; 69: 4116-24.

4. $\quad$ Massague J. TGFbeta in Cancer. Cell 2008; 134: 215-30.

5. Taylor MA, Parvani JG, Schiemann WP. The pathophysiology of epithelial-mesenchymal transition induced by transforming growth factor-beta in normal and malignant mammary epithelial cells. J Mammary Gland Biol Neoplasia; 15: 169-90.

6. Shipitsin M, Campbell LL, Argani P, et al. Molecular definition of breast tumor heterogeneity. Cancer Cell 2007; 11: 259-73.

7. Scheel C, Eaton EN, Li SH, et al. Paracrine and autocrine signals induce and maintain mesenchymal and stem cell States in the breast. Cell; 145: 926-40.

8. Schafer M, Werner S. Cancer as an overhealing wound: an old hypothesis revisited. Nat Rev Mol Cell Biol 2008; 9: 628-38. 
9. Margadant C, Sonnenberg A. Integrin-TGF-beta crosstalk in fibrosis, cancer and wound healing. EMBO Rep; 11: 97-105.

10. Kalluri R. EMT: when epithelial cells decide to become mesenchymal-like cells. J Clin Invest 2009; 119: 1417-9.

11. Ting SB, Caddy J, Hislop N, et al. A homolog of Drosophila grainy head is essential for epidermal integrity in mice. Science 2005; 308: 411-3.

12. Boglev Y, Wilanowski T, Caddy J, et al. The unique and cooperative roles of the Grainy head-like transcription factors in epidermal development reflect unexpected target gene specificity. Dev Biol; 349: 512-

22.

13. Pyrgaki C, Liu A, Niswander L. Grainyhead-like 2 regulates neural tube closure and adhesion molecule expression during neural fold fusion. Dev Biol; 353: 38-49.

14. Werth M, Walentin K, Aue A, et al. The transcription factor grainyhead-like 2 regulates the molecular composition of the epithelial apical junctional complex. Development; 137: 3835-45.

15. Wilanowski T, Caddy J, Ting SB, et al. Perturbed desmosomal cadherin expression in grainy head-like 1-null mice. EMBO J 2008; 27: 886-97.

16. Harrison MM, Botchan MR, Cline TW. Grainyhead and Zelda compete for binding to the promoters of the earliest-expressed Drosophila genes. Dev Biol; 345: 248-55.

17. Chen W, Dong Q, Shin KH, et al. Grainyhead-like 2 enhances the human telomerase reverse transcriptase gene expression by inhibiting DNA methylation at the 5'-CpG island in normal human keratinocytes. J Biol Chem; 285: 40852-63.

18. Dompe N, Rivers CS, Li L, et al. A whole-genome RNAi screen identifies an 8q22 gene cluster that inhibits death receptor-mediated apoptosis. Proc Natl Acad Sci U S A; 108: E943-51.

19. Darido C, Georgy SR, Wilanowski T, et al. Targeting of the Tumor Suppressor GRHL3 by a miR-21Dependent Proto-Oncogenic Network Results in PTEN Loss and Tumorigenesis. Cancer Cell; 20: 635-48.

20. Debnath J, Walker SJ, Brugge JS. Akt activation disrupts mammary acinar architecture and enhances proliferation in an mTOR-dependent manner. J Cell Biol 2003; 163: 315-26.

21. Mani SA, Guo W, Liao MJ, et al. The epithelial-mesenchymal transition generates cells with properties of stem cells. Cell 2008; 133: 704-15.

22. Dave N, Guaita-Esteruelas S, Gutarra S, et al. Functional cooperation between Snail1 and twist in the regulation of ZEB1 expression during epithelial to mesenchymal transition. J Biol Chem; 286: 12024-32.

23. Kumar S, Park SH, Cieply B, et al. A pathway for the control of anoikis sensitivity by E-cadherin and epithelial-to-mesenchymal transition. Mol Cell Biol; 31: 4036-51.

24. Rifat Y, Parekh V, Wilanowski T, et al. Regional neural tube closure defined by the Grainy head-like transcription factors. Dev Biol; 345: 237-45.

25. Creighton CJ, Li X, Landis M, et al. Residual breast cancers after conventional therapy display mesenchymal as well as tumor-initiating features. Proc Natl Acad Sci U S A 2009; 106: 13820-5.

26. Varelas X, Samavarchi-Tehrani P, Narimatsu M, et al. The Crumbs complex couples cell density sensing to Hippo-dependent control of the TGF-beta-SMAD pathway. Dev Cell; 19: 831-44.

27. Gregory PA, Bracken CP, Smith E, et al. An autocrine TGF-beta/ZEB/miR-200 signaling network regulates establishment and maintenance of epithelial-mesenchymal transition. Mol Biol Cell; 22: 1686-98.

28. Brabletz S, Brabletz T. The ZEB/miR-200 feedback loop--a motor of cellular plasticity in development and cancer? EMBO Rep; 11: 670-7.

29. Guaita S, Puig I, Franci C, et al. Snail induction of epithelial to mesenchymal transition in tumor cells is accompanied by MUC1 repression and ZEB1 expression. J Biol Chem 2002; 277: 39209-16.

30. Taube JH, Herschkowitz JI, Komurov K, et al. Core epithelial-to-mesenchymal transition interactome gene-expression signature is associated with claudin-low and metaplastic breast cancer subtypes. Proc Natl Acad Sci U S A; 107: 15449-54.

31. Smit MA, Peeper DS. Zeb1 is required for TrkB-induced epithelial-mesenchymal transition, anoikis resistance and metastasis. Oncogene. 
32. Aigner K, Dampier B, Descovich L, et al. The transcription factor ZEB1 (deltaEF1) promotes tumour cell dedifferentiation by repressing master regulators of epithelial polarity. Oncogene 2007; 26: 6979-88.

33. Grooteclaes ML, Frisch SM. Evidence for a function of CtBP in epithelial gene regulation and anoikis. Oncogene 2000; 19: 3823-8.

34. Spaderna S, Schmalhofer O, Wahlbuhl M, et al. The transcriptional repressor ZEB1 promotes metastasis and loss of cell polarity in cancer. Cancer Res 2008; 68: 537-44.

35. Wellner U, Schubert J, Burk UC, et al. The EMT-activator ZEB1 promotes tumorigenicity by repressing stemness-inhibiting microRNAs. Nat Cell Biol 2009; 11: 1487-95.

36. Herschkowitz JI, Simin K, Weigman VJ, et al. Identification of conserved gene expression features between murine mammary carcinoma models and human breast tumors. Genome Biol 2007; 8: R76.

37. Schmalhofer O, Brabletz S, Brabletz T. E-cadherin, beta-catenin, and ZEB1 in malignant progression of cancer. Cancer Metastasis Rev 2009; 28: 151-66.

38. Tuckfield A, Clouston DR, Wilanowski TM, Zhao LL, Cunningham JM, Jane SM. Binding of the RING polycomb proteins to specific target genes in complex with the grainyhead-like family of developmental transcription factors. Mol Cell Biol 2002; 22: 1936-46.

39. Postigo AA, Depp JL, Taylor JJ, Kroll KL. Regulation of Smad signaling through a differential recruitment of coactivators and corepressors by ZEB proteins. EMBO J 2003; 22: 2453-62.

40. Brown KA, Aakre ME, Gorska AE, et al. Induction by transforming growth factor-beta1 of epithelial to mesenchymal transition is a rare event in vitro. Breast Cancer Res 2004; 6: R215-31.

41. Ganapathy V, Ge R, Grazioli A, et al. Targeting the Transforming Growth Factor-beta pathway inhibits human basal-like breast cancer metastasis. Mol Cancer; 9: 122.

42. Neve RM, Chin K, Fridlyand J, et al. A collection of breast cancer cell lines for the study of functionally distinct cancer subtypes. Cancer Cell 2006; 10: 515-27.

\section{ACKNOWLEDGMENTS.}

The authors wish to thank Kathy Brundage (flow cytometry), Kimmi Alonge, and the laboratories of Peter Stoilov, Mike Ruppert, Laura Gibson, Antonio Garcia de Herreros, Antonio Postigo, Richard Myers and KaiSchmidt-Ott for help, advice and reagents. We thank Wioletta Szeszel-Fedorowicz for performing the microarray experiment. S.M.F. was supported by NIH grant R01CA123359. The flow cytometry core facility (Mary Babb Randolph Cancer Center) was supported by NIH grants RR020866 and P20 RR16440. J.D. was supported in part by the West Virginia IDEA Network of Biomedical Research Excellence (INBRE) P20 RR 016477-12 (Rankin, Gary, PI). A.V.I. was supported by NIH grant P20 RR16440, American Cancer Society grant 122300-IRG-09-061-04-IRG and Susan G. Komen for the Cure grant KG110350. 


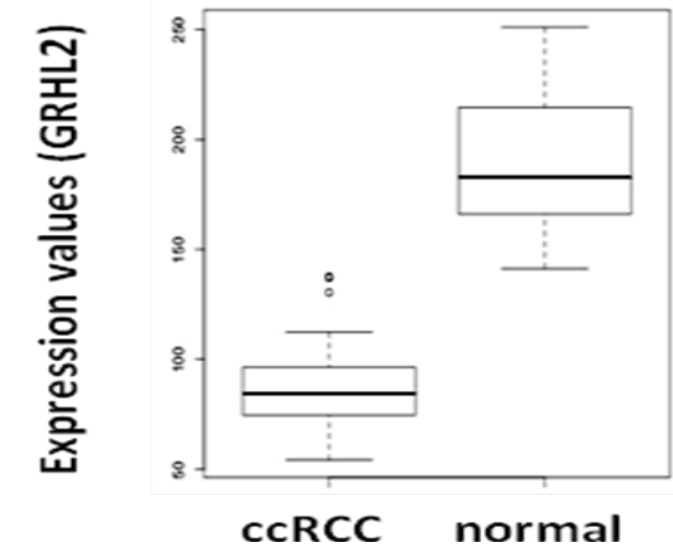

Figure S1. GRHL2 is down-regulated in clear cell Renal Cell Carcinoma (ccRCC). Primary data were derived from the NCBI-GEO database GSE15641 from the study by Jones, et al. (Clin Cancer Res 2005;11:

5730-9)

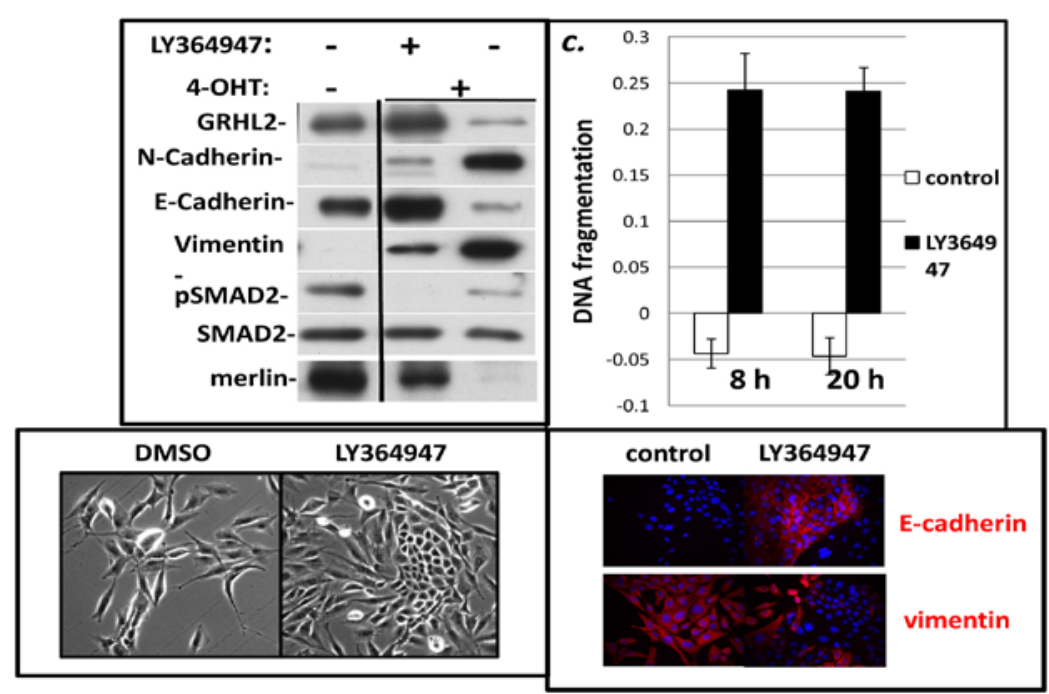

Figure S2. TGF-b is critical for EMT and anoikis-resistance induced by Twist. HMLE+Twist-ER cells were induced with 4-OHT, to activate the twist-ER protein, in the presence or absence of LY364947. Cells were assayed for epithelial and mesenchymal marker genes (western blot, upper left panel), morphology (phase contrast, lower left panel), anoikis (DNA fragmentation ELISA, upper right panel) or E-cadherin and vimentin staining (immunofluorescence, lower right panel). 


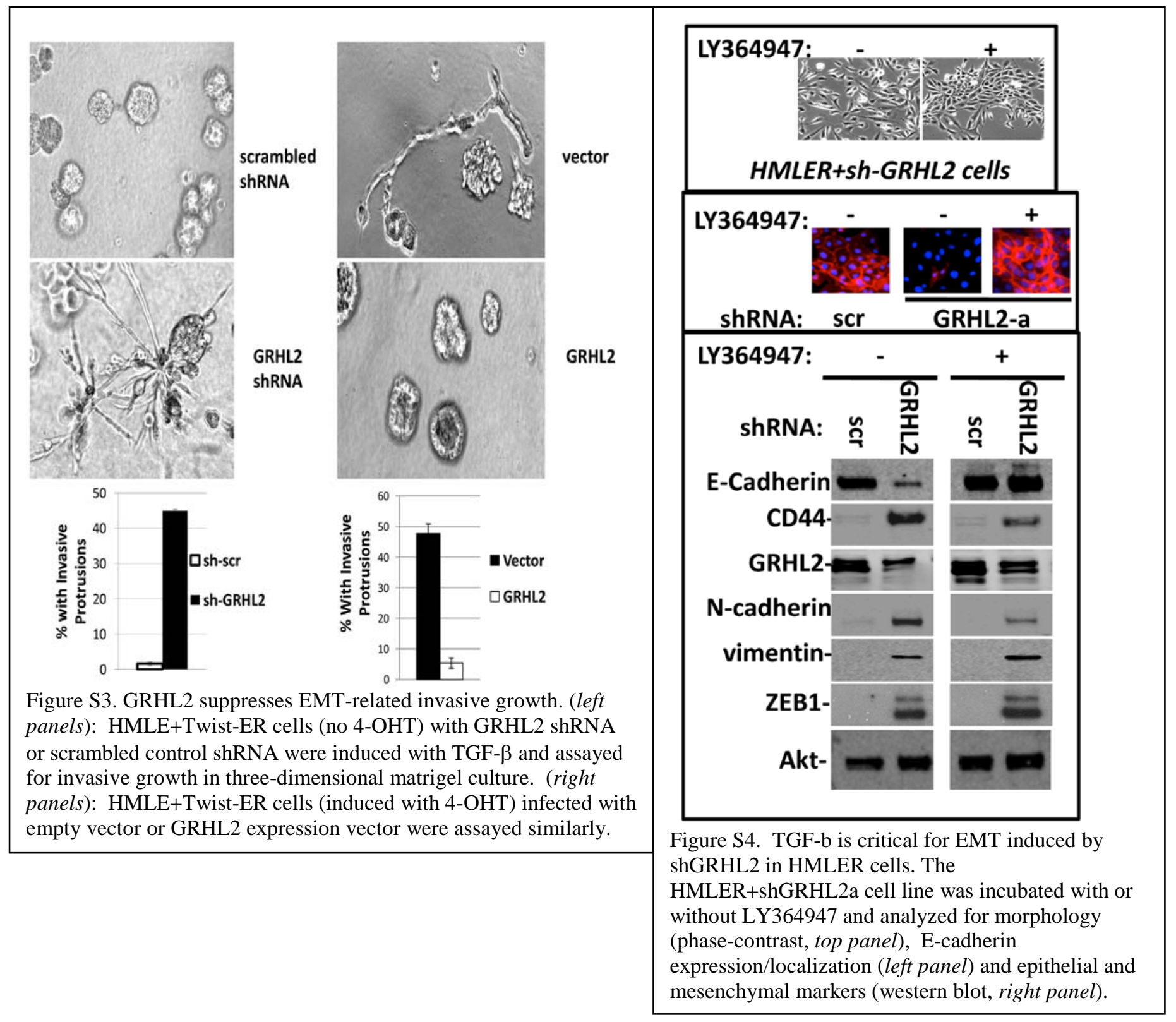




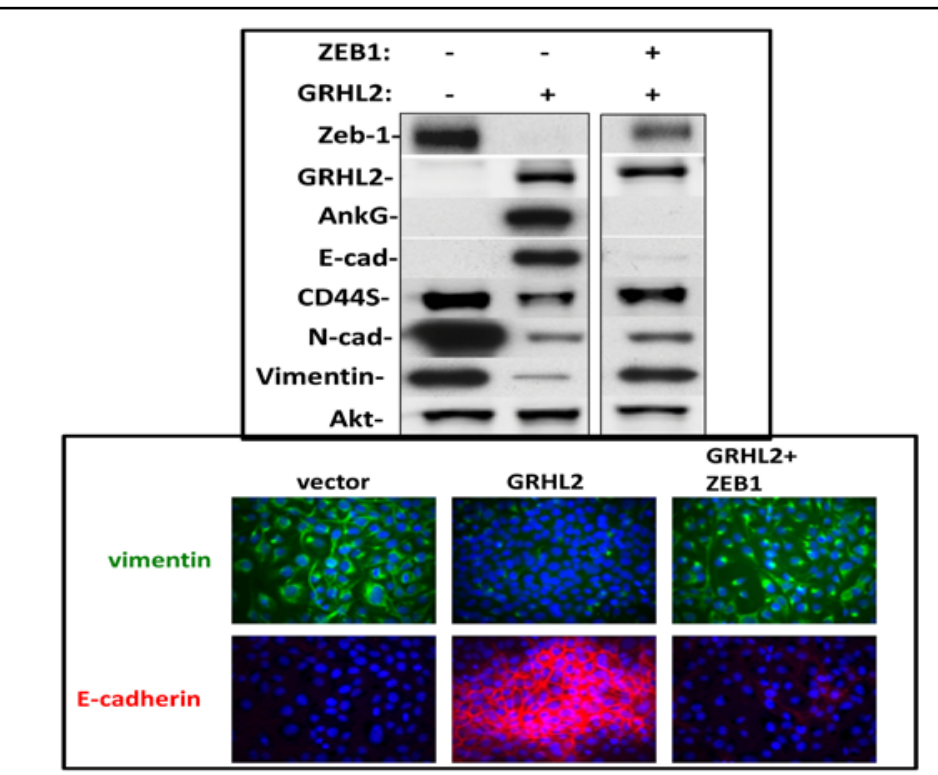

Figure S5. Re-expression of ZEB1 in MSP cells with constitutive GRHL2 expression restores EMT. MSP+GRHL2 that were transduced with a doxycycline-inducible ZEB1 expression vector were analyzed for epithelial and mesenchymal markers (western blot, upper panel) or E-cadherin expression/localization (immunofluorescence, lower panel).

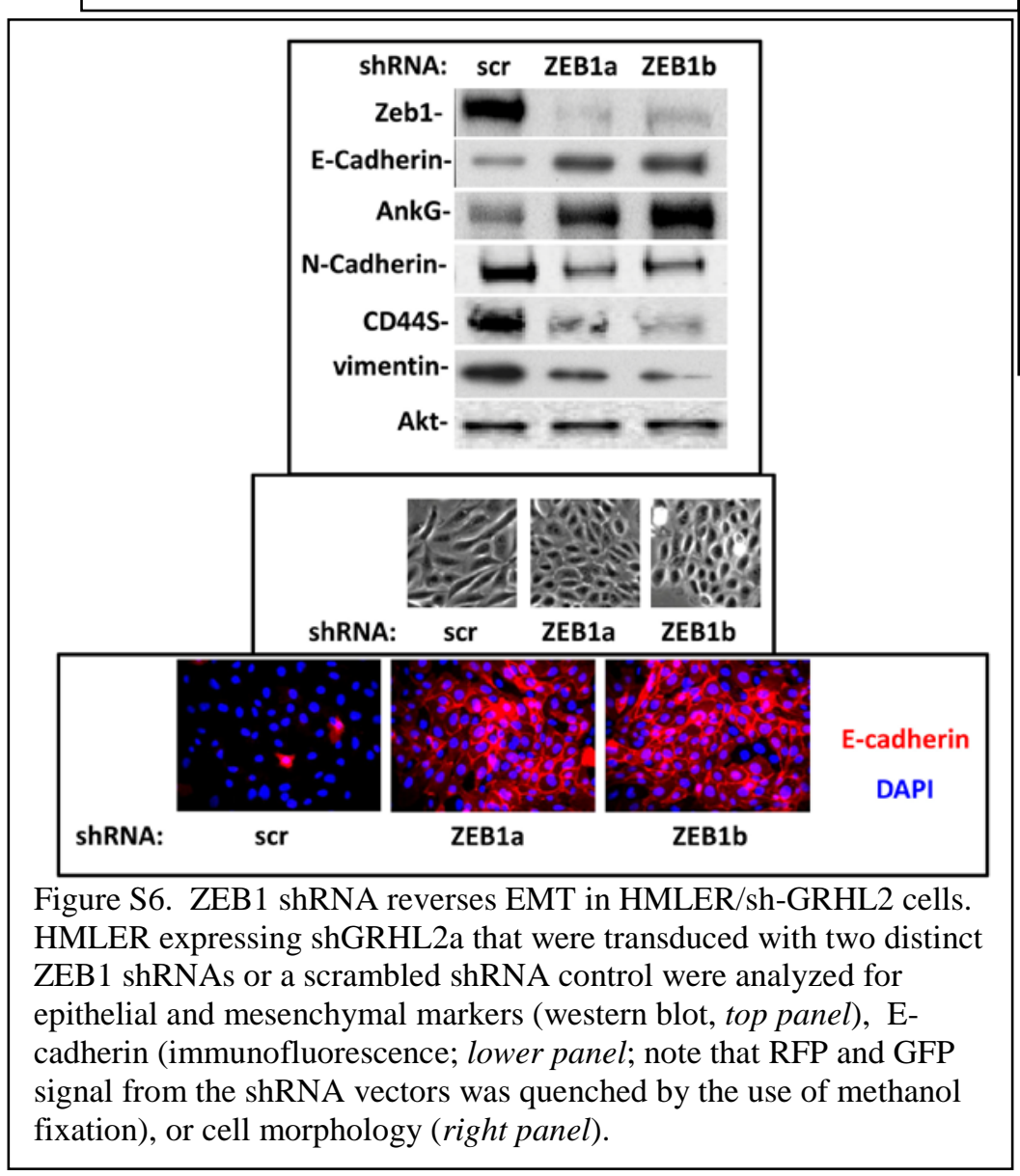

\section{GRHL2-} Akt-

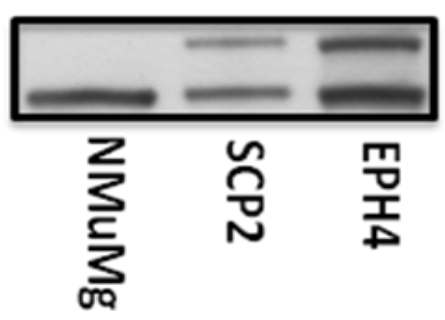

Figure S7. Comparison of GRHL2 expression in the TGF- $\beta$-responsive mouse mammary epithelial cell line NMuMg vs. two nonresponsive lines, SCP2 and Eph4. 
Chapter 3

\section{A RECIPROCAL FEEDBACK LOOP BETWEEN GRAINYHEAD-LIKE-2 AND ZEB1 \\ CONTROLS EMT AND TUMOR SUPPRESSION}

This manuscript is being revised for re-submission to Cancer Research 


\begin{abstract}
The oncogenic Epithelial-Mesenchymal Transition (EMT) enhances malignant progression by promoting invasion and survival of tumor cells. EMT is induced by microenvironmental factors including TGF- $\beta$ and Wnt agonists, and transcription factors including the E-box binding factors Twist, Snail and ZEB.

Previously, we reported that a member of the mammalian Grainyhead family of wound healingregulatory transcription factors, Grainyhead-like-2 (GRHL2), is a potent, generalized suppressor of EMT that functions by repressing ZEB1 expression and inhibiting TGF- $\beta$ signaling. Here we elucidate the functional relationship between GRHL2 and ZEB1 in EMT/ MET and tumor biology. At least three homeodomain proteins, Six1, LBX1, and HoxA5, transactivated the ZEB1 promoter; for Six1, this was through direct protein-promoter interaction. GRHL2 inhibited this transactivation and altered the Six1DNA complex. Correspondingly, GRHL2 expression prevented tumor initiation in xenograft assays, a measure of cancer stem cell frequency. GRHL2 sensitized breast cancer cells to taxol, and prevented the taxol-driven emergence of cancer stem cells. GRHL2 was down-regulated in recurrent, oncogeneindependent, mouse tumors, supporting a role for GRHL2 down-regulation in tumor evolution to an EMT/ stem cell-enhanced phenotype. Conversely, the combination of TGF- $\beta$ and Wnt activation repressed GRHL2 expression through direct interaction of ZEB1 with the GRHL2 promoter, inducing EMT. These observations indicate that a reciprocal feedback loop between GRHL2 and ZEB1 controls epithelial vs. mesenchymal phenotypes and EMT-driven tumor progression.
\end{abstract}




\section{Introduction}

The oncogenic epithelial-mesenchymal transition (EMT) contributes to tumor progression by enhancing tumor cell invasiveness and anoikis-resistance, which may enhance the early steps of metastasis, as has been demonstrated in certain contexts. Chemoresistance and radioresistance also accompany EMT, confounding patient responses to treatment (1-4), especially pronounced in, for example, the claudin-low subclass of breast cancer, where a frank EMT-like pattern of genes is expressed.

EMT also provides a permissive cellular environment for expression of the cancer stem cell/tumor initiating cell phenotype, thus increasing the probability of tumor initiation. Only a fraction of the cells that have undergone EMT adopt cancer stem cell characteristics, and recently emerging data suggest that cancer stem cells with an epithelial phenotype may exist as well (5). Nevertheless, compelling evidence for the EMT/stem cell connection exists in cell culture, mouse models and analysis of patient samples (6-9). The cancer stem cell/tumor initiating cell phenotype, which was initially assumed to be cell-intrinsic, is now known to be dynamic, as is the EMT phenotype. Tumor stem cells inter-convert with non-stem cells in response to microenvironmental signals $(6,10,11)$. Analogously, basal and luminal mammary epithelial cells are interconvertible $(11,12)$. The hope arising from this body of work is that manipulating factors in the tumor microenvironment, whether arising from autocrine or paracrine signaling, can reprogram cancer stem cells to become non-stem cells, improving treatment outcome. In particular, cancer stem cells, which emerge during the course of chemotherapy, are thought to be the primary precursor cells for disease recurrence, indicating the importance of understanding how they are generated and/or suppressed.

The barrier to this progress resides in the apparent diversity of EMT/stem cell regulatory genes and signaling pathways, For example, there is a complex network of receptor signaling, transcription factors, cell adhesion factors and cell cohesion factors determining the epithelial vs. mesenchymal phenotype. This 
complexity seems therapeutically confounding. But, a cancer stem cell phenotype represents a commitment to autocrine signaling pathways that render the cell semi-autonomous (6). An understanding of how this autonomy is achieved would provide an Achilles heel for suppressing the cancer stem cell in breast cancer, significantly promoting long-term response to chemotherapy.

The transcription factors ZEB1 and ZEB2 (SIP1) are pivotal activators of EMT. ZEB1 and, subsequently, ZEB2 were originally identified as the first repressors of the mammalian E-cadherin promoter (13). They are now known to regulate cytoskeletal, cell polarity, cell adhesion and apoptosis-regulatory genes that collectively suffice for EMT induction. ZEB1 is induced by transcription factors that include NF-kB (14), Twist/Snail, acting in concert (15)), TCF4 (16) and LBX1 (17). Conversely, ZEB1 expression is translationally attenuated by mir-200b/c, whose expression is, in turn, repressed by TGF- $\beta$ signaling, explaining (in part) the engagement of stable autocrine TGF- $\beta$ signaling in the maintenance of EMT.

Grainyhead-like-2 is a transcription factor that regulates wound healing, epidermal junction assembly, and neural tube closure, processes related to or regulated by EMT (18-21). Previously, we reported that GRHL2 is a generalized suppressor of oncogenic EMT, through at least two mechanisms, direct repression of ZEB1 expression and inhibition of the TGF- $\beta$ pathway. Here, we show that GRHL2 inhibited transactivation of the ZEB1 promoter mediated by the homeodomain proteins Six1, LBX1 and HoxA5. GRHL2 acted as a tumor suppressor gene in an assay for the frequency of tumor initiation, a measure of cancer stem cell abundance, indicating that it suppressed the cancer stem cell phenotype. Consistent with this, GRHL2 sensitized tumor cells to a chemotherapy agent in culture and prevented the emergence of cancer stem cells during treatment with this agent. The combination of Wnt and TGF- $\beta$ pathway activation up-regulated ZEB1 expression. ZEB1 reciprocally repressed GRHL2 expression through a direct interaction with the GRHL2 promoter. This revealed a novel GRHL2-ZEB1 reciprocal negative feedback loop that drives EMT vs. MET in response to extracellular signals.

\section{Materials and Methods}


Cell lines: HMLE and HMLE+twist-ER were kindly provided by R. Weinberg (Whitehead Institute); MDAMB-231LN were from E. Pugacheva (West Virginia University). Cells were cultured and stable cell lines were generated via retroviral transduction as described previously (22) GRHL2 was expressed using either MSCVIRES-puro or MSCV-IRES-GFP (pMIG, Addgene) and mixed populations were used (except in the case of GRHL2/MSCV-IRES-puro, where a strong selection for GRHL2-negative cells necessitated the use of clonal populations to achieve $100 \%$ positivity). The $\square$-catenin S33Y mutant (provided by S.P.S. Monga, University of Pittsuburgh) was subcloned into the pMXS-IRES-PURO retroviral vector (contributed by Russ Carstens , University of Pennsylvania in-frame with a C-terminal FLAG tag). The human Six1 sequence was also subcloned into the pMXS-IRES-PURO vector. ZEB1 shRNA (V3LHS_356186, Open Biosystems) and ZEB1 cDNA were expressed via the PTRIPZ and pLUT lentivrial vectors, respectively, as described previously (22). Human H-rasV12 in MSCV-IRES-Blast (Addgene) was used to express activated Ras in CD44 ${ }^{\text {low }}$ (flow-sorted) HMLE cells for tumor assays described below. HMLE+Ras cells were subjected to stable GRHL2 knockdown (Open Biosystems RHS4430-99291384) using the pGIPZ, followed by selection for puromycin resistance and sorting for GFP.

Xenograft Assays: MDA-MB-231LN stably expressing either empty-MSCV-IRES-Puro or GRHL2-IRES-Puro were trypsinized and re-suspended in growth media and $1 \times 10^{5}$ cells in $0.1 \mathrm{ml}$ were injected into the $4^{\text {th }}$ inguinal mammary fat pad of female BALB/c nude mice (Charles River) at approximately 4 weeks of age. HMLE+Ras cells with GRHL2 or control shRNA (see above) were trypsinized and suspended in growth medium; $1 \times 10^{6}$ cells were injected in $0.1 \mathrm{ml}$ into the $4^{\text {th }}$ inguinal mammary fat pad of female NOD/SCID (Charles River). Assays were carried out for 8 weeks. Tumor volume was determined using the formula $\pi\left(\mathrm{L} 1 \times \mathrm{L} 2^{2}\right) / 6$, where $\mathrm{L} 1$ is the long axis and L2 is the short axis. Tumor burden was monitored according to the WVU ACUC Tumor Burden Policy. Animal studies were approved by the West Virginia University Animal Care and Use Committee. 
Western blotting: Electrophoresis, transfer, immunoblotting and antibodies used were described in (22). Other antibodies used here were: rabbit anti-vimentin (Cell Signaling), mouse anti-FLAG (M2; Sigma) and mouse anti-GAPDH (Thermo Scientific).

Chemosensitivity assays: MDA-MB-231 cells with stable GRHL2-MSCV-IRES-puro or empty MSCV-IRESpuro were plated in 96-well dishes at 5,000 cells per well and assayed in triplicate for cell viability after three days of incubation, with the indicated concentration of paclitaxel, using Presto-Blue (Invitrogen) according to the manufacturer's protocol. For the chemo-induced stem cell analysis, the protocol was modeled after (7). HMLE cells expressing empty-MSCV-IRES-GFP or GRHL2-MSCV-IRES-GFP were treated with paclitaxel (10nM) for 4 days, followed by 7 days recovery and flow analysis for CD44 using a CD44-PE antibody (BD Biosciences). HMLE induced to undergo EMT by ectopic twist were used as a positive control for the CD44 ${ }^{\text {high }}$ phenotype.

qRT-PCR analysis of primary vs. recurrent mouse tumors: RNAs from primary and recurrent tetO-neuNT (23) or tetO-Wnt1 (24) were provided by L. Chodosh (University of Pennsylvania) or E. Gunther (Penn State University, Hershey) and analyzed for GRHL2 expression using a $\beta 2$-microglobulin internal control as described previously (22), using the primers: mGRHL2-f: caaggacgaccagcgcagca; mGRHL2-r: ggccctcccctgcttctga; mB2M-f: tggtcttctggtgcttgtc; mB2M-r: gggtggaactgtgttacgtag BIO, TGF- $\beta$ and BMP2 treatments: HMLE cells were treated with $5 \square \mathrm{M}$ 6-bromo-3-[(3E)-1,3-dihydro-3(hydroxyimino)-2H-indol-2-ylidene]-1,3-dihydro-(3Z)-2H-indol-2-one (BIO;(25)) and/or TGF- $\beta 1$ (5ng/ml) for 4 days. BIO was removed and the TGF- $\beta$ was continued for another 6 day; samples were then analyzed by western blotting. HMLE+twist-ER were treated with either $50 \mathrm{nM}$ 4-hydroxy-tamoxifen (4OHT), $0.5 \mu \mathrm{g} / \mathrm{ml}$ BMP-2 (R and D Biosystems) or both for 7-10 days and then analyzed by western blotting.

Reporter Assays: Co-transfections, luciferase and $\beta$-galactosidase assays as well as the GRHL2 expression vector and ZEB1-WT- promoter reporter were described previously (22). The transcription factors used in the co-transfection/reporter assays were obtained and cloned as follows: hLBX1 was obtained from D. Haber 
(Dana-Farber Cancer Center) in pBABE and cloned into pCDNA3.1. hHOXA5 was purchased from Addgene and subcloned from pET28B into pCDNA-3.1. mTwist (pBABE-mTWIST-ER) was purchased from Addgene and the twist cDNA was subcloned into pCDNA-3.1 (GC rich Phusion buffer). HA-Snail-pCDNA-3.1 was purchased from Addgene. The GRHL2 genomic sequence from -625 to +335 (relative to the transcription start site of the standard GRHL2 transcript) was subcloned into pGL4.14 using the following primers: Graprom-f3: CTCACCTGTTTGAAAATCTG and Gra-prom-r12: TGTTTGATCCAATGAACTTGC, using the Bacterial Artificial Chromosome clone 2058A8 (Invitrogen) as a template; these coordinates were based on the GRHL2 transcript NM_024915. The band resulting from this PCR was re-amplified with similar primers containing NheI (forward) and BglII (reverse) restriction sites, and subcloned into pGL4.14 (Promega).

The ZEB1 promoters containing a mutant downstream homeobox site or deleted upstream homeobox site or both were generated as follows. The downstream site was mutated by using the mutagenic primers Mut-f3: cgtgcctccctctccccaccagtccgtaggaaaacttttccc Mut-r3: gggaaaagttttcctacggactggtggggagagggaggcacg in the Quickchange-IIXL kit (Agilent) with the ZEB1 promoter/pGL3basic clone (provided by Antonio Garcia de Herreros, University of Barcelona) as a template. The deletion of the upstream site was generated by amplifying the same template in two separate PCR reactions, using Ant-f:

TAATTTACGCGTCCTTAAGGTCCTGCACGGCG, Antr: TTTAAAAAGCTTCCGCCATGATCCTCTCGC (reaction 1) and Ant-f2: tatataGCGGCCGCAAGGGAAGGGAAGGGAGTCC, Ant-r2: TTTAAAGCGGCCGCTTCAATGAGATTGAACTTCA. Following restriction digestion and isolation from an agarose gel, fragments were three-way ligated into pGL3basic.

Chromatin Immunoprecipitation (CHIP) assays: The protocol for crosslinking, immunoprecipitation, de-crosslinking and qPCR analysis was as described (22). For Six1 protein interaction with the ZEB1 promoter, 5 dishes of HMLE+ empty vector (pMXS-IRES-puro) or FLAG-Six1 were immunoprecipitated with mouse anti-FLAG-M2-agarose or mouse IgG (Santa Cruz BioTechnology)-agarose in conjunction with DNA/proteinblocked protein A/G agarose (Pierce/Thermo). Primers to amplify the ZEB1 promoter were: f: 
gccgccgagcctccaacttt; r: tgctagggaccgggcggttt. For interaction of ZEB1 protein with the GRHI2 promoter, 5 dishes HMLE expressing ZEB1 (in pLUT vector) were processed. To pull down ZEB1 1 ug of the following antibodies (3 ug total) were used: ZEB1, rb, Sigma HPA004820; ZEB1, rb, Cell Signalling 3396S; ZEB1, rb, Santa Cruz Biotechnology SC-25388. Control antibody was rabbit IgG (3 ug) Santa Cruz Biotechnology. Primers to analyzed the ZEB1 chIP were: Positive control: Ecad-ZEB1-f: ggccggcaggtgaaccctca; Ecad-ZEB1-r: gggctggagtctgaactga; GRHL2 promoter set 3: f: cgccgctccactcgggtaaa ; r: tgcgcgatgattggctgggg; GRHL2 promoter set4: f: tcagctctcacaggctgccg; r: gaggcgcgctcaggtaaggc. Negative control primer set for all CHIP assays was from an intergenic region upstream of the GAPDH locus: GAPDH-f: atgggtgccactggggatct; GAPDH-r: tgccaaagcctaggggaaga.

Electrophoretic mobility shift assay: Purified recombinant Six1 protein was generated as described previously (26). Purified recombinant GRHL2 protein was obtained by expressing the GRHL2 coding sequence in E. coli BL21 using the pGEX-6P3 vector and purifying the fusion protein as described previously (13). After binding to the Glutathione Sepharose resin (GE Healthcare) the protein was cleaved free of GST sequence using PreScission Protease, which was then dialyzed against EMSA buffer (see below) using Slide-A-Lyzer Minidialysis Unit (Thermo Scientific). 2x EMSA buffer was: 30mM HEPES pH 7.6, 20\% Glycerol, 1mM EDTA, 200mM KCL, $0.5 \%$ NP40, 5mg/ml BSA (added fresh), 10mM DTT (added fresh). For 20ul binding reactions: 10ul 2x EMSA Buffer+1 uL poly dIdC (0.5 ug/uL)+2 $\square \mathrm{L}$ annealed $100 \mathrm{nM}$ oligonucleotide, and recombinant protein (as indicated). Oligonucleotides for EMSA were synthesized with Cy5 groups on both 5' ends (Operon) and annealed at $10 \mathrm{mM}$ Tris $/ 1 \mathrm{mM}$ EDTA $/ 100 \mathrm{mM} \mathrm{NaCl}$. Binding reactions were incubated at 4 degrees for twenty minutes, fifteen minutes at room temperature and analyzed on $6 \%$ polyacrylamide/TBE gels in $0.25 \mathrm{x}$ TBE buffer (pre-run for 1h) at 170V. The fluorescent signals were imaged using the LiCor Odyssey imaging system.

Oligo sequences(Forward strands) 
ZEB1-WT-Promoter: (Cy5)-

GGAAGGTGATGTCGTAAAGCCGGGAGTGTCGTAAACCAGGTGCGGTGGG

ZEB1-MT-Promoter: (Cy5)-

GGAAGGTGATGTCGTCCCGCCGGGAGTGTCGTCCCCCAGGTGCGGTGGG

GRHL2-Pos-Con: (Cy5)-AACTATAAAACCGGTTTATCTAGTTGG

Six1-Pos-Con: (Cy5)-GGGGGCTCAGGTTTCTGTGGC

Negative Control (From E-cadherin promoter):

TGGCCGGCAGGTGAACCCTCAGCCAATCAGCGCTACGGGGGGCGGTGCTCCGGGGCTCACCTGGC

TGCAG 


\section{Results}

GRHL2 inhibits the activation of ZEB1 expression by homeodomain proteins

Previously, we reported that GRHL2 binds and represses the ZEB1 promoter so as to suppress EMT (22). To characterize this transcriptional regulation further, we analyzed the ZEB1 promoter using a transcription factor binding prediction program (Genomatix) and identified two tandem homeodomain consensus binding sites,

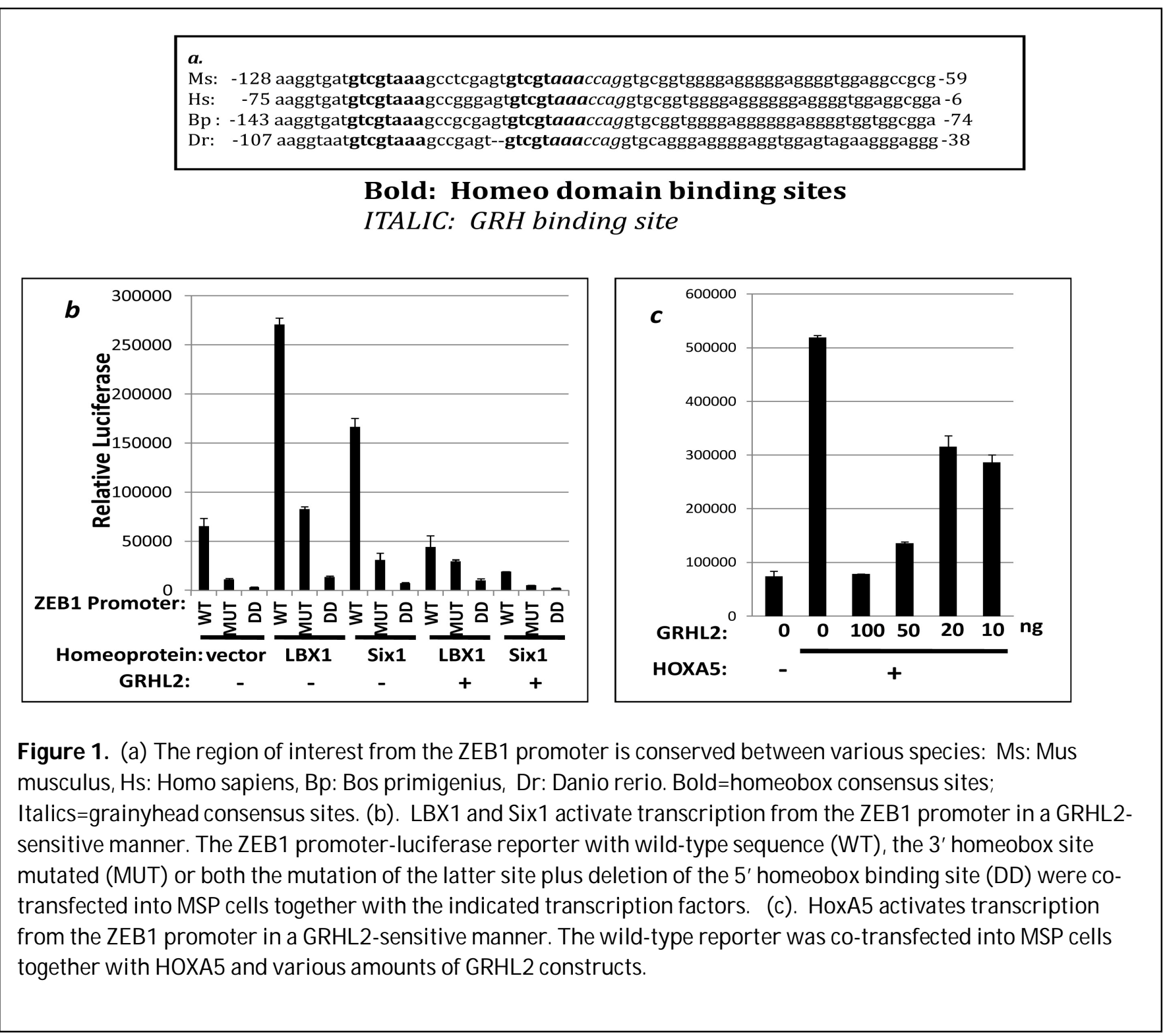

overlapping with and just upstream of the putative GRHL2 site (Figure 1a). Alignment of this sequence between several species revealed that both the putative GRHL2 binding site as well as these homeobox sites were highly conserved. In this light, we tested the effect of two homeodomain factors that were previously 
shown to be involved in EMT induction in breast cancer cells, LBX1 and Six1, on the activity of the ZEB1 promoter $(17,27)$. These factors activated transcription of the ZEB1 promoter significantly (Figure 1b,c).

HoxA5, another factor that was predicted to bind these two sites, also demonstrated robust activation as well as

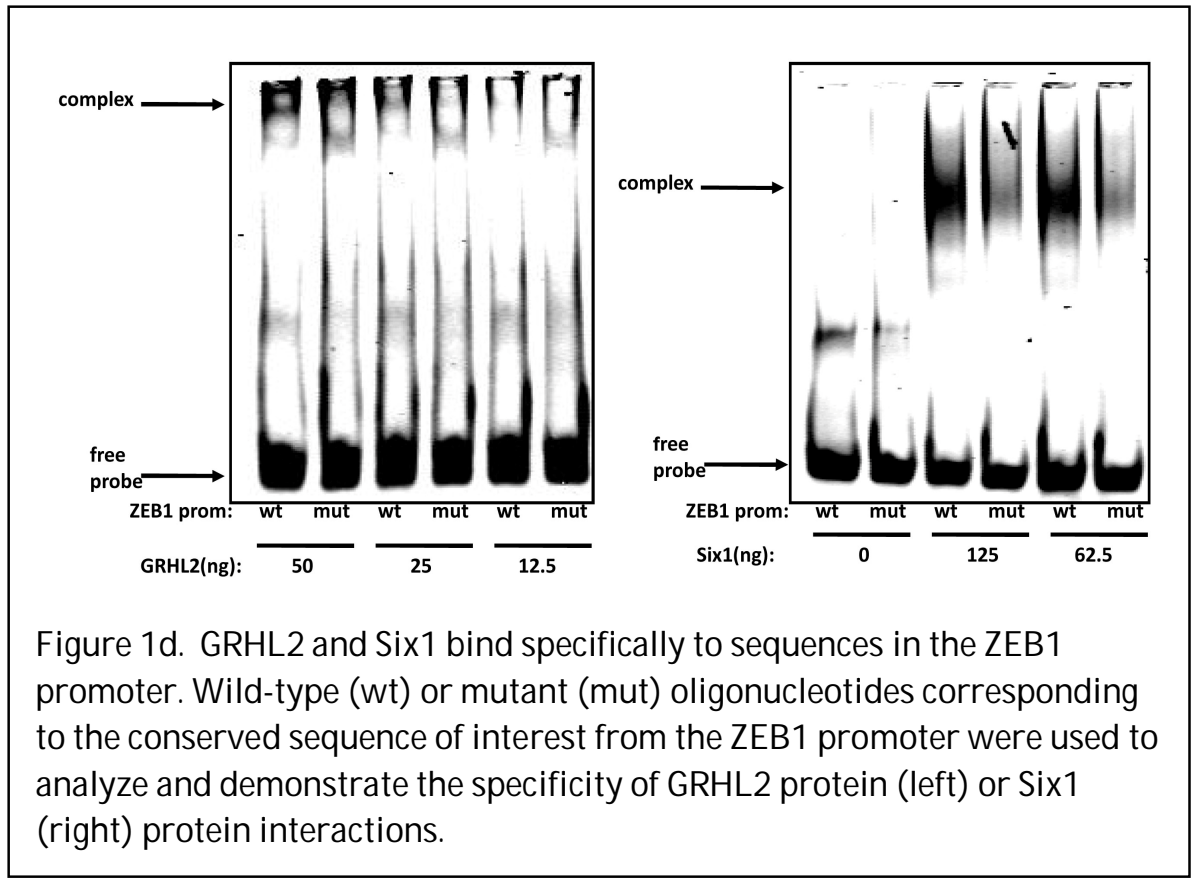

the ability to induce mammosphere

formation in HMLE cells, although

frank EMT was not evident (figure S1,

data not shown). Mutation of the 3'

homeodomain binding site

substantially diminished

transactivation by these factors. The

double deletion totally eliminated it,

and, interestingly, GRHL2 co-

transfection inhibited the

transactivation by all three factors (Figure 1b,c, S3).

LBX1 was shown previously to interact directly with the ZEB1 promoter and to activate its expression

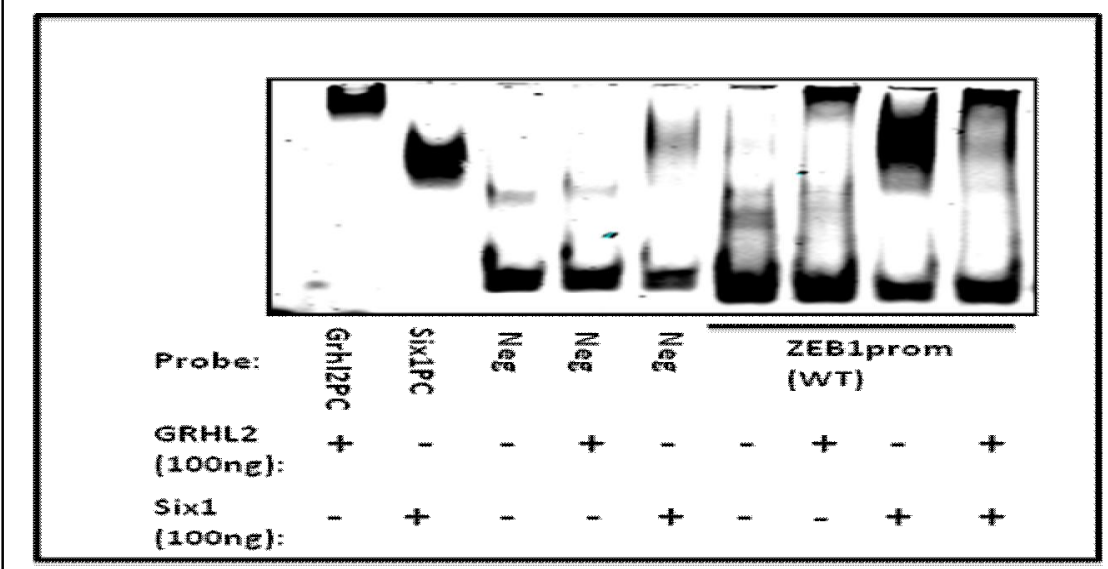

Figure 1e. GRHL2 alters the Six1-DNA complex. GRHL2 positive control oligo (GRHL2PC), Six1 positive control oligo (Six1PC), oligo from the E-cadherin promoter which neither protein is predicted to bind (Neg), and WT ZEB1 promoter oligo were used in an EMSA with the indicated combinations of GRHL2 and Six1 proteins.
(17). We tested Six1 for selective,

direct binding to an

oligonucleotide corresponding to

the conserved sequence of the

ZEB1 promoter. Six1 protein

interacted preferentially with the

wild-type but not the doubly

mutated (transcriptionally

inactive) sequence, as did GRHL2 
protein (figure 1d). The addition of stoichiometric amounts of GRHL2 protein diminished the Six1-DNA complex dramatically, indicating either a competition for DNA binding or an inhibitory Six1-GRHL2 interaction, which the data do not allow us to distinguish (figure 1e).

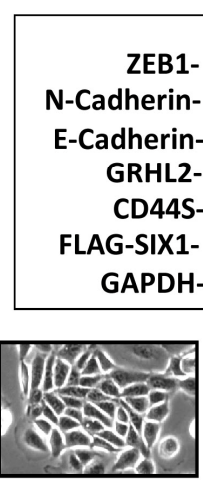

vector

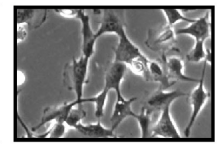

Six1

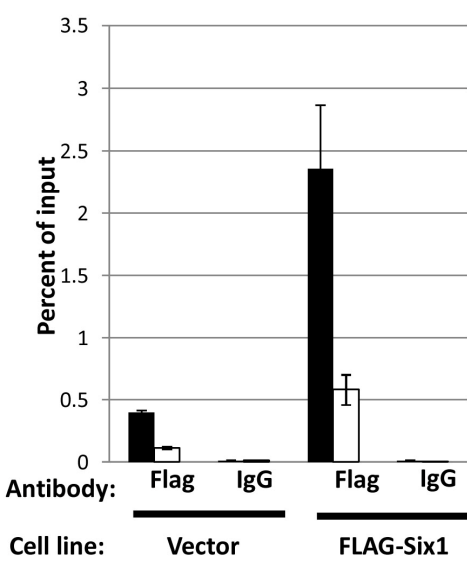

- ZEB1 Prom $\square$ GAPDH Prom

Figure 1f (left) and 1g(right) (f) Six1 induces the endogenous ZEB1 gene and EMT in unfractionated HMLE cells. HMLE cells expressing vector or FLAG-Six1 were analyzed for the indicated EMT markers (upper panel); or morphologic changes (lower panel). (g). Six1 protein interacts with the ZEB1 promoter in vivo. Chromatin from HMLE expressing either vector or FLAG-Six1 were used in a CHIP assay and analyzed by QRTPCR using ZEB1 promoter primers or GAPDH control primers.
We then tested the effect of Six1 on endogenous ZEB1 expression. HMLE cells are a mixed population containing 5$10 \%$ CD $44^{\text {high }} \mathrm{CD} 24^{\text {low }}$ mesenchymal cells in equilibrium with epithelial cells (7). Mixed-population HMLE

cells or flow-sorted CD44 ${ }^{\text {low }}$ HMLE cells, with or without shRNA-mediated GRHL2 knockdown, were infected with Six1 retroviral expression constructs. Interestingly, Six1 by itself up-regulated ZEB1, down-regulated GRHL2 and induced EMT in the unfractionated HMLE cells (figure 1f). In flow-sorted CD44 ${ }^{\text {low }}$ cells, induction of ZEB1 expression required Six1 expression plus the concomitant knockdown of GRHL2 through an shRNA (previously shown to have identical effects with other shRNAs targeting GRHL2), consistent with the antagonistic effect of GRHL2 that we observed previously (figure S2, (22)). CHIP analysis of the mixedpopulation cells revealed that Six1 was recruited to the endogenous ZEB1 promoter, indicating a direct Six1 protein-ZEB1 promoter interaction (figure 1g).

Knockdown of the individual homeodomain proteins examined here failed to block ZEB1 induction during EMT, indicating that multiple redundant factors, likely to include additional, unidentified factors, 
activate ZEB1 (data not shown). Nevertheless, the combined data support a model under which GRHL2 is a general inhibitor of homeodomain-induced ZEB1 expression.

GRHL2 suppresses primary tumor growth and sensitizes tumor cells to the chemotherapy-induced cytotoxicity

Previously, we reported that GRHL2 suppressed or reversed the oncogenic EMT, in part, through the repression of the ZEB1 gene (22). EMT increases the frequency of breast cancer stem cells (CSC), and consistent with this, GRHL2 suppressed mammosphere generation and down-regulated CD44 (22, 28). Here, we tested the effects of GRHL2 on tumor initiation frequency, a measure of CSC frequency. HMLER cells are immortalized mammary epithelial cells that express HrasV12 ectopically and have not undergone EMT, but are induced to do so by stable GRHL2 knockdown using multiple, independently targeting shRNAs $(22,29)$. As reported previously, the input cell number $\left(1 \times 10^{6}\right)$ of parental HMLER cells (with control shRNA) that we injected into immuno-compromised mice produced no detectable tumors (figure 2A; (28). By contrast, a representative GRHL2 knockdown derivative cell line usually (6/8) formed tumors. To extend this to another cell line, the triple-negative breast cancer lines, MDAMB-231, with or without ectopically expressed GRHL2,

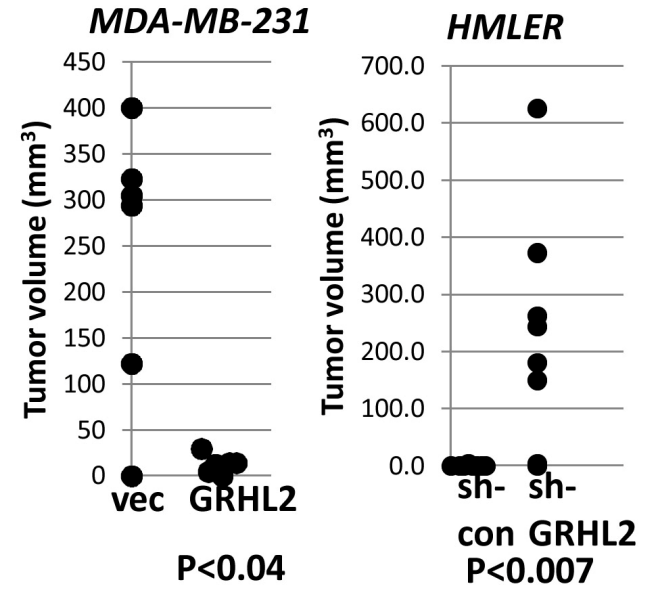

. (A) GRHL2 suppresses tumor initiation. Immunodeficient mice were injected orthotopically with pre-optimized cell numbers of MDA-MB231LN cells expressing GRHL2 vs. empty vector (left) or HMLE+Ras cells expressing GRHL2 shRNA vs. control shRNA (right). Results shown are based on measurements at five weeks and eight weeks, respectively. $N=8$ per group of HMLER and $N=6$ per group of MDA-MB-231LN. P-values are shown below the graphs.

(22) were injected. GRHL2 suppressed the frequency of tumors dramatically (5/6 vs. 0/6). These data were consistent with a tumor-promoting effect of $\operatorname{EMT}(7,28,30)$ that GRHL2 suppressed. In conjunction with the functional assays and clinical correlations - downregulation of GRHL2 expression in EMT-like tumors -- that we published previously (22), these results identify GRHL2 as a tumor suppressor gene. 
EMT is associated with chemoresistance $(31,32)$. We reasoned that the mesenchymal to epithelial transition induced by GRHL2 would be associated with enhanced sensitivity to the microtubule-targeting
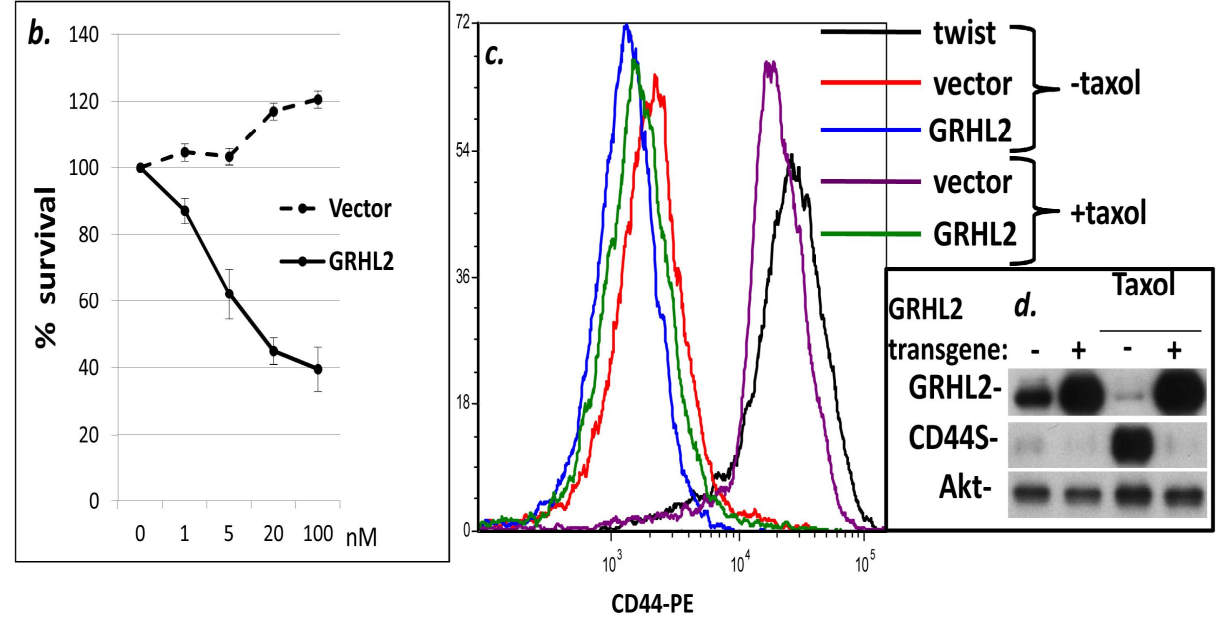

GRHL2 sensitizes tumor cells to paclitaxel: dose response comparing cell survival of MDA-MB-231LN cells with or without stable GRHL2 expression. (c) GRHL2 suppresses the emergence of stem cells after paclitaxel treatment: CD44 flow cytometric analysis, of HMLE cells with or without GRHL2 transgenes. (d) Loss of GRHL2 from the population of taxol-treated HMLE cells; note the up-regulation of CD44 in these cells as well (lanes 1 and 3), which was suppressed by a GRHL2 transgene (lanes 2 and 4).
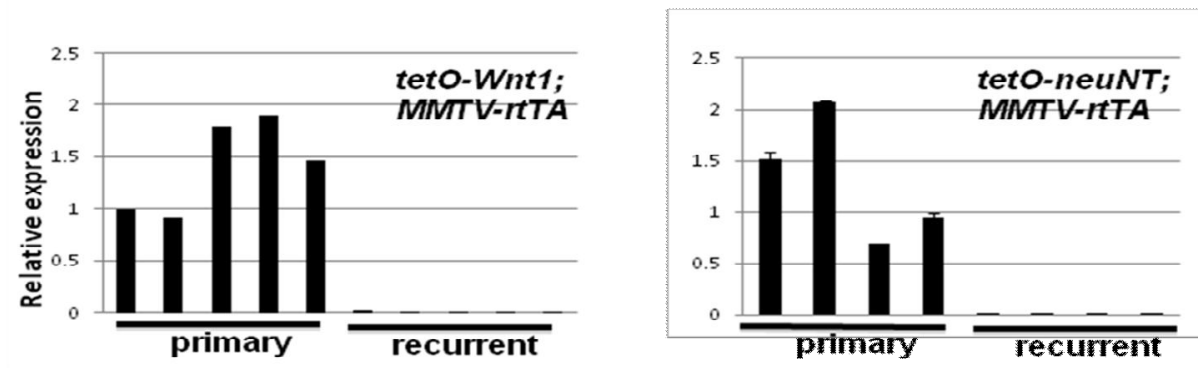

Figure 2e. GRHL2 is down-regulated during the transition from primary to recurrent phenotype in tetO-Wnt1 and tetO-neuNT mouse models: qRT-PCR on RNAs from independent tumors, normalized against $\beta 2$-microglobulin. chemotherapy drug, paclitaxel.

Ectopic GRHL2 expression

induced dose-dependent cell

death in the otherwise refractory

MDA-MB231LN tumor cell line

(Figure 2b). HMLE cells contain

a sub-fraction of

CD $44^{\text {high }} \mathrm{CD} 24^{\text {low }}$

mesenchymal/stem-like cells,

which are enriched by paclitaxel

selection $(7,32)$. We confirmed

that, following paclitaxel treatment and recovery, essentially $100 \%$ of HMLE (control) cells exhibited a CD44 ${ }^{\text {high }}$ phenotype, analogous to that induced by ectopic twist expression; these cells also

expressed lower levels of GRHL2 than the original population. By contrast, ectopic GRHL2 expression prevented the chemotherapy-induced emergence of CD44 ${ }^{\text {high }}$ stem like cells, consistent with its suppression of EMT (figures 2c,d and (22)).

In doxycyline-inducible mouse mammary tumor models models, the expression of neuNT, Wnt1 or c-myc promotes primary tumors that regress upon the removal of doxycyline. The tumors recur frequently, and the 
recurrent tumor cells have undergone EMT, providing a model for evolution from oncogene/proliferation ratedriven tumors to oncogene-independent, EMT-driven recurrences $(23,24,33)$. We analyzed RNA from the tetO-neuNT and tetO-Wnt1 mouse models for GRHL2 expression by qRT-PCR. In both cases, GRHL2 expression was greatly reduced in the recurrent tumor relative to primary (figure 2e). These findings indicate that GRHL2 is down-regulated during tumor evolution to an EMT phenotype, further supporting the tumor suppressor function of GRHL2.

Based on the extensive data supporting an oncogenic role for EMT, the suppression of EMT by GRHL2, the effects of GRHL2 on tumorigenicity and chemo-sensitivity, and the down-regulation of GRHL2 during EMT in cell culture, patient and mouse models, we set out to identify pathways that down-regulate GRHL2 expression.

GRHL2 is down-regulated by Wnt and TGF- $\beta$

TGF- $\beta$ is able to induce EMT in only restricted cell contexts (34). In HMLE cells, TGF- $\beta$ induced EMT only in conjunction with Wnt pathway agonists or in cells where GRHL2 had been knocked down, providing insight into this restriction $(7,22)$.

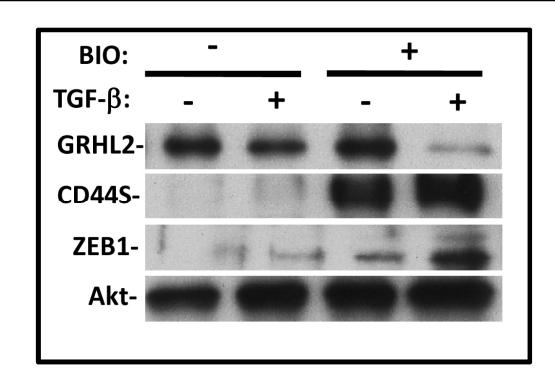

Figure 3a(left) and 3b(right) HMLE cells treated with the Wnt pathway agonist BIO (a) or stably expressing $\beta$-catenin S33Y (b) were assayed for GRHL2 down-regulation in response to TGF- $\beta$ treatment by Western blotting.

\section{Activation of the Wnt signaling pathway by transient} treatment with the GSK-3 inhibitor, 6-bromo-3-[(3E)-1,3-

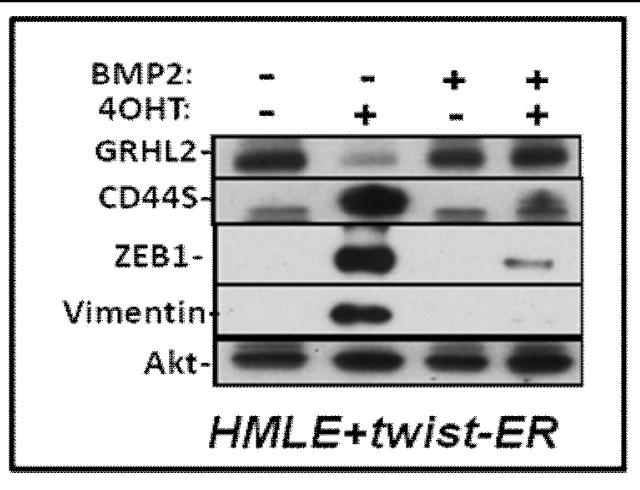

Figure 3c. HMLE cells that stably expressed Twist-ER protein were treated with or without 4-OHT (to activate TwistER) in the presence or absence of the TGF$\beta$ pathway antagonist BMP2, and cell lysates were assayed for GRHL2 and other indicated protein expression.

dihydro-3-(hydroxyimino)-2H-indol-2-ylidene]-1,3-dihydro-(3Z)-2H-indol-2-one (BIO;(25)) or, by stable expression of the degradation-resistant $\square$-catenin S33Y mutant (35), down-regulated GRHL2 expression only 
modestly in this short-term assay, as did extended treatment with TGF- $\beta$. Co-activation of both pathways, however, caused a dramatic down-regulation of GRHL2 expression (figure 3a,b), accompanied by upregulation of the GRHL2-repressed target gene, ZEB1. BMP2, a functional antagonist of TGF- $\beta$ signaling and Twist-induced EMT $(7,36)$, alleviated both GRHL2 down-regulation and ZEB1 induction in response to the activation of Twist-ER protein by 4-hydroxytamoxifen (figure 3c).

These observations signified that Wnt and TGF-ßpathways collaborated to down-regulate GRHL2 as an intermediate step in EMT, and prompted us to investigate the potential role of ZEB1 in this down-regulation.

ZEB1 represses the GRHL2 promoter directly

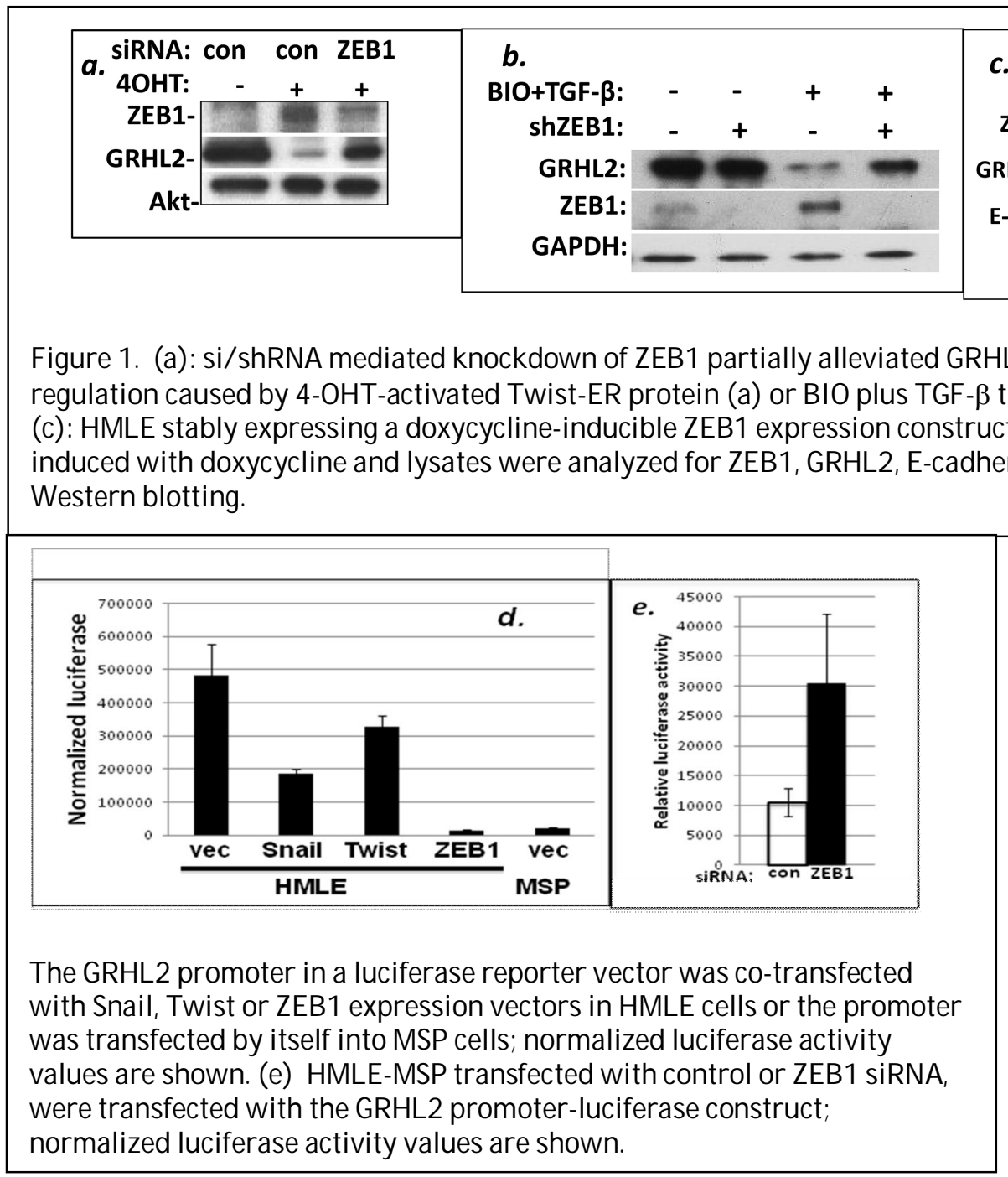

(HMLE+Twist-ER) were induced to undergo EMT by the addition of 4hydroxytamoxifen. As we reported previously, this up-regulated ZEB1 and down-regulated GRHL2 (22). Suppression of ZEB1 with siRNA, however, largely prevented the GRHL2 down-regulation (figure 4a). 
To test this in a different context using a different knockdown reagent, HMLE cells with stable GRHL2 shRNA expression or empty vector control cells were induced with the combination of BIO and TGF- $\beta$. Analogously, depletion of ZEB1 by GRHL2 shRNA (targeting a different sequence) alleviated the down-regulation of GRHL2 (figure 4b). Conversely, we expressed ZEB1 ectopically in HMLE cells using a doxycycline-inducible lentiviral vector. Induction of ZEB1 down-regulated GRHL2 expression as well as the previously characterized ZEB1 target, E-cadherin ((13) and figure 4c).

We then explored the possibility that ZEB1 protein might repress the GRHL2 gene through direct interaction with promoter sequences. As an initial test, we subcloned a genomic fragment containing the sequences from 625 to +335 (relative to the transcription start site of the standard GRHL2 transcript) into a luciferase reporter vector and assayed this for transcriptional activity. The transcriptional activity of this promoter clone was substantially greater in HMLE cells than in the mesenchymal subpopulation (MSP) cells derived from HMLE,

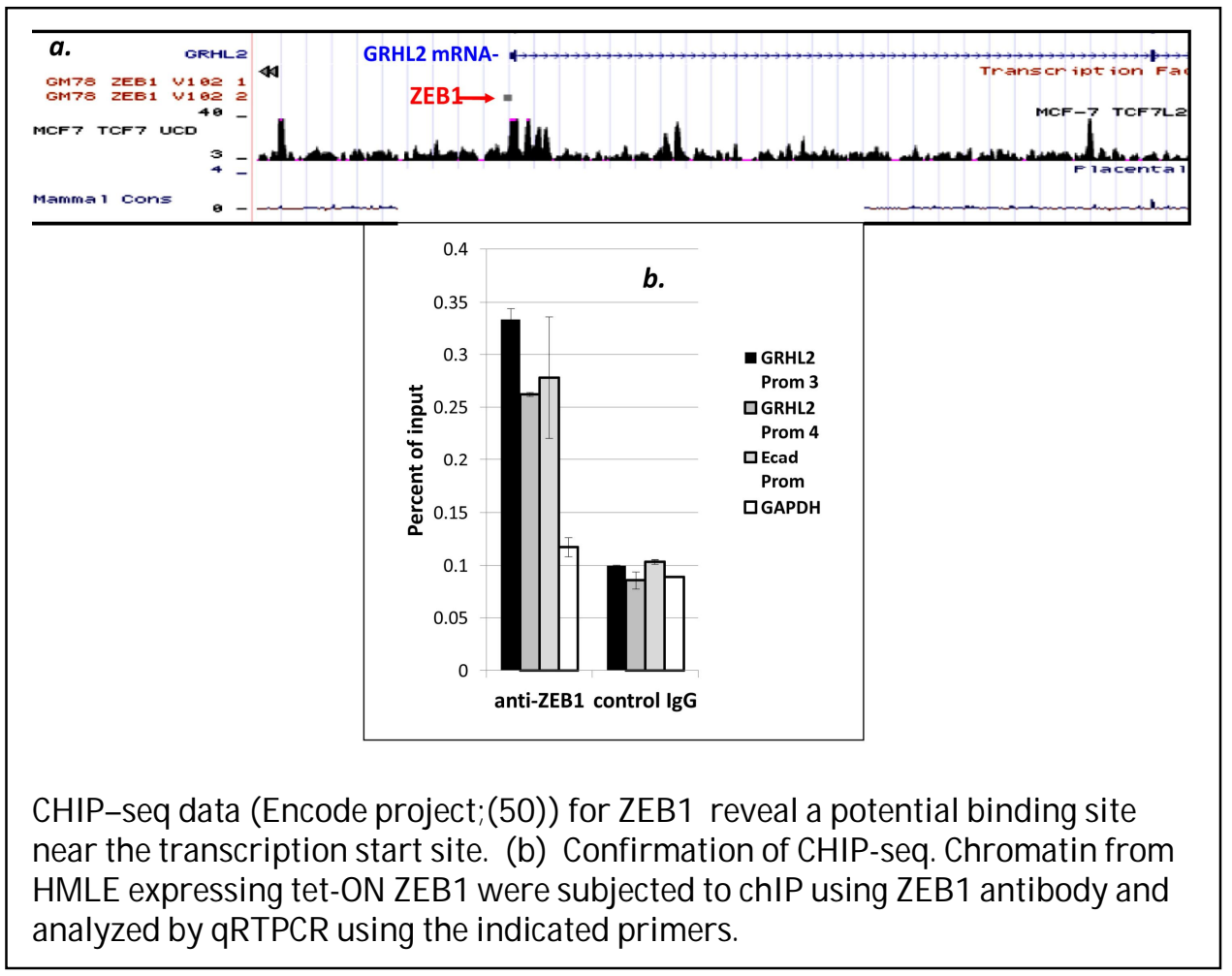

consistent with the downregulation of endogenous GRHL2 in the latter, validating this promoter clone ((22) and figure 4d). Co-transfected ZEB1 repressed the promoter, nearly to background level. By contrast, two other E-box binding EMTrelated transcription factors, Snail and Twist, only modestly repressed the promoter.

Conversely, the promoter activity assayed in MSP cells was stimulated by transfection of ZEB1 siRNA (figure $4 \mathrm{e})$. 
Inspection of published ZEB1 CHIP-seq data indicated binding sites positioned near the transcription start site of GRHL2 (Figure 5a). By CHIP analysis using anti-ZEB1 antibody, we detected an interaction of ZEB1 protein with GRHL2 sequences near the transcription start site, with efficiency comparable to that of the Ecadherin promoter and significantly stronger than a negative control sequence (the intergenic region upstream of the GAPDH gene; figure 5b). When combined, these data indicated that ZEB1 protein represses the GRHL2 promoter directly, establishing that a mutual antagonism between expression of ZEB1 and GRHL2 directs tumor cells toward epithelial or mesenchymal phenotypes.

\section{Discussion}

Our observations inform a model of reciprocal antagonism between ZEB1 and GRHL2 as a pivotal mechanism underlying EMT (figure 6). Under this model, GRHL2 and ZEB1 - each regulated by microenvironmental factors - repress each other's transcription. GRHL2 represses ZEB1 by inhibiting at least three activators of the ZEB1 promoter: LBX1, Six1 and HoxA5.

We focused on these three transcription factors in light of the functional importance of homeodomain consensus sites for activity of the ZEB1 promoter (figure 1). Although numerous homeodomain proteins may have partially redundant functions, confounding efforts to show an effect of knockdown/knockout of an individual factor, their overall significance in diverse cancer types is established (reviewed in (37)). In particular, previous reports have implicated LBX1 and Six1 in breast cancer-related EMT $(17,27,38)$. While

Six1 was shown previously to induce ZEB1 expression, this was proposed to be post-transcriptional in colorectal cancer cell lines (39), in contrast with our evidence indicating a direct interaction of Six1 with the ZEB1 promoter; the basis for this discrepancy is unclear.

Importantly, GRHL2 protein, the first direct transcriptional repressor of the ZEB1 gene to be reported (22), interfered with the transcriptional activation of the ZEB1 promoter by all three of these factors. The precise molecular mechanism underlying this effect remains to be elucidated. While Six1 and GRHL2 proteins interacted with an overlapping sequence in the ZEB1 promoter (figure 1), a simple competition for DNA 
binding is unlikely because the oligonucleotide probe was in excess. While GRHL2 protein effectively abolished the Six1 protein-DNA complex on the ZEB1 promoter oligonucleotide that contained two tandem Six1 binding sites, there was no effect on Six1 protein binding to a positive control sequence containing only one binding site (data not shown), suggesting that GRHL2 prevents the dimerization of two Six1 protein molecules on DNA. We were unable to detect an interaction of GRHL2 with Six1 protein in co-transfection assays (data not shown), suggesting that they interact only on DNA.

The antagonistic effects of GRHL2 vs. ZEB1, mediated, in part, by homeodomain activators of ZEB1, may relate conceptually to previously reported developmental roles of these genes. GRHL2 is required for neural tube closure, the stage of development directly preceding delamination. Subsequently, anterior HOX genes (HoxA1, HoxB1) induce EMT during delamination of the neural crest, through activation of Snail and Msx1/2 transcription (40). Speculatively, the homeodomain factors may also activate EMT factors such as ZEB1, thereby repressing GRHL2 expression, which would indicate, analogously, functional opposition of these factors during development that mirrors their respective oncogenic EMT functions.

We have now shown the other half of the reciprocal feedback loop (figure 6) as well: ZEB1 is also a direct repressor of GRHL2 (figures 4,5). When combined, this represents switch that dictates cellular phenotype between epithelial and mesenchymal states, formally analogous to the relationship between ZEB1 and mir200 (41). Thus, the effect of inducing ZEB1 expression by micro-environmental factors is to repress GRHL2 expression, promoting stable expression of ZEB1. In this connection, we found that neither TGF- $\beta$ nor canonical Wnt pathway stimulation was sufficient to induce ZEB1/down-regulate GRHL2; however, the two in conjunction tipped the balance in favor of ZEB1. This finding is precisely consistent with those showing that multiple micro-environmental signals are needed to regulate EMT or MET $(6,42)$ and may prove to be the underlying mechanism. Other combinations of factors induce ZEB1 and EMT, at least in specific cell contexts, including TGF- $\beta+$ FGF2, TGF- $\beta+$ TNF-alpha, TGF- $\beta+E G F(R)$, TGF- $\beta+$ mechanotransduction from extracellular matrix, or factors in the "senescent cell secretory phenotype" (SASP) $(14,43-46)$. It is also 
notable that Six1 expression activates autocrine TGF- $\beta$ and Wnt signaling loops, suggesting that it activates ZEB1 both directly and indirectly (27).

Our results indicate that these combinations of factors may down-regulate GRHL2 as an intermediate step leading to EMT. Moreover, the suppression of EMT by stable GRHL2 expression suppresses EMT, the cancer stem cell phenotype and sensitizes tumor cells to the effects of chemotherapeutic drugs. Thus each of these stimuli could serve as potential targets for therapies aimed at inhibiting the tumor-initiating cell/chemoresistance phenotype that is accompanies GRHL2 down-regulation during chemotherapy-driven tumor evolution to a recurrent state. Therapeutic stabilization of GRHL2 expression represents a potential treatment strategy, given its tumor suppressive role described here and its sensitivity to regulation by microenvironmental factors through established receptors. This function of GRHL2 in suppressing tumors agrees with other recent reports identifying the related gene, GRHL3, as a tumor suppressor in squamous cell carcinoma that up-regulates the tumor suppressor, PTEN $(47,48)$. During development, these factors regulate some unique and some common genes (49), identifying which targets are unique and common in tumor biology will undoubtedly be the focus of future investigation.

Cellular commitment to undergo an oncogenic EMT is formally analogous to cell cycle control in that both involve a transition from dependence on extracellular signals to an autonomous, stable state. For example, the cell cycle becomes autonomous past the mitogen-driven restriction point, activation of cyclinD-CDK4/6 complexes, and maintains that state by a number of mechanisms, including stable activation of cyclin $\mathrm{E}$ expression by free E2F. Similarly, oncogenic EMT is initiated by micro-environmental factors, for example, TGF- $\beta$ and Wnt agonists. We propose that the transition to an autonomous state is defined, in part, by downregulation of GRHL2, stabilizing autocrine signaling through ZEB1, TGF- $\beta$, Wnt, and other factors. Thus, GRHL2 down-regulation is an "oncogenic EMT restriction point.”

\section{Acknowledgments}


We wish to thank Sarah McLaughlin for technical assistance with mouse tumor assays, Kathy Brundage for flow cytometry, Philip Riley IV for assistance with molecular biology, Daniel Haber, Stephen Jane, and Paul Monga for constructs and advice.

\section{Grant Support}

S.M. Frisch was supported by NIH grant R01CA123359. The flow cytometry core facility (Mary Babb Randolph Cancer Center) was supported by NIH grants RR020866 and P20 RR16440.

\section{References}

1. Iwatsuki M, Mimori K, Yokobori T, et al. Epithelial-mesenchymal transition in cancer development and its clinical significance. Cancer Sci; 101: 293-9.

2. Guadamillas MC, Cerezo A, Del Pozo MA. Overcoming anoikis--pathways to anchorageindependent growth in cancer. J Cell Sci; 124: 3189-97.

3. Ito Y, Iwase T, Hatake K. Eradication of breast cancer cells in patients with distant metastasis: the finishing touches? Breast Cancer.

4. Woodward WA, Chen MS, Behbod F, Alfaro MP, Buchholz TA, Rosen JM. WNT/ beta-catenin mediates radiation resistance of mouse mammary progenitor cells. Proc Natl Acad Sci U S A 2007; 104: 618-23.

5. Liu S, Clouthier SG, Wicha MS. Role of microRNAs in the regulation of breast cancer stem cells. J Mammary Gland Biol Neoplasia; 17: 15-21.

6. Scheel C, Weinberg RA. Phenotypic plasticity and epithelial-mesenchymal transitions in cancer and normal stem cells? Int J Cancer; 129: 2310-4.

7. Scheel C, Eaton EN, Li SH, et al. Paracrine and autocrine signals induce and maintain mesenchymal and stem cell States in the breast. Cell; 145: 926-40.

8. Taube JH, Herschkowitz JI, Komurov K, et al. Core epithelial-to-mesenchymal transition interactome gene-expression signature is associated with claudin-low and metaplastic breast cancer subtypes. Proc Natl Acad Sci U S A; 107: 15449-54.

9. Creighton CJ, Chang JC, Rosen JM. Epithelial-mesenchymal transition (EMT) in tumor-initiating cells and its clinical implications in breast cancer.J Mammary Gland Biol Neoplasia; 15: 253-60.

10. Brabletz S, Brabletz T. The ZEB/ miR-200 feedback loop--a motor of cellular plasticity in development and cancer? EMBO Rep; 11: 670-7.

11. Gupta PB, Fillmore CM, Jiang G, et al. Stochastic state transitions give rise to phenotypic equilibrium in populations of cancer cells. Cell; 146: 633-44.

12. Kouros-Mehr H, Kim JW, Bechis SK, Werb Z. GATA-3 and the regulation of the mammary luminal cell fate. Curr Opin Cell Biol 2008; 20: 164-70.

13. Grooteclaes ML, Frisch SM. Evidence for a function of CtBP in epithelial gene regulation and anoikis. Oncogene 2000; 19: 3823-8. 
14. Chua HL, Bhat-Nakshatri P, Clare SE, Morimiya A, Badve S, Nakshatri H. NF-kappaB represses Ecadherin expression and enhances epithelial to mesenchymal transition of mammary epithelial cells: potential involvement of ZEB-1 and ZEB-2. Oncogene 2007; 26: 711-24.

15. Dave N, Guaita-Esteruelas S, Gutarra S, et al. Functional cooperation between Snail1 and twist in the regulation of ZEB1 expression during epithelial to mesenchymal transition.J Biol Chem; 286: 1202432.

16. Sanchez-Tillo E, de Barrios O, Siles L, Cuatrecasas M, Castells A, Postigo A. beta-catenin/ TCF4 complex induces the epithelial-to-mesenchymal transition (EMT)-activator ZEB1 to regulate tumor invasiveness. Proc Natl Acad Sci U SA; 108: 19204-9.

17. Yu M, Smolen GA, Zhang J, et al. A developmentally regulated inducer of EMT, LBX1, contributes to breast cancer progression. Genes Dev 2009; 23: 1737-42.

18. Wang S, Samakovlis C. Grainy head and its target genes in epithelial morphogenesis and wound healing. Curr Top Dev Biol; 98: 35-63.

19. Schafer M, Werner S. Cancer as an overhealing wound: an old hypothesis revisited. Nat Rev Mol Cell Biol 2008; 9: 628-38.

20. Pyrgaki C, Liu A, Niswander L. Grainyhead-like 2 regulates neural tube closure and adhesion molecule expression during neural fold fusion. Dev Biol; 353: 38-49.

21. Kerosuo L, Bronner-Fraser M. What is bad in cancer is good in the embryo: importance of EMT in neural crest development. Semin Cell Dev Biol; 23: 320-32.

22. Cieply B, Riley Pt, Pifer PM, et al. Suppression of the Epithelial-Mesenchymal Transition by Grainyhead-like-2. Cancer Res; 72: 2440-53.

23. Moody SE, Perez D, Pan TC, et al. The transcriptional repressor Snail promotes mammary tumor recurrence. Cancer Cell 2005; 8: 197-209.

24. Debies MT, Gestl SA, Mathers JL, et al. Tumor escape in a Wnt1-dependent mouse breast cancer model is enabled by p19Arf/ p53 pathway lesions but not p16 Ink4a loss. J Clin Invest 2008; 118: 51-63. 25. Sato N, Meijer L, Skaltsounis L, Greengard P, Brivanlou AH. Maintenance of pluripotency in human and mouse embryonic stem cells through activation of Wnt signaling by a pharmacological GSK-3-specific inhibitor. Nat Med 2004; 10: 55-63.

26. Patrick AN, Schiemann BJ, Yang K, Zhao R, Ford HL. Biochemical and functional characterization of six SIX1 Branchio-oto-renal syndrome mutations.J Biol Chem 2009; 284: 20781-90.

27. Micalizzi DS, Christensen KL, Jedlicka P, et al. The Six1 homeoprotein induces human mammary carcinoma cells to undergo epithelial-mesenchymal transition and metastasis in mice through increasing TGF-beta signaling. J Clin Invest 2009; 119: 2678-90.

28. Mani SA, Guo W, Liao MJ, et al. The epithelial-mesenchymal transition generates cells with properties of stem cells. Cell 2008; 133: 704-15.

29. Elenbaas B, Spirio L, Koerner F, et al. Human breast cancer cells generated by oncogenic transformation of primary mammary epithelial cells. Genes Dev 2001; 15: 50-65.

30. Wellner U, Schubert J, Burk UC, et al. The EMT-activator ZEB1 promotes tumorigenicity by repressing stemness-inhibiting microRNAs. Nat Cell Biol 2009; 11: 1487-95.

31. Creighton CJ, Li X, Landis M, et al. Residual breast cancers after conventional therapy display mesenchymal as well as tumor-initiating features. Proc Natl Acad Sci U S A 2009; 106: 13820-5.

32. Gupta PB, Onder TT, Jiang G, et al. Identification of selective inhibitors of cancer stem cells by highthroughput screening. Cell 2009; 138: 645-59.

33. Leung JY, Andrechek ER, Cardiff RD, Nevins JR. Heterogeneity in MYC-induced mammary tumors contributes to escape from oncogene dependence. Oncogene.

34. Brown KA, Aakre ME, Gorska AE, et al. Induction by transforming growth factor-beta1 of epithelial to mesenchymal transition is a rare event in vitro. Breast Cancer Res 2004; 6: R215-31.

35. Yook JI, Li XY, Ota I, et al. A Wnt-Axin2-GSK3beta cascade regulates Snail1 activity in breast cancer cells. Nat Cell Biol 2006; 8: 1398-406. 
36. Candia AF, Watabe T, Hawley SH, et al. Cellular interpretation of multiple TGF-beta signals: intracellular antagonism between activin/ BVg1 and BMP-2/ 4 signaling mediated by Smads. Development 1997; 124: 4467-80.

37. Shah N, Sukumar S. The Hox genes and their roles in oncogenesis. Nat Rev Cancer; 10: 361-71.

38. McCoy EL, Iwanaga R, Jedlicka P, et al. Six1 expands the mouse mammary epithelial stem/ progenitor cell pool and induces mammary tumors that undergo epithelial-mesenchymal transition. J Clin Invest 2009; 119: 2663-77.

39. Ono H, Imoto I, Kozaki K, et al. SIX1 promotes epithelial-mesenchymal transition in colorectal cancer through ZEB1 activation. Oncogene.

40. Gouti M, Briscoe J, Gavalas A. Anterior Hox genes interact with components of the neural crest specification network to induce neural crest fates. Stem Cells; 29: 858-70.

41. Gregory PA, Bracken CP, Smith E, et al. An autocrine TGF-beta/ ZEB/ miR-200 signaling network regulates establishment and maintenance of epithelial-mesenchymal transition. Mol Biol Cell; 22: 168698.

42. Gao D, Vahdat LT, Wong S, Chang JC, Mittal V. Microenvironmental regulation of epithelialmesenchymal transitions in cancer. Cancer Res; 72: 4883-9.

43. Shirakihara T, Horiguchi K, Miyazawa K, et al. TGF-beta regulates isoform switching of FGF receptors and epithelial-mesenchymal transition. EMBOJ; 30: 783-95.

44. Ohashi S, Natsuizaka M, Wong GS, et al. Epidermal growth factor receptor and mutant p53 expand an esophageal cellular subpopulation capable of epithelial-to-mesenchymal transition through ZEB transcription factors. Cancer Res; 70: 4174-84.

45. Laberge RM, Awad P, Campisi J, Desprez PY. Epithelial-mesenchymal transition induced by senescent fibroblasts. Cancer Microenviron; 5: 39-44.

46. Gjorevski N, Boghaert E, Nelson CM. Regulation of Epithelial-Mesenchymal Transition by Transmission of Mechanical Stress through Epithelial Tissues. Cancer Microenviron; 5: 29-38.

47. Bhandari A, Gordon W, Dizon D, et al. The Grainyhead transcription factor Grhl3/ Get1 suppresses miR-21 expression and tumorigenesis in skin: modulation of the miR-21 target MSH2 by RNA-binding protein DND1. Oncogene.

48. Darido C, Georgy SR, Wilanowski T, et al. Targeting of the Tumor Suppressor GRHL3 by a miR-21Dependent Proto-Oncogenic Network Results in PTEN Loss and Tumorigenesis. Cancer Cell; 20: 635-48. 49. Boglev Y, Wilanowski T, Caddy J, et al. The unique and cooperative roles of the Grainy head-like transcription factors in epidermal development reflect unexpected target gene specificity. Dev Biol; 349: 512-22.

50. Bernstein BE, Birney E, Dunham I, Green ED, Gunter C, Snyder M. An integrated encyclopedia of DNA elements in the human genome. Nature; 489: 57-74. 


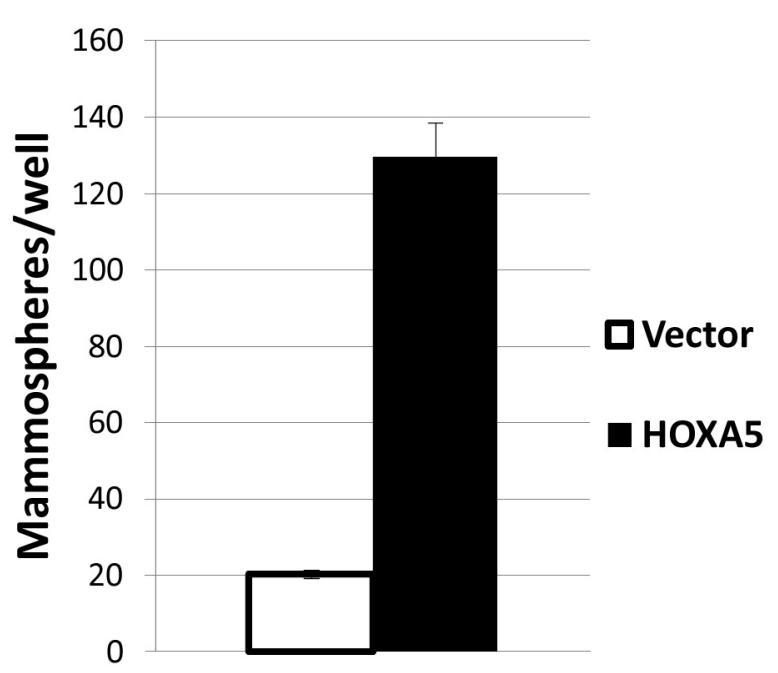

Figure S1.

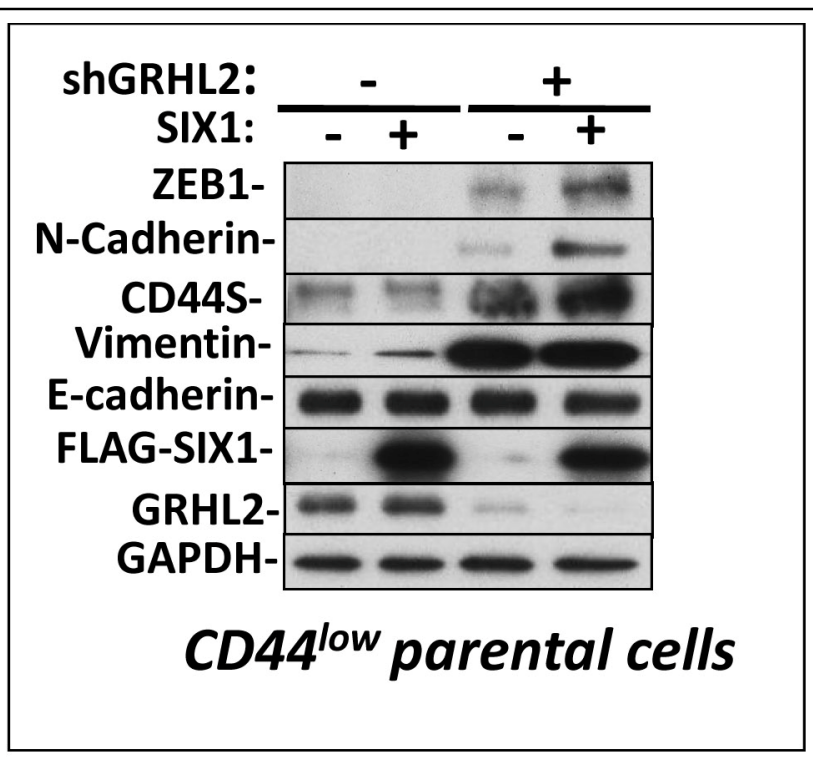

Fiaure S2.

Figure S1. Ectopic HOXA5 expression induces mammospheres. HMLE expressing either empty-pBABE puro or HOXA5-pBABE puro were cultured in methylcellulose with complete medium to test for their ability to form mammospheres.

Figure S2. SIX1 induces ZEB1 expression only in the context of GRHL2 knockdown, in a CD44low parental cell line. CD44low HMLE cells expressing empty vector or SIX1, with or without GRHL2 shRNA, were western blotted for various epithelial and mesenchymal markers.

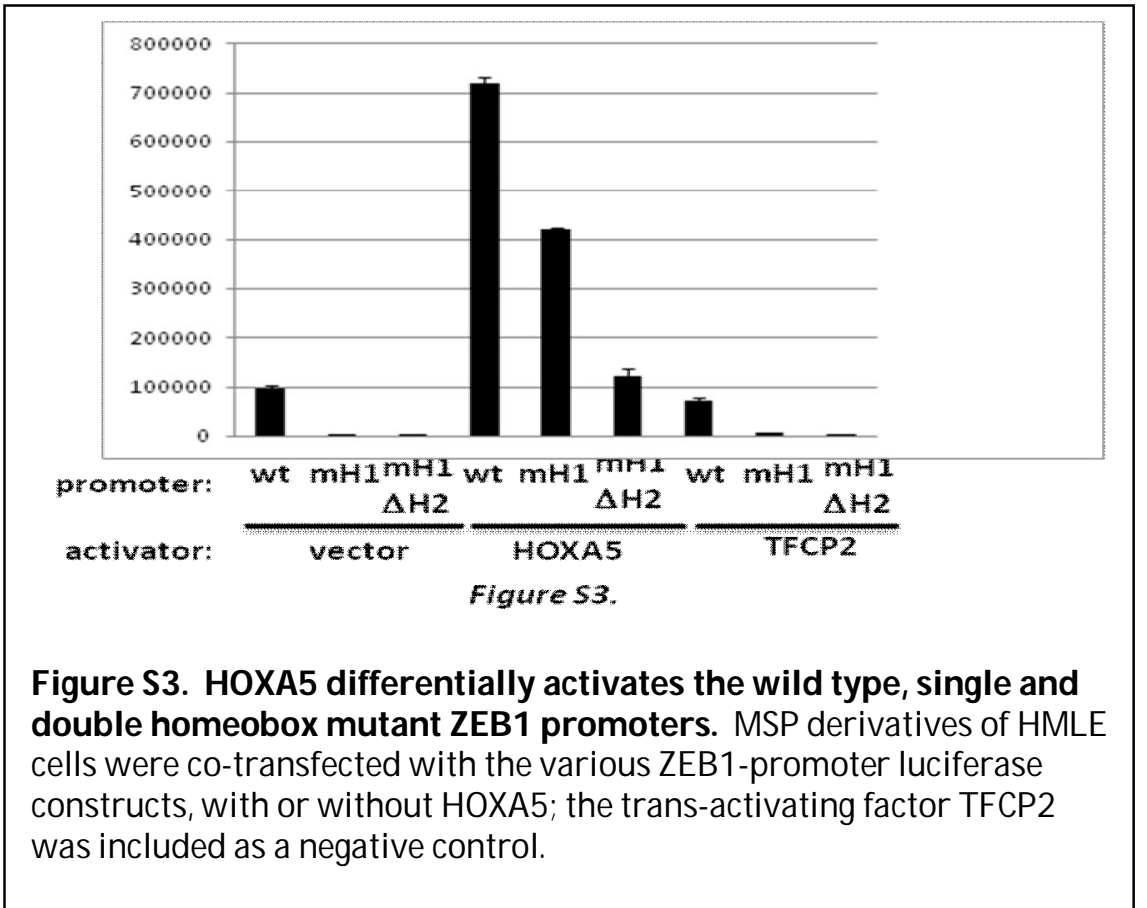


Chapter 4

\section{Overall Discussion}


The present work has established that GRHL2 is a potent inhibitor of EMT and can induce MET. This effect is due, in part, to a direct repression of the ZEB1 promoter by GRHL2. GRHL2 also suppressed TGF$\beta /$ Smad dependent transactivation. In-vivo, GRHL2 was down-regulated in human claudin-low breast cancer, renal cell carcinoma, recurrent tumors in mice and it suppressed tumorigenicity in xenograft assays. In experimental systems, GRHL2 enhanced anoikis, suppressed anchorage-independent, mammosphere-generating growth, invasion and sensitivity to chemo-therapeutics. Micro-environmental factors Wnt and TGF- $\beta$ collaborated to down-regulate GRHL2 and this was, surprisingly, dependent on direct repression of the GRHL2 promoter by ZEB1. Therefore this thesis has established that GRHL2 is a tumor suppressor gene that engages in a reciprocal negative repression loop with ZEB1, which regulates EMT and tumorigenicity.

Several other GRHL2 targets that were identified in our microarray analysis represent interesting opportunities. First, GRHL2 appeared to induce a vestigial-like (VGLL) switch, where VGLL1 was upregulated and VGLL4 was down regulated. Vestigial like genes are co-factors for the DNA binding transcription factor, TEAD [1]. The role of VGLL's in vertebrate biology is widely unknown however TEAD is the transcription factor that YAP and TAZ bind in order to activate transcription. So, by regulating TEAD binding factors, GRHL2 has the potential to modulate YAP and TAZ function, which as describe in the introduction, are important regulators of anoikis and EMT. We showed that GRHL2 expression interfered with the activity of a Smad responsive reporter construct, but the exact mechanism for this was not elucidated. In the micro array analysis CITED2 was down regulated by GRHL2 and could be the key to this phenomenon.

CITED2 interacts with Smads and serves as a transcriptional co-activator [2], so GRHL2 may regulate the TGF$\beta /$ Smad by repressing CITED2. The vitamin D receptor (VDR) was up-regulated by GRHL2 (we confirmed this by RT-PCR) and VDR can interact with and alter $\beta$-catenin transactivation [3-5]. This is one potential model by which GRHL2 can not only regulate wnt signaling, but could stabilize its own expression based on what we've shown regarding the effect of active wnt on GRHL2 levels. TP63 was shown to be upregulated by GRHL2 and this was confirmed by RT-PCR (S.F., E.A. unpublished data). Consistent with published data in 
prostate cancer cells and MCF10a [6,7], p63 knockdown induced frank EMT in HMLE (S.F., P.R., E.A. unpublished data), so it is very likely that the regulation of p63 is a key downstream effector of the GRHL2ZEB1 axis with the precise relationship to be determined by future studies. These are a few representative examples of intriguing GRHL2 target genes that remain to be tested for their significance in the tumor suppressive role of GRHL2.

We chose to test the effect of GRHL2 on EMT based on its role in wound healing and regulation of epithelial adhesion genes. However, we did not examine the other two mammalian grainy-head genes, GRHL1 and GRHL3. Based on the high level of homology of the three mammalian grainyhead genes and the fact that they share some target genes during development and wound healing (see Introduction), we cannot rule out the possibility of their functional significance in regulating certain aspects of EMT. In fact, some recently published data would indicate that this is quite likely. First, GRHL3 (as was GRHL2) was shown to be down regulated by EMT in prostate cells; this was not a focus of the paper and the significance of GRHL3 down regulation was not tested [8]. As was noted in the introduction here, GRHL2 and 3 have common and distinct gene targets, so based on the down-regulation of GRHL3 during EMT its functional significance should not be ignored. Also, whether GRHL2 regulates epithelial and mesencymal genes as a homo or heterodimer with GRHL1 or GRHL3 and which genes are unique and common targets remain to be tested. Indeed, GRHL2 expression was sufficient to induce MET, however we did not test whether endogenous GRHL1 or 3 were involved in this phenomenon.

In anoikis resistant mesenchymal stem cells, mir-125b was shown to be critical for their anchorage independent survival [9]. Interestingly, mir-125b is predicted to target GRHL1 by the micro-RNA prediction program “Target Scan”. These data would inform the hypothesis that mir-125b establishes mesenchymal cell anoikis resistance in part, through GRHL1 down regulation. While a role for GRHL1 in anoikis has not been shown, its known target gene, DSG1, raises some intriguing possibilities, which warrant experimentation. DSG1 or desmoglein1 is a component of epithelial desmosomes which are unique cell-cell adhesion complexes. 
It was shown to be co-regulated with E-cadherin and lost in melanoma [10], and while anoikis was not measured, melanoma cell lines are well known to be anoikis resistant [11-13]. Furthermore, other desmosome components, DSG2 and PERP have been shown to activate apoptosis [10,14-17]. So GRHL1 may regulate the anoikis sensitive state of epithelial cells by transcriptionally activating desomsomal genes, which is another potentially interesting model worth pursuing. Several desmosomal genes were also upregulated by GRHL2 on our microarray (JUP, PERP, DSG3, DSP, DSC2) indicating that perhaps desomosomal components are general targets of mammalian grainyhead factors.

Based on this novel role for GRHL2 and the known oncogenic role for EMT, antagonizing pathways that repress GRHL2 expression and/or function would be the rational basis of MET inducing cancer therapies. We have identified two pathways, in culture, that collaborate to down regulate GRHL2, Wnt and TGF- $\beta$. Wnt and TGF- $\beta$ inhibitors could theoretically be tested as a pre-treatment to standard cytotoxic chemotherapies with the intention of reverting the mesenchymal/ breast cancer stem cell sub-fraction of the tumor to epithelial and restoring sensitivity to chemotherapy. This could potentially alter the TIC phenotype, which would reduce recurrences. An analogous strategy is being pursued in glioma where TGF- $\beta$ R inhibitors have been shown to revert the $\mathrm{CD} 44^{\mathrm{HIGH}}$ sub population of primary glioma cells, which reduced the tumor initiation frequency experimentally. Such inhibitors are being tested in glioma clinical trials[18-20]. Other stimuli undoubtedly regulate GRHL2 expression and await discovery, several external stimuli that regulate ZEB1 and EMT are listed in the chapter 2 discussions, and they potentially serve as additional targets for the strategy described here.

Further support for the tumor suppressive role of GRHL2 could be generated by testing the effect of GRHL2 in additional mouse models. Crossing GRHL2 inducible transgenic lines with the inducible oncogene models would test the functional significance of the GRHL2 loss that we showed in oncogene independent recurrences in chapter 3. The prediction would be that stabilizing GRHL2 expression would prevent the mesenchymal, oncogene independent tumor formation. Also, since the GRHL2 expression prevented tumor 
formation in 231LN xenograft assays, an inducible GRHL2 will be required to test the chemotherapy sensitivity in vivo. In this experiment 231LN tumor will be allowed to form, followed by induction of the GRHL2 transgene and chemotherapy treatment. Based on the results in culture, the GRHL2 positive tumors will respond to the treatment while the controls will not.

We also showed that BMP2 stabilized GRHL2 in the context of EMT and two other reports have shown BMPs to be upstream of grainyhead factors. First in xenopus, GRHL1 expression was shown to be activated by BMP4 and this was required for epidermal differentiation. [21] And, during the generation of induced pluripotent stem cells, BMP7 driven MET lead to the upregulation of all 3 mammalian grainyheads [22]. While it is not clear if this is a direct transcriptional effect of Smad 1 or 5, stimulating BMP signaling could be an alternative strategy to inducing MET in cancer to elicit the chemo sensitivity effect associated with GRHL2 expression. We have now shown that both GRHL2 stimulates BMP2 expression and BMP2 stabilizes GRHL2. In contrast to the reciprocal repression between GRHL2 and ZEB1, it appears that GRHL2 and BMP2 engage in a feed forward loop that stabilizes the epithelial phenotype.

Subsequent to the publication of the role of GRHL2 in regulating EMT/MET presented here in chapter 2, two more reports have now shown the significance of GRHL2 in regulating epithelial morphogenesis and phenotype in liver and lung cells [23,24]; these data support our findings and suggest that GRHL2 is a master regulator of epithelial characteristics regardless of the tissue-type. The generation of GRHL2 ${ }^{\text {flox/flox }}$ mice will be critical to test its function in vivo in the context of various physiological and pathological processes. Also, in accordance with the tumor-suppressive role for GRHL2 that we have established, a recent report has shown that an oncogenic micro-RNA, mir273, targets GRHL2 in breast cancer [25] but the significance of this regulation was not addressed.

GRHL2 is the first transcriptional repressor of ZEB1 and EMT to be identified. Several inducible models for EMT exist and include twist-ER, snail-ER(developed by the Weinberg group, MIT) and ZEB1- 
pLUT(developed by Alexey Ivanov,West Virginia University), these are extremely useful models for studying the temporal regulation of genes and cellular processes during EMT. Analogous to these, inducible GRHL2 expression in mesenchymal cells can now be used to examine various aspects of the MET process. Also, the TGF- $\beta$ field has been limited by the relatively small number of cell lines that respond to TGF- $\beta$ by undergoing EMT. Based on our findings, GRHL2 shRNAs provide a rational strategy for inducing TGF- $\beta$ responsiveness that widens the context under which it can be investigated.

In conclusion, the research presented in this thesis identifies the transcription factor, GRHL2, as a novel EMT regulator and tumor suppressor. Identifying pathways which regulate its expression will provide new targets for cancer therapy based on the suppression of EMT.

\section{References}

1. Faucheux C, Naye F, Treguer K, Fedou S, Thiebaud P, Theze N: Vestigial like gene family expression in Xenopus: common and divergent features with other vertebrates. Int J Dev Biol 54:1375-1382.

2. Chou YT, Wang H, Chen Y, Danielpour D, Yang YC: Cited2 modulates TGF-beta-mediated upregulation of MMP9. Oncogene 2006, 25:5547-5560.

3. Beildeck ME, Islam M, Shah S, Welsh J, Byers SW: Control of TCF-4 expression by VDR and vitamin D in the mouse mammary gland and colorectal cancer cell lines. PLoS One 2009, 4:e7872.

4. Palmer HG, Gonzalez-Sancho JM, Espada J, Berciano MT, Puig I, Baulida J, Quintanilla M, Cano A, de Herreros AG, Lafarga $M$, et al.: Vitamin $D(3)$ promotes the differentiation of colon carcinoma cells by the induction of $E$ cadherin and the inhibition of beta-catenin signaling. J Cell Biol 2001, 154:369-387.

5. Shah S, Islam MN, Dakshanamurthy S, Rizvi I, Rao M, Herrell R, Zinser G, Valrance M, Aranda A, Moras D, et al.: The molecular basis of vitamin D receptor and beta-catenin crossregulation. Mol Cell 2006, 21:799-809.

6. Lindsay J, McDade SS, Pickard A, McCloskey KD, McCance DJ: Role of DeltaNp63gamma in epithelial to mesenchymal transition. J Biol Chem 286:3915-3924.

7. Tucci P, Agostini M, Grespi F, Markert EK, Terrinoni A, Vousden KH, Muller PA, Dotsch V, Kehrloesser S, Sayan BS, et al.: Loss of p63 and its microRNA-205 target results in enhanced cell migration and metastasis in prostate cancer. Proc Natl Acad Sci U S A 109:15312-15317.

8. Ke XS, Qu Y, Cheng Y, Li WC, Rotter V, Oyan AM, Kalland KH: Global profiling of histone and DNA methylation reveals epigenetic-based regulation of gene expression during epithelial to mesenchymal transition in prostate cells. BMC Genomics 11:669.

9. Yu X, Cohen DM, Chen CS: miR-125b Is an adhesion-regulated microRNA that protects mesenchymal stem cells from anoikis. Stem Cells 30:956-964.

10. Nava P, Laukoetter MG, Hopkins AM, Laur O, Gerner-Smidt K, Green KJ, Parkos CA, Nusrat A: Desmoglein-2: a novel regulator of apoptosis in the intestinal epithelium. Mol Biol Cell 2007, 18:4565-4578.

11. Shao Y, Aplin AE: Akt3-mediated resistance to apoptosis in B-RAF-targeted melanoma cells. Cancer Res 70:66706681. 
12. Boisvert-Adamo K, Aplin AE: B-RAF and PI-3 kinase signaling protect melanoma cells from anoikis. Oncogene 2006, 25:4848-4856.

13. Frisch SM: E1a induces the expression of epithelial characteristics. J Cell Biol 1994, 127:1085-1096.

14. Attardi LD, Reczek EE, Cosmas C, Demicco EG, McCurrach ME, Lowe SW, Jacks T: PERP, an apoptosis-associated target of p53, is a novel member of the PMP-22/gas3 family. Genes Dev 2000, 14:704-718.

15. Ihrie RA, Marques MR, Nguyen BT, Horner JS, Papazoglu C, Bronson RT, Mills AA, Attardi LD: Perp is a p63-regulated gene essential for epithelial integrity. Cell 2005, 120:843-856.

16. Beaudry VG, Jiang D, Dusek RL, Park EJ, Knezevich S, Ridd K, Vogel H, Bastian BC, Attardi LD: Loss of the p53/p63 regulated desmosomal protein Perp promotes tumorigenesis. PLoS Genet 6:e1001168.

17. Ihrie RA, Reczek E, Horner JS, Khachatrian L, Sage J, Jacks T, Attardi LD: Perp is a mediator of p53-dependent apoptosis in diverse cell types. Curr Biol 2003, 13:1985-1990.

18. Anido J, Saez-Borderias A, Gonzalez-Junca A, Rodon L, Folch G, Carmona MA, Prieto-Sanchez RM, Barba I, MartinezSaez E, Prudkin L, et al.: TGF-beta Receptor Inhibitors Target the CD44(high)/Id1(high) Glioma-Initiating Cell Population in Human Glioblastoma. Cancer Cell 18:655-668.

19. Zhang M, Herion TW, Timke C, Han N, Hauser K, Weber KJ, Peschke P, Wirkner U, Lahn M, Huber PE: Trimodal glioblastoma treatment consisting of concurrent radiotherapy, temozolomide, and the novel TGF-beta receptor I kinase inhibitor LY2109761. Neoplasia 13:537-549.

20. Bogdahn U, Hau P, Stockhammer G, Venkataramana NK, Mahapatra AK, Suri A, Balasubramaniam A, Nair S, Oliushine $\mathrm{V}$, Parfenov $\mathrm{V}$, et al.: Targeted therapy for high-grade glioma with the TGF-beta2 inhibitor trabedersen: results of a randomized and controlled phase Ilb study. Neuro Oncol 13:132-142.

21. Tao J, Kuliyev E, Wang X, Li X, Wilanowski T, Jane SM, Mead PE, Cunningham JM: BMP4-dependent expression of Xenopus Grainyhead-like 1 is essential for epidermal differentiation. Development 2005, 132:1021-1034.

22. Samavarchi-Tehrani P, Golipour A, David L, Sung HK, Beyer TA, Datti A, Woltjen K, Nagy A, Wrana JL: Functional genomics reveals a BMP-driven mesenchymal-to-epithelial transition in the initiation of somatic cell reprogramming. Cell Stem Cell 7:64-77.

23. Senga K, Mostov KE, Mitaka T, Miyajima A, Tanimizu N: Grainyhead-like 2 regulates epithelial morphogenesis by establishing functional tight junctions through the organization of a molecular network among claudin3, claudin4, and Rab25. Mol Biol Cell 23:2845-2855.

24. Varma S, Cao Y, Tagne JB, Lakshminarayanan M, Li J, Friedman TB, Morell RJ, Warburton D, Kotton DN, Ramirez MI: The Transcription Factors Grainyhead-like 2 and NK2-Homeobox 1 Form a Regulatory Loop That Coordinates Lung Epithelial Cell Morphogenesis and Differentiation. J Biol Chem 287:37282-37295.

25. Yan GR, Xu SH, Tan ZL, Liu L, He QY: Global identification of miR-373-regulated genes in breast cancer by quantitative proteomics. Proteomics 11:912-920. 


\section{CURRICULUM VITAE}

\section{Benjamin Cieply}

\section{Personal Information:}

Office Address: West Virginia University

Room 2838 HSS

1 Medical Center Drive

Morgantown, WV 26506

Cell Phone: (724) 972-2513

Email: bcieply@hsc.wvu.edu, cieply992002@yahoo.com

\section{Education:}

1999-2003

B.Sc. in Biology, Geneva College, Beaver Falls, PA

2008-Pres.

Cancer Cell Biology Ph.D.Program, West Virginia University School of Medicine, Morgantown, WV

Positions:

2005-2007

Research III, Department of Pathology, University of Pittsurgh School of Medicine, Pittsburgh, PA. Lab of Satdarshan P.S.Monga, MD.

2007-2008

Research IV, Department of Pathology, University of Pittsurgh School of Medicine, Pittsburgh, PA. Lab of Satdarshan P.S.Monga, MD.

2008-Pres. Graduate Assistant, Cancer Cell Biology, WestVirginiaUniversity School of Medicine, Morgantown, WV. Mentor: Steven Frisch, PhD.

\section{Teaching Experience:}

2009(Fall)

Tutor, Cell Biology, West Virginia University Biomedical Sciences

Graduate Program

2011(Spring) Tutor, Biochemistry, West Virginia University Pharmacy Program 
2011-pres.

Graduate student representative at Cancer Cell Biology Faculty meetings. West Virginia University Cancer Cell Biology Graduate Progragm

Poster Presenations:

"Using Tyrosine 654 Phosphorylation of Beta-Catenin to Predict HCC Pathology” Experimental Biology, San Diego, Ca

2008

2010

“Beta-Catenin Expression in Pediatric Malignancies”, Experimental Biology, San Diego, Ca

"Regulation of anoikis by CD44" Cancer Cell Biology Training Consortium, Tucson, $\mathrm{Az}$

2012 (First Place) "Suppression of the epithelial-mesenchymal transition by grainyhead like 2” E.J. Van Liere Memorial Convocation and HSC Research Day, West Virginia School of Medicine, Morgantown, WV

2012

"Suppression of the epithelial-mesenchymal transition (EMT) by a wound-healing gene, Grainyhead-like-2” AACR Annual Meeting, Chicago, Il

\section{Oral Presentations:}

2012

"Opposite Roles of CD44S and CD44E in the regulation of Anoikis" E.J. Van Liere Memorial Convocation and HSC Research Day, West Virginia School of Medicine, Morgantown, WV

"Suppression of the epithelial-mesenchymal transition by grainyhead like 2" E.J. Van Liere Memorial Convocation and HSC Research Day, West Virginia School of Medicine, Morgantown, WV

Manuscripts, Peer-Reviewed:

1. Apte U, Zeng G, Muller P, Tan X, Micsenyi A, Cieply B, Dai C, Liu Y, Kaestner KH, Monga SP. Activation of Wnt/beta-catenin pathway during hepatocyte growth factorinduced hepatomegaly in mice. Hepatology. 2006;44(4):992-1002. 
2. Tan X, Behari J, Cieply B, Michalopoulos GK, Monga SP. Conditional deletion of betacatenin reveals its role in liver growth and regeneration. Gastroenterology.

2006;131(5):1561-72.

3. Apte U, Zeng G, Thompson MD, Muller P, Micsenyi A, Cieply B, Kaestner KH, Monga SP. beta-Catenin is critical for early postnatal liver growth. Am.J Physiol Gastrointest.Liver Physiol. 2007;292(6):G1578-G1585.

4. Zeng G, Apte U, Cieply B, Singh S, Monga SP. siRNA-mediated beta-catenin knockdown in human hepatoma cells results in decreased growth and survival. Neoplasia. 2007;9(11):951-9. PMCID: PMC2077886.

5. Apte U, Thompson MD, Cui S, Liu B, Cieply B, Monga SP. Wnt/beta-catenin signaling mediates oval cell response in rodents. Hepatology. 2008;47(1):288-95.

6. Tan X, Yuan Y, Zeng G, Apte U, Thompson MD, Cieply B, Stolz DB, Michalopoulos GK, Kaestner KH, Monga SP. Beta-catenin deletion in hepatoblasts disrupts hepatic morphogenesis and survival during mouse development. Hepatology. 2008;47(5):166779.

7. Apte U, Singh S, Zeng G, Cieply B, Virji MA, Wu T, Monga SP. Beta-catenin activation promotes liver regeneration after acetaminophen-induced injury. Am.J Pathol. 2009;175(3):1056-65. PMCID: PMC2731124.

8. Cieply B, Zeng G, Proverbs-Singh T, Geller DA, Monga SP. Unique phenotype of hepatocellular cancers with exon-3 mutations in beta-catenin gene. Hepatology. 2009;49(3):821-31. PMCID: PMC2657345.

9. Nejak-Bowen KN, Zeng G, Tan X, Cieply B, Monga SP. Beta-catenin regulates vitamin C biosynthesis and cell survival in murine liver. J Biol.Chem. 2009;284(41):28115-27.

PMCID: PMC2788862.

10. Behari J, Yeh TH, Krauland L, Otruba W, Cieply B, Hauth B, Apte U, Wu T, Evans R, Monga SP. Liverspecific beta-catenin knockout mice exhibit defective bile acid and cholesterol homeostasis and increasedsusceptibility to diet-induced steatohepatitis. Am.J Pathol. 2010;176(2):744-53. PMCID: PMC2808081.

11. Kumar S, Park SH, **Cieply B**, Schupp J, Killiam E, Zhang F, Rimm DL, Frisch SM. A pathway for the control of anoikis sensitivity by E-cadherin and epithelial-tomesenchymal transition. Mol Cell Biol. 2011 Oct;31(19):4036-51. Epub 2011 Jul 11.

**Co-first author** 
12. Cieply B, Riley P 4th, Pifer PM, Widmeyer J, Addison JB, Ivanov AV, Denvir J, Frisch SM. Suppression of the epithelial-mesenchymal transition by grainyhead like 2. Cancer Res. 2012 May 1;72(9):2440-53. Epub 2012 Feb 29.PMID:22379025 